Florida International University FIU Digital Commons

\title{
Laurel Wilt Disease: Early Detection through Canine Olfaction and "Omics" Insights into Disease Progression
}

Julian L. Mendel

Florida International University, jmend065@fiu.edu

DOI: $10.25148 /$ etd.FIDC001920

Follow this and additional works at: https:// digitalcommons.fiu.edu/etd

Part of the Agriculture Commons, Biochemistry Commons, Bioinformatics Commons, and the Plant Pathology Commons

\section{Recommended Citation}

Mendel, Julian L., "Laurel Wilt Disease: Early Detection through Canine Olfaction and "Omics" Insights into Disease Progression" (2017). FIU Electronic Theses and Dissertations. 3475.

https://digitalcommons.fiu.edu/etd/3475 


\section{FLORIDA INTERNATIONAL UNIVERSITY}

Miami, Florida

\section{LAUREL WILT DISEASE: EARLY DETECTION THROUGH CANINE OLFACTION AND OMICS INSIGHTS INTO DISEASE PROGRESSON.}

A dissertation submitted in partial fulfillment of the requirements for the degree of DOCTOR OF PHILOSOPHY

in

BIOLOGY

by

Julian Lior Mendel 
To: Dean Michael R. Heithaus

College of Arts, Sciences and Education

This dissertation, written by Julian Lior Mendel, and entitled Laurel Wilt Disease: Early Detection through Canine Olfaction and Omics Insights into Disease Progression, having been approved in respect to style and intellectual content, is referred to you for judgment.

We have read this dissertation and recommend that it be approved.

Heather Bracken-Grissom

$\begin{array}{r}\hline \text { Kenneth G. Furton } \\ \hline \text { Jeffrey Wells } \\ \hline \text { Eric Von Wettberg } \\ \hline \text { DeEtta Mills, Major Professor }\end{array}$

Date of Defense: June 8, 2017

The dissertation of Julian Lior Mendel is approved.

Dean Michael R. Heithaus

College of Arts, Sciences and Education

Andrés G. Gil

Vice President for Research and Economic Development and Dean of the University Graduate School

Florida International University, 2017 


\section{DEDICATION}

I dedicate this dissertation to my parents Mark and Leonie who have sacrificed all for

their children. It is through their nurturing, tutelage and most of all their love that I am able to reach for the stars. 


\section{ACKNOWLEDGMENTS}

I would like to acknowledge the FIU MBRS-RISE program for their support

during the course of my research. Their dedication to student professional development and education is exceptional. I would also like to thank Dr. DeEtta Mills for her mentoring and guidance, as without her I would not be here. Thank you to my esteemed committee members for their guidance, time and constructive criticism. Lastly but not least, I acknowledge my wife Shari, my friends and family who supported me throughout this journey. 
ABSTRACT OF THE DISSERTATION

\title{
LAUREL WILT DISEASE: EARLY DETECTION THROUGH CANINE OLFACTION AND OMICS INSIGHTS INTO DISEASE PROGRESSON.
}

\author{
by \\ Julian Lior Mendel \\ Florida International University, 2017 \\ Miami, Florida \\ Professor DeEtta Mills Major Professor
}

Laurel wilt disease is a vascular wilt affecting the xylem and water conductivity in trees belonging to the family Lauraceae. The disease was introduced by an invasive species of ambrosia beetle, Xyleborus glabratus. The beetle, together with its newly described fungal symbiont Raffaelea lauricola (pathogenic to host trees), has lead to the devastation and destruction of over 300 million wild redbay trees in southeastern forests. Ambrosia beetles make up a very unique clade of beetle and share a co-evolved obligatory mutualistic relationship with their partner fungi. Rather than consuming host tree material, the beetles excavate galleries or canals within them. These galleries serve two purposes: reproduction and fungal gardening. The beetles house fungal spores within specialized sacs, mycangia, and essentially inoculate host trees with the pathogenic agent. They actively grow and cultivate gardens of the fungus in galleries to serve as their sole food source. Once the fungus reaches the xylem vessels of the host tree, it thrives and leads to the blockage of water flow, both because of fungal accumulation and to the host response of secreting gels, gums and tyloses to occlude vessels in an attempt to quarantine the fungus. 
This disease spreads rapidly, and as a result, once symptoms become visible to the naked eye, it is already too late to save the tree, and it has likely already spread to adjacent ones. The present study presents the first documented study involving the early detection of disease from deep within a tree through the use of scent-discriminating canines. In addition, the present study has lead to the development of a novel sample collection device enabling the non-destructive sampling of beetle galleries. Finally, a metabolomics approach revealed key biochemical pathway modifications in the disease state, as well as potential clues to disease development. 


\section{CHAPTER 1}

Introduction

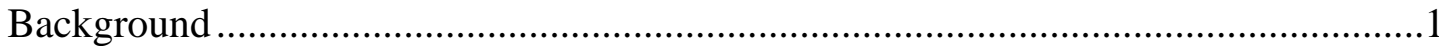

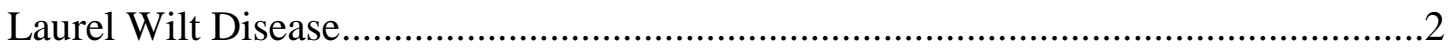

Plant/Microbe interactions with respect to disease and resistance .............................4

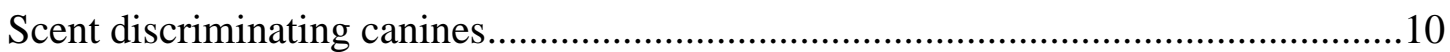

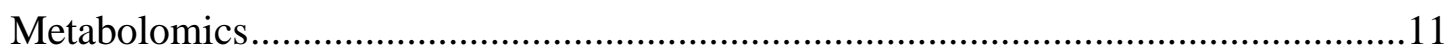

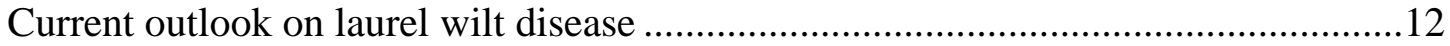

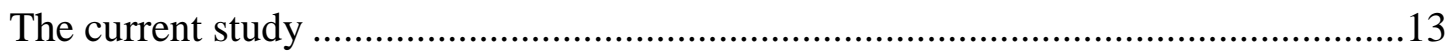

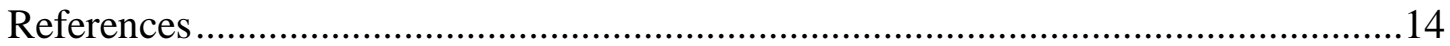

\section{CHAPTER 2}

An evaluation of scent discriminating canines for rapid response to

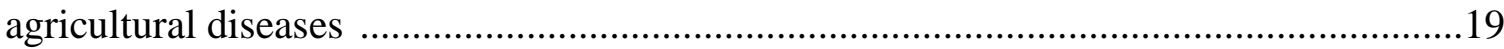

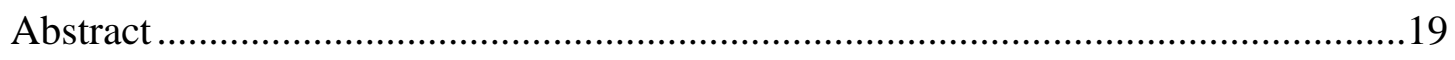

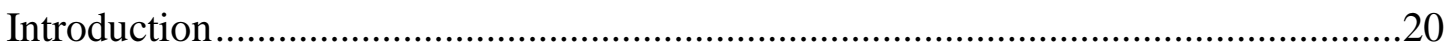

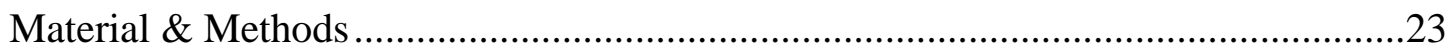

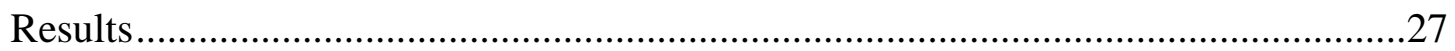

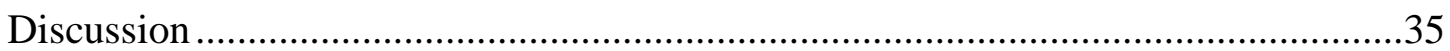

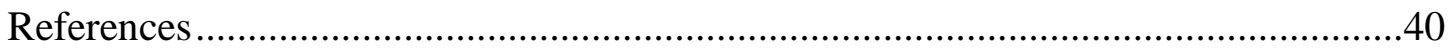

\section{CHAPTER 3}

Agri-Dogs: Using canines for earlier detection of laurel wilt disease affecting avocado trees (Persea americana) in South Florida ..................................................43

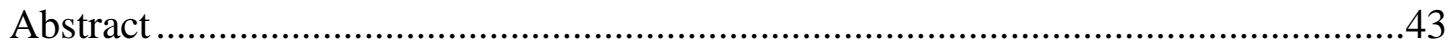

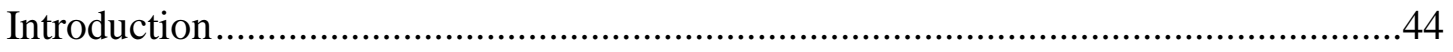

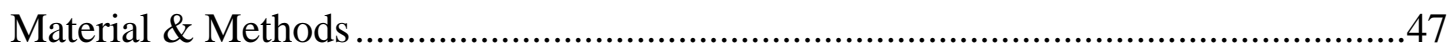

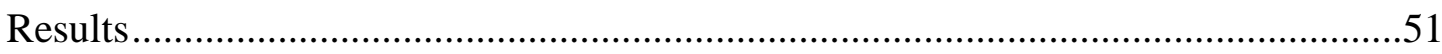

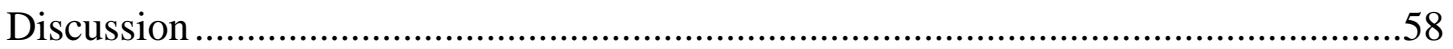

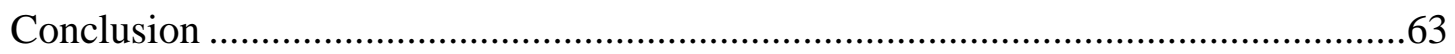

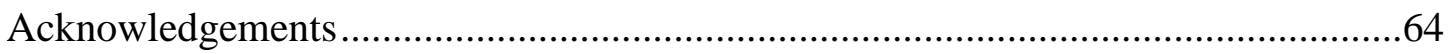

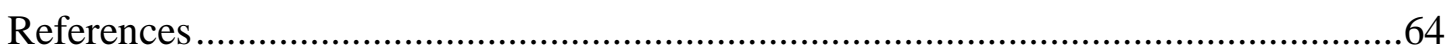

\section{CHAPTER 4}

Enhancing sample collection for the diagnosis and profiling of laurel wilt disease .........68

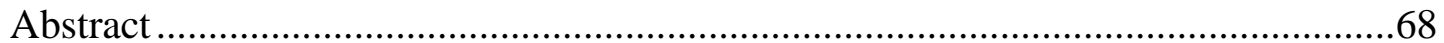

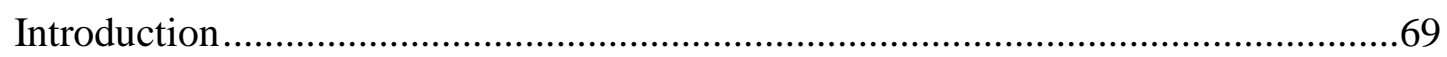




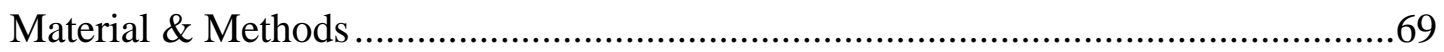

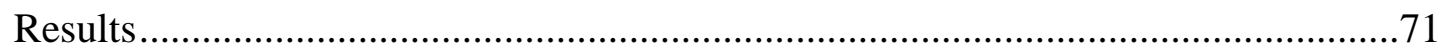

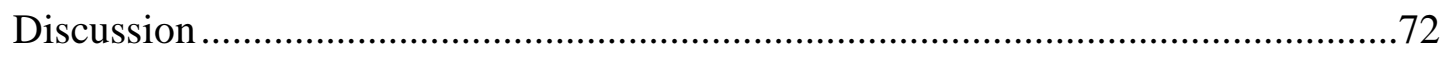

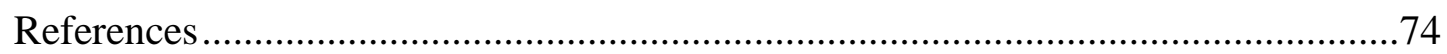

\section{CHAPTER 5}

The laurel wilt metabolome: A non-targeted UPLC-HRMS approach reveals

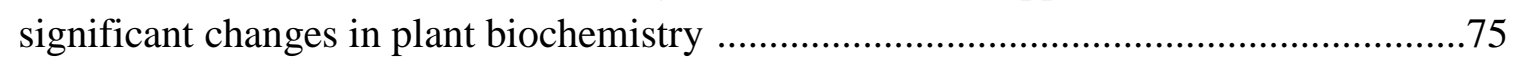

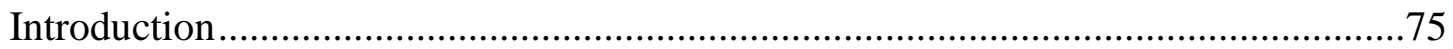

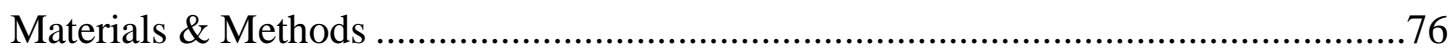

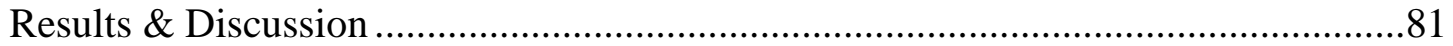

Conclusion........................................................... 102

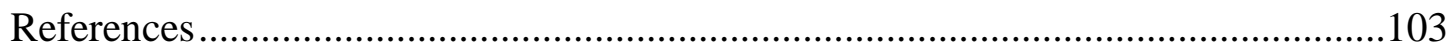

Supplementary data................................................. 108

\section{CHAPTER 6}

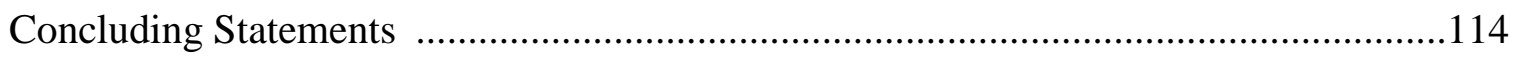

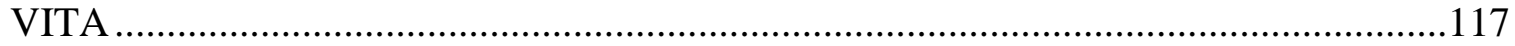




\section{LIST OF TABLES}

TABLE

PAGE

\section{CHAPTER 2}

1. Summary results of the canine searches $(n=229, \operatorname{Candy}(78), \operatorname{Cobra}(73)$

OneBetta(78)) during the time period of September 2014 to April 2015. There was no significant difference between the canines in terms of average time to alert correctly to a training aid (ANOVA $\mathrm{p}>0.05$ ). The average accuracy of all three canines was $\sim 99.4 \%$.

2. A summary for the controlled three day evaluations with ANOVA results indicating no significant differnce between canines as well as no significant difference between time of day $(\mathrm{p}>0.05)$. However, comparing the average from routine training to the more controlled randomized three day trial the average time to locate training aids was significantly higher in the three day trial $(\mathrm{p}<0.05)$

3. The results of a two week trial with the laurel wilt pathogen cultures and negative control training aid materials for two canines cobra and OneBetta.

\section{CHAPTER 3}

1. Laurel wilt DNA results for trees canines identified as pre-symptomatic for laurel wilt disease using root samples.

2. The number of commercial avocado trees canines detected as laurel wilt suspects, number of suspect trees treated with TILT $^{\circledR}$ fungicide and number of trees dead 14 months after fungicide treatment

3. Disease management results for three individual avocado groves where grove owners followed recommended prophylactic propiconazole $\left(\right.$ TILT $\left.^{\circledR}\right)$ treatment and guidelines based on canine alerts.

4. Cost and simple economic feasibility analysis of canines as an early detection tool for laurel wilt disease in a five-acre commercial grove.

\section{CHAPTER 5}

1. Showing the significantly different compounds observed when comparing healthy to infected xylem samples. Significance was determined with a Student's T-test $(\mathrm{p}<0.05)$.

2. The top mapped pathways in the KEGG compound database associated with differentially expressed compounds in healthy xylem (HX) and infected xylem (IX) as well as those found exclusively in infected xylem..... 
3. The top mapped pathways in the KEGG compound database associated with differentially expressed compounds in infected xylem (IX) and Gallery flush samples (GF) as well as those found exclusively in only one sample type (IX only or GF only)

4. The classification accuracy of healthy versus infected trees using the machine learning algorithm Random Forest. Trial 1 involved building the model with $2 / 3$ of the total healthy and infected xylem samples $(N=24)$ and testing for classification with the remaining samples. Trial 2 involved training with the entire data set of healthy and infected samples followed by testing with gallery flush samples from infected trees $(\mathrm{N}=45)$.

5. The biological activity associated with compounds increasing temporally during the artificial inoculation experiment in a young avocado tree. The top mapped compounds show increases from pre-inoculation through disease progression

6. The KEGG pathway mapping of compounds present in Raffaelea lauricola (RL) in pure culture and the number of compounds that increased over time upon contact with healthy xylem tissue. 


\section{LIST OF FIGURES}

FIGURE

PAGE

\section{CHAPTER 2}

1. The three canines used in the present study, from left to right: Candy, Cobra and OneBetta

2. The controlled odor mimic permation system with infected avocado wood sealed inside

3-5. The canine data for the three canines with respect to temperature, relative humidity and wind speed. General trends indicate that while the canines are capable of performing well under all the conditions evaluated, increasing temperature $(\mathrm{p}<0.05)$ results in faster target location, with relative humidity $(\mathrm{P}>0.05)$ showing a reverse trend and wind speed showing a slight trend toward faster target location with lower speeds $(\mathrm{p}>0.05)$

6. The graph is showing the relationship between total number of false alerts with increasing wind speed . Red indicates false alerts. With the exception of two false alerts by "OneBetta" at $\sim 0.8 \mathrm{Km} / \mathrm{h}$ all false alerts came when wind speed was $\sim 4.8 \mathrm{Km} / \mathrm{h}$ and higher.

\section{CHAPTER 3}

1. A map showing the trees canines alerted to as pre-symptomatic for the laurel wilt pathogen during trial 2 . Trees were visually monitored for six-weeks before the grove was bulldozed. Of the 100 trees with canine alerts, 22 trees progressed to laurel wilt with all the visible symptoms, nine more showed early signs of the disease before the grove was bulldozed..

2 Image taken of an avocado tree in a commercial grove at the time of the canine alerts (A), and two weeks post canine alert (B and C), showing symptoms of laurel wilt, during Trial 2.

\section{CHAPTER 4}

1. The prototype syringe modified Venturi vacuum device used to collect gallery samples.

2. Photograph of fungal growth from polycarbonate filters used on avocado trees with vacuum collection from beetle galleries. Fungal growth was observed on malt extract plates indicating that fungal spores were successfully collected using the vacuum device. This application can prove useful in the diagnosis of various plant pathogens that are not easily accessible by other means. 


\section{CHAPTER 5}

1a. A 2D-PLSDA plot for the metabolites in healthy xylem versus laurel wilt infected xylem in avocado trees. (Group 1:Healthy (red), Group 2: Infected (green)).

$\left(\mathrm{R}^{2} / \mathrm{Q}^{2}\right.$ ratio $\left.>0.8\right)$. The clear clusters formed by each sample type or group indicates success in class separation. The high $\mathrm{R}^{2} / \mathrm{Q}^{2}$ validates the model as being due to the data variations rather than over fitting.

1b. The top 15 classifying compounds between the two sample types.

Group1: Healthy (red), Group 2: Infected (green). PLSDA variable importance (VIP) scores above 1.5 are considered of high significance in the separation of classes. The colored boxes to the right represent the relative concentrations of the compounds in the two sample types.

2a. A 2D-PLSDA plot for infected xylem tissue and beetle gallery flushes from laurel wilt infected avocado trees (Group 1: Xylem (red), Group 2: Gallery (green)). $\left(\mathrm{R}^{2} / \mathrm{Q}^{2}\right.$ ratio $\left.>0.7\right)$. The clear clusters formed by each sample type or group indicates success in class separation. The high $\mathrm{R}^{2} / \mathrm{Q}^{2}$ validates the model and group separation as being due to the data variations rather than over fitting.

2b. The top 15 classifying compounds between the two sample types.

(Group 1: Xylem (red), Group 2: Gallery (green)). PLSDA variable importance (VIP) scores above 1.5 are considered of high significance in the separation of classes. The colored boxes to the right represent the relative concentrations of the compounds in the two sample types.

3. The disease progression in artificially inoculated avocado trees. Days 60, 65 and 72 , respectively from left to right shows the early progression of symptoms from early leaf curling to brown leaves and ultimately complete wilt

4. The top 15 compounds across time in the artificial inoculation study in a young avocado plant (Group 0: Healthy Xylem control, Groups 1-3: gallery flushes at early mid and late stage infection). PLSDA variable importance (VIP) scores above 1.5 are considered of high significance in the separation of classes. The colored boxes to the right represent the relative concentrations of the compounds in the two sample types.....98

5a. A 2D-PLSDA plot for the in situ time series experiment showing changes in Raffaelea lauricola over 120 hours after coming in contact with xylem tissue. Key: Red-Pathogen (0), Green (1)- 3h, Purple (2)-24h, Blue (3)-48h Pink (4)-72h and yellow (5)-120h.

5b. Important compounds involved in classification/discrimination of each time point. Key: Red-Pathogen (0), Green (1)- 3h, Purple (2)-24h, Blue (3)-48h Pink (4)-72h and yellow (5)-120h. PLSDA variable importance (VIP) scores above 1.5 are considered of high significance in the separation of classes. The colored boxes to the right represent the relative concentrations of the compounds in the two sample types 


\section{Supplementary Figures}

1. The heat maps generate a visual picture of the differences between compounds present in healthy xylem (HX) versus infected xylem (IX). Color intensities represent concentration fold changes of $\log _{2}$ normalized data. Red indicates higher concentration in the numerator $(\mathrm{HX})$ and blue indicates higher in the denominator (IX) Black indicates no difference.

2. The heat maps generate a visual picture of the differences between compounds present in gallery flushes (GF) from infected trees versus infected xylem (IX). Color intensities represent concentration fold changes of $\log _{2}$ normalized data. Red indicates higher concentration in the numerator (GF) and blue indicates higher in the denominator (IX). Black indicates no difference.

3. The up-regulated compounds (red dots) in infected xylem within the TCA cycle. Pyruvate, cis-Aconitate, Succinate, Fumarate and Oxaloacetate are all significantly increased in infected trees.

4. The up (red) and down (blue) regulated compounds involved in glutamate metabolism in laurel infected trees

5. The up (red) and down (blue) regulated compounds involved with carbon metabolism in infected trees.

6. The up regulation of compounds (red in color) and down regulation (blue) involved in plant hormone synthesis in laurel wilt diseased trees 


\section{ABBREVIATIONS AND ACRONYMS}

$\begin{array}{ll}\text { ABA } & \text { Abscisic acid } \\ \text { GF } & \text { Gallery flush } \\ \text { HX } & \text { Healthy xylem } \\ \text { HR } & \text { Hypersensitive response } \\ \text { IX } & \text { Infected xylem } \\ \text { JA } & \text { Jasmonic acid } \\ \text { PLSDA } & \text { Partial least squares discriminate analysis } \\ \text { PCD } & \text { Programmed cell death } \\ \text { Raf or RL } & \text { Raffaelea lauricola } \\ \text { ROS } & \text { Reactive oxygen species } \\ \text { RAB } & \text { Redbay ambrosia beetle } \\ \text { SA } & \text { Salicylic acid } \\ \text { UPLC-HRMS } & \begin{array}{l}\text { Ultra-high performance liquid chromatography coupled with } \\ \text { high resolution mass spectrometry }\end{array} \\ \text { VVD } & \text { Venturi vacuum device }\end{array}$




\section{CHAPTER 1}

\section{Introduction}

\section{$\underline{\text { Background }}$}

All living organisms have basic nutrient requirements for growth and reproduction and all organisms share habitats and ecosystems with others. As a result, resource acquisition and usage can become a competitive race for survival and invasive species often gain niche advantage over native residents (Ploetz et al. 2013). Mutualistic,

commensal, parasitic and predatory relationships are general categories that inadequately describe the complexity of the wide spectrum of interactive relationships that occur between organisms. From a molecular standpoint, the vigorous competition between organisms for limited resources places heavy selection pressures on genes and phenotypes that are best suited for success - Darwin's survival of the fittest. The relationship between plants and fungi is one that dates back to the time of the first land plants, over 400 million years ago. Recent DNA evidence shows endophytic associations that were similar to arbuscular mycorrhiza with the first bryophytes even before roots had evolved (Brundrett 2002). This evolutionary interaction, spanning millions of years, has led to a diverse and complex array of plant-fungal interactions and, therefore, it should come as no surprise that over $70 \%$ of all plant pathogens are fungi (Deacon 2006). 


\section{Laurel Wilt Disease}

Xyleborus glabratus, the invasive ambrosia beetle that was introduced to the USA, along with is fungal partner Raffaelea lauricola, has resulted in one of the most complex and devastating plant diseases in recent times. The beetle, originally from Asia, probably entered the Untied States through shipping channels, via untreated wooden pallets, boxes or crates, through Port Wentworth in Georgia (Mayfield and Thomas 2006). The disease was first detected in redbay trees (Persea borbonia) and was associated with this invasive beetle, thus given the common name the Redbay Ambrosia beetle (RAB) (Fraedrich et al. 2008, Hanula et al. 2008, Mayfield and Thomas 2006). Ambrosia refers to a very special symbiosis existing between these beetles and fungi, partners that are always found together. Through co-evolution they developed this relationship where by both are mutually dependent on each other for survival and dispersal. The beetles belong to the sub-family Scolytinae, which accounts for the most common and the most devastating pests to plants known to date (Hulcr and Dunn 2011, Ploetz et al. 2013).

The newly described Rafaelea lauricola (Raf), an asexual ascomycete, was found to be associated with beetles found in native Asia, confirming both the disease-causing fungal partner and the beetle originated there (Fraedrich et al. 2008, Harrington et al. 2011). Fungal spores are stored within specialized sacs that are known as mycangia and can be found on or inside the body of the ambrosia beetle. The location and number of these sacs has been shown to vary somewhat among beetle species but their function is always the same (Batra 1967). Xyleborus glabratus (RAB) possesses dual mandibular mycangia that store and excrete their fungal symbiont during the invasion of a host tree during the boring or excavation of the gallery and tunnels. This action of boring into 
trees leads to the inoculation with the fungus, which thrives by feeding off the host tree. The beetle actively cultivates its fungal partner within these galleries like an agricultural crop and, in return for tree-to-tree transport, the fungus provides the food source for young and adult beetles (Hulcr and Dunn 2011, Ploetz et al. 2013). The presence of the fungus in the host tree leads to the activation of host's defense systems. The subsequent production of tyloses, phenolic, pectin, and lipid-containing gums or gels by the host is its response to attempt to halt or kill the spread of the pathogen throughout the xylem vessels (Inch et al. 2012). Unfortunately, this also leads to the unwanted consequence of blocked xylem vessels, reduction and eventual shutdown of water and nutrient flow throughout the tree. This lack of flow soon manifests itself as visible symptoms such as wilting leaves, tissue necrosis and ultimately, the death of the tree. The black/brown stained sapwood marks the disease foci and can be observed visually when the bark is removed (Fraedrich et al. 2008, Inch and Ploetz 2012, Inch et al. 2012). Although the disease was discovered in redbay trees, studies have demonstrated that most members of the Laureaceae family are susceptible and as such the name "laurel wilt disease" was coined (Fraedrich et al. 2008). Of particular commercial interest is the commercially important avocado tree (Persea americana).

Laurel wilt disease is one of the most aggressive plant diseases, demonstrated by its inoculation potency where as few as 100 fungal conidia can lead to the death of a tree. That means even one beetle, carrying thousands of spores in its mycangia is sufficient to inoculate and kill a tree (Hanula et al. 2008). Since its initial introduction this disease has led to the death of over 300 million Lauraceae in the wild, reshaping coastal forests and having widespread impacts on ecosystems (Hughes et al. 2017). Initial hopes that the 
disease would be curbed and the beetle populations would drop once most of its preferred host trees have been lost, but instead it jumped hosts and is having a major impact on the \$54M a year avocado industry, Florida's second largest fruit crop next to citrus (Ploetz et al. 2011). The estimated cost of replacing trees lost if nothing is done has been estimated to be $\geq \$ 400$ million. This is a great concern for local farmers and the larger avocado industries in Mexico and California who are paying keen attention to the Florida situation.

\section{Plant/Microbe interactions with respect to disease and resistance}

\section{Pathogens}

Plant pathogens can be generally classified as either necrotrophic or biotrophic. Necrotrophic pathogens invade a host, kill it and feed through tissue decay, while biotrophic pathogens feed on living tissue often through tapping of host systems (Deacon 2006). A third group called hemibiotrophic pathogens begin as biotrophs but eventually lead to the death of the host and then progresses as necrotrophs (Deacon 2006). These phytopathogens possess a wide range of tools enabling successful host colonization and subsequent defeat of plant defenses. Some include the secretion of enzymes such as pectinases, cellulases and lignases that serve as cell wall degrading enzymes and can be more general or very specific to the cell wall components of the host tree (Deacon 2006, Glass et al. 2013). Some fungal pathogens have also been known to produce chemicals to aid in host degradation as well as molecules for enhanced nutrient acquisition such as iron chelating siderophores and even compounds or enzymes capable of manipulating the hosts natural systems to their benefit (Deacon 2006, Gururani et al. 2012, Johnson 2008, 
Philpott 2006). Fungi can penetrate host cells through invading hyphal outgrowths, called penetration pegs or injection pegs, and can even establish feeding systems by creating an invagination, a haustoria, in the membrane of the host cell without damaging it (Deacon 2006). These are just a few of the mechanisms utilized by fungi to invade and infect its host.

\section{Plant defense mechanisms}

Plants likewise have developed intricate structures, systems and mechanisms for their protection and survival in the event of a pathogen attack. These can generally be considered as physical barriers or chemical defenses, localized responses, and systemic responses. Physical defenses include excessive cuticle formation and strengthening of cell wall components upon pathogen contact with papillae, calloses, and additional lignification (Deacon 2006). Typically these physical barriers are geared towards slowing down pathogen growth and further penetration into the nutrient rich intra-cellular space. These barriers force the pathogen to deplete its resources in an attempt to overcome physical barriers and thus having a lower chance of success in causing disease.

In addition to physical defenses, plants also possess chemical and molecular defenses against pathogens. These include phytoanticipins and phytoalexins, which are either constitutively produced in active or precursor forms (phytoanticipins), or are produced when the tree's immune response is triggered (phytoalexins). Phytoalexins are flavonoids, phenolics, terpenoids, and low molecular weight compounds (Deacon 2006). Their production leads to an oxidative burst and hypersensitive responses that result in reactive oxygen species, which, in turn, can be toxic to the pathogens or lead to programmed cell death in the host plants or cell wall strengthening (Deacon 2006). In 
addition, plants produce enzymes such as glucanases and chitinases that target and degrade fungal cell walls. These localized responses can be triggered in two ways: (a) the recognition of fungal wall components (or byproducts of their breakdown), collectively called pathogen associated molecular patterns (PAMPS); or (b) through effectors that the recognized pathogen secreted molecules and compounds that invade the cells of the host, such as enzymes for nutrient acquisition or those targeting host defense systems (Maor and Shirasu 2005, Yadeta and Thomma 2013). Pathogen associated molecular pattern triggered immunity (PAMP-TI) normally involves the basal immune response such as reinforcing physical structures and the hypersensitive ROS response. Effector triggered immunity (ETI) is more specialized using genetic remodeling and production of specific enzymes and toxins to kill the invader. Effectors tend to be coded by specific fungal genes involved in pathogenesis and are termed Avirulence (Avr) genes, while genes in the host that recognize the Avr gene products, trigger specific gene responses from Resistance $(\mathrm{R})$ genes. The gene-for-gene pathogen-host response system is seen repeatedly with ETI and is often very specific to deal with special classes of phytopathogens (Maor and Shirasu 2005, Philpott 2006). Resistance gene-mediated defense is therefore the main defense against specific pathogen attacks and is an intense area of research. Resistance gene products may interact directly with effectors produced by the pathogens, or monitor effector targets for changes much like a security system (Maor and Shirasu 2005).

In addition to localized responses to infection, plants also possess systemic acquired resistance (SAR) and induced systemic resistance (ISR). Systemic acquired resistance is a result of signaling pathways and molecules that mobilize not just in the 
infected cells, but also throughout the entire plant. The SAR primes the immune system of the host in all tissues granting it immunity and allowing for stronger/faster responses to repeated attacks. Induced systemic resistance is resistance that develops from the interaction of the host with non-pathogenic fungi such as endophytes and symbionts. Systemic acquired resistance and ISR are mediated by hormone signaling by salicylic acid and jasmonic acid-ethylene, respectively (Robert-Seilaniantz et al. 2011, Burkhanova et al. 2014).

\section{Plant hormones in defense response}

Hormones and hormone crosstalk play a key role in systemic immunity and subsequent resistance. There is an increasingly complex picture emerging with respect to plant hormones, hormone interaction, and their roles in plant pathogen interactions and resistance. In general, salicylic acid signaling increases resistance to biotrophs and hemibiotrophs while jasmonic acid-ethelene pathways are antagonistic to salicylic acid and promote resistance to necrotrophic pathogens (Burkhanova et al. 2014). The antagonistic nature of the two signaling pathways means resistance to any one pathogen can be a trade-off causing host susceptibility to other pathogens.

In addition to salicylic acid and jasmonic acid, other plant hormones play key roles in defense and immunity. Gibberellins, for example, lead to the degradation of DELLA protein growth receptors leading to increased production of reactive oxygen species as well as increased salicylic acid signaling (Robert-Seilaniantz et al. 2011). Auxins, on the other hand, are antagonistic to salicylic acid, and the auxin signaling pathway has been shown to promote disease susceptibility (Robert-Seilaniantz et al. 2011). Abscisic acid production, also linked to abiotic stress, leads to increased pathogen susceptibility 
(Robert-Seilaniantz et al. 2011), giving "molecular meaning" to the idea that environmental stress can weaken a plant's defense systems. Other classes of hormones, brassinosteroids and cytokinins have been shown to promote resistance against biotrophs through SA pathways as well as independently (Robert-Seilaniantz et al. 2011).

Interestingly, pathogens possess means of hijacking plant hormone signaling (Maor and Shirasu, 2005). Some pathogens may secrete plant hormones or hormone mimics in order to manipulate the host signaling to their benefit. The two main pathways studied, salicylic acid and jasmonic acid/ethylene are still missing key information about the receptors and proteins involved and the effects of signaling are largely a result of the specific activity of the pathogen involved. Salicylic acid signaling is largely mediated by NPR1 (non-expressor of pathogenesis-related) genes, and is localized in the cell cytoplasm. Upon salicylic acid production, NPR1 moves into the nucleus, binding to TGA transcription factors, enhancing their binding to TGACGTCA activation sites thus regulating gene expression. There are NPR1-independent pathways, suggesting that unknown receptors may be involved. Jasmonic acid signaling has been shown to involve COI1 proteins, AtMyC2 and other proteins containing jasmonate ZIM binding domains (JAZ) proteins (Robert-Seilaniantz et al. 2011). These interact to regulate gene expression. Ethylene signaling involves several ethylene receptors, one in particular EIN3 is involved heavily in plant defense, and receptors are bound and stabilized by ethylene leading to the expression of genes that are involved in binding other transcription factors for defense genes (Robert-Seilaniantz et al. 2011).

Defense in the xylem 
Xylem consists of long dead straw-like elements called vessel elements, which are associated with living cells called parenchyma (Yadeta and Thomma 2013). While the xylem is a nutrient poor tissue, containing mostly water with limiting amounts of organic and inorganic compounds and minerals, vascular wilt pathogens are capable of thriving within it and are likely specialized to survive in such conditions to avoid competition (Yadeta and Thomma 2013). The same kind of receptors such as PAMP receptors and effector receptors are involved in the xylem cells. Upon the perception of fungal pathogens through xylem receptors, the host's defense responses are initially physical, followed by chemical responses. Initial physical responses include the production of callose and other wall thickening coatings within the infected regions. Additionally, a common response in xylem is the production of tyloses, outgrowths of the parenchyma cells that protrude into the xylem vessels. The physical barrier traps and contains the fungus. These outgrowths are commonly associated with secretion of gels and gums completely sealing a xylem vessel (Yadeta and Thomma 2013). Chemical weapons are activated and drastic metabolic changes occur in the accompanying parenchymal cells, which leads to the accumulation of many compounds related to defense, or displaying anti microbial activity. These include proteins, proteases, chitinases, peroxidases, fungal, cell wall degrading proteins, inhibitors, phenols, phytoalexins and lignin-like compounds (Yadeta and Thomma 2013). Reactive oxygen species toxic to fungi are also produced due to the activity of peroxidases. In addition to these phytoalexins produced by plants, inorganic compounds such as elemental sulfur and sulfur containing compounds have been shown to accumulate in xylem upon infection and play a role in toxicity. 


\section{$\underline{\text { Scent discriminating canines }}$}

Genetic and archaeological evidence suggests the earliest ancestors of Canis familiaris, the domestic dog, to be $>20,000$ years before present (YBD) and the first evidence of dogs being buried with humans to be around 15,000 YBD (Freedman et al. 2014, Skogulund et al. 2015). These discoveries support that, in addition to being the first animals domesticated by man, they were domesticated during a period of huntergatherers and were likely used as hunting companions for their remarkable tracking and searching capabilities. What makes canines exceptionally capable for such tracking skills is the physiology and biochemistry of their olfactory system. The canine olfactory system contains over 100 times more receptor cells than in humans', 200-300 million vs 5 million, respectively (Craven et al. 2010, Furton and Myers 2001). In addition to the high number of receptor cells, the olfactory receptor cells of canines have significantly higher numbers of cilia for increased surface area. The canine olfactory system is also larger and more complex, with higher concentration of neurons, all together making the canine nose 10,000 to 100,000 times more sensitive than humans and capable of detecting odors at even the most minimal of concentrations: 1-2 parts per trillion (Craven et al. 2010, Furton and Myers 2001). While the earliest use of dogs was as hunting companions, their highly sensitive olfactory prowess has lead to their use in a multitude of fascinating and intricate tasks, aiding in human safety, health and law enforcement. Canines are a well-known asset to law enforcement departments demonstrating the ability to detect, drugs and explosives (Craven et al. 2010, Harper et al. 2005), locate missing 
persons, cadavers as well as guns and ammunition. Lesser known are the various niche uses for canines that are fast growing and have large potential impacts on detecting various cancers (Godfrey 2014, McCulloch et al. 2006, Moser and McCulloch 2010), toxic molds (Griffith et al. 2007) and in animal and plant conservation efforts as well as the management of invasive species (Cablk an Heaton 2006, Goodwin et al. 2010, Nussear et al. 2008, Savidge et al. 2011). The abilities of the canine nose, combined with their temperament and trainability make them an incomparable tool for the detection of even the subtlest changes in odor concentrations in a virtually endless range of fields.

\section{$\underline{\text { Metabolomics }}$}

Metabolomics, similar to transcriptomics, enables one to evaluate an organism or system from a snapshot of the metabolic (end product) profile at a particular time or under various conditions or stresses. Byproducts of metabolism give key insights into the biochemical processes and pathways that are occurring and can be correlated to gene and protein expression. Metabolomics analysis of plant-microbe interactions is a critical step in the true understanding of what occurs during mutualistic and pathogenic systems. However, many technical and analytical issues exist with the interpretation and sampling procedures for metabolic data (Draper et al. 2011). One major problem is that plantmicrobe metabolites are still largely not or under described in the literature. A wide range of compounds exists but only about $60 \%$ are actually known or found in analytical chemical libraries (Draper et al. 2011). Nevertheless, metabolic profiles are considered useful and are a logical companion to more commonly used transcriptomics data, as gene expression changes may not depict the post-translational story. Therefore, metabolomics 
data can be considered a direct snapshot of biochemical processes that are occurring in real time (Draper et al. 2011, Weckwerth 2003) and can be used to correlate with transcriptomics data (Macel et al. 2010, Weckwerth 2003). Many studies have demonstrated the ability of metabolomics to provide key information about plant/microbe interactions (de Sa et al. 2014, Draper et al. 2011, Allwood et al. 2008).

\section{Current outlook on laurel wilt disease}

Currently there is no treatment for laurel wilt disease and the remediation and grove sanitation recommendations are for the immediate removal of diseased trees plus close neighbors as the fungus also spreads via root grafting. The propaconizole fungicide, TILT $^{\circledR}$, is the only approved prophylactic treatment for neighboring trees and the current practice is to infuse trees in a circular pattern, two to three rings around any one infected tree. Ideally, entire groves should be infused and can provide up to a year's protection. However, the application is tedious and costly and needs to be repeated periodically (Ploetz et al. 2011).

Initial work on the disease targeted the beetles. Studies analyzed the volatile organic compounds (VOCs) to which the beetles were attracted, so as to design baits that could be used to lure the RABs into insect traps (Hanula and Sullivan 2008, Nigoret et al. 2011). However, it has now been shown that native beetles indigenous to South Florida are picking up the laurel wilt fungus as an exoskeleton contaminant and, thus unintentionally inoculating trees (Carillo et al. 2013).

Very little is currently known about $R$. lauricola, especially with respect to its genetic makeup and biology. As of the time of my dissertation, no genome has been 
published nor have there been any functional genetic studies. Two methods have been developed to enable genetic confirmation of the pathogen, one using PCR detection of Simple Sequence Repeats (SSR) loci using a species-specific molecular probe (Jeyaprakash et al. 2014) and another using microsatellite markers (Dreaden and Davis 2014) and gel electrophoresis-based detection. But, as a result of uneven distribution of the pathogen in an infected tree the current false negative rate is high (University of Florida-Tropical Research and Education Center). This rate has lead to DNA testing being deemed unnecessary if the grove was previously confirmed to have had laurel wilt disease. Florida International University through its Disease, Dogs and Drones project is aiming to improve the early detection of this pathogen through the use of Unmanned Aerial Vehicles (UAV) and canines. Equipped with multi-spectral and/or infrared cameras, these UAVs or drones enable stressed or diseased trees to be detected earlier than visual signs appear by measuring the stress via a change in spectral signatures from chlorophyll in the leaves. This detection can locate 'suspect regions or hot spots' within avocado groves. The ground truthing is performed by scent discriminating canines trained to 'sniff' out diseased trees early in infection and before visual symptoms appear. The VOCs produced during the disease process are being used to train the canines to detect the disease.

\section{The current study}

This study aimed to improve the ability to detect pre-symptomatic trees through the use of canine olfaction. In addition, the goal was to elucidate the biochemical changes that occur when a tree has become infected with laurel wilt through metabolic profiling. The use of dogs trained to detect laurel wilt at an early stage was successful and will be 
discussed within this dissertation in subsequent chapters. In addition to the improvement of the detection and confirmation of laurel wilt disease through canine olfaction, the present study highlighted the effectiveness of canine detection in managing the disease in active commercial groves including its economic feasibility for improved decision making. In addition, this study provided novel information about the disease progression and dynamics through biochemical analysis with metabolomics.

\section{References}

(2013, April 11). Retrieved October 5, 2016, from http://trec.ifas.ufl.edu/RAB-LW2/pdfs/ Current status and recommendations for control of LW and RAB 4-10-13 pdf version.pdf

Allwood, J. W., Ellis, D. I., \& Goodacre, R. (2008). Metabolomic technologies and their application to the study of plants and plant-host interactions. Physiologia Plantarum, 132(2), 117-135.

Batra, L. R. (1967). Ambrosia fungi: a taxonomic revision, and nutritional studies of some species. Mycologia, 59(6), 976-1017.

Brundrett, M. C. (2002). Coevolution of roots and mycorrhizas of land plants. New Phytologist, 154(2), 275-304.

Burkhanova, G. F., \& Maksimov, I. V. (2014). Interaction between salicylate-and jasmonate-induced signal transduction pathways in the development of potato resistance to late blight with the involvement of peroxidase gene M21334. Russian Journal of Plant Physiology, 61(4), 489-495.

Cablk, M. E., \& Heaton, J. S. (2006). Accuracy and reliability of dogs in surveying for desert tortoise (Gopherus agassizii). Ecological Applications, 16(5), 1926-1935.

Carrillo, D., Duncan, R. E., Ploetz, J. N., Campbell, A. F., Ploetz, R. C., \& Peña, J. E. (2014). Lateral transfer of a phytopathogenic symbiont among native and exotic ambrosia beetles. Plant Pathology, 63(1), 54-62.

Craven, B. A., Paterson, E. G., \& Settles, G. S. (2010). The fluid dynamics of canine olfaction: unique nasal airflow patterns as an explanation of macrosmia. Journal of The Royal Society Interface, 7(47), 933-943. 
de Sá, M., Ferreira, J. P., Queiroz, V. T., Vilas Boas, L., Silva, M. C., Almeida, M. H., ... \& Bronze, M. R. (2014). A liquid chromatography/electrospray ionisation tandem mass spectrometry method for the simultaneous quantification of salicylic, jasmonic and abscisic acids in Coffea arabica leaves. Journal of the Science of Food and Agriculture, 94(3), 529-536.

Draper, J., Rasmussen, S., \& Zubair, H. (2011). Metabolite analysis and metabolomics in the study of biotrophic interactions between plants and microbes. Annual Plant Reviews Volume 43: Biology of Plant Metabolomics, 25-59.

Dreaden, T. J., Davis, J. M., Harmon, C. L., Ploetz, R. C., Palmateer, A. J., Soltis, P. S., $\&$ Smith, J. A. (2014). Development of multilocus PCR assays for Raffaelea lauricola, causal agent of laurel wilt disease. Plant Disease, 98(3), 379-383.

Fraedrich, S. W., Harrington, T. C., Rabaglia, R. J., Ulyshen, M. D., Mayfield III, A. E., Hanula, J. L., ... \& Miller, D. R. (2008). A fungal symbiont of the redbay ambrosia beetle causes a lethal wilt in redbay and other Lauraceae in the southeastern United States. Plant Disease, 92(2), 215-224.

Fraedrich, S., \& Aghayeva, D. N. (2008). Raffaelea lauricola, a new ambrosia beetle symbiont and pathogen on the Lauraceae. Mycotaxon 104: 399-404, 104, 399-404

Freedman, A. H., Gronau, I., Schweizer, R. M., Ortega-Del Vecchyo, D., Han, E., Silva, P. M., ... \& Beale, H. (2014). Genome sequencing highlights the dynamic early history of dogs. PLoS Genetics, 10(1), e1004016.

Furton, K. G., \& Myers, L. J. (2001). The scientific foundation and efficacy of the use of canines as chemical detectors for explosives. Talanta, 54(3), 487-500.

Glass, N. L., Schmoll, M., Cate, J. H., \& Coradetti, S. (2013). Plant cell wall deconstruction by ascomycete fungi. Annual Review of Microbiology, 67, 477-498.M.A. Gururani et al. Plant disease resistance genes: Current status and future directions, Physiological and Molecular Plant Pathology (2012), 78: 51-65

Godfrey, A. (2014). Canine scent detection of human cancers: Is this a viable technique for detection? Veterinary Nursing Journal, 29(12), 392-394.

Goodwin, K. M., Engel, R. E., \& Weaver, D. K. (2010). Trained dogs outperform human surveyors in the detection of rare spotted knapweed (Centaurea stoebe). Invasive Plant Science and Management, 3(2), 113-121.

Griffith, R. T., Jayachandran, K., Whitstine, W., \& Furton, K. G. (2007). Differentiation of toxic molds via headspace SPME-GC/MS and canine detection. Sensors, 7(8), 14961508. 
Hanula, J. L., \& Sullivan, B. (2008). Manuka oil and phoebe oil are attractive baits for Xyleborus glabratus (Coleoptera: Scolytinae), the vector of laurel wilt. Environmental Entomology, 37(6), 1403-1409.

Hanula, J. L., Mayfield, A. E., Fraedrich, S. W., \& Rabaglia, R. J. (2008). Biology and host associations of redbay ambrosia beetle (Coleoptera: Curculionidae: Scolytinae), exotic vector of laurel wilt killing redbay trees in the southeastern United States. Journal of Economic Entomology, 101(4), 1276-1286.

Harper, R. J., Almirall, J. R., \& Furton, K. G. (2005). Identification of dominant odor chemicals emanating from explosives for use in developing optimal training aid combinations and mimics for canine detection. Talanta, 67(2), 313-327.

Harrington, T. C., Yun, H. Y., Lu, S. S., Goto, H., Aghayeva, D. N., \& Fraedrich, S. W. (2011). Isolations from the redbay ambrosia beetle, Xyleborus glabratus, confirm that the laurel wilt pathogen, Raffaelea lauricola, originated in Asia. Mycologia, 103(5), 10281036.

Hughes, M.A.; Riggins, J.J.; Koch, F.H.; Cognato, A.I.; Anderson, C.; Formby, J.P.; Dreaden, T.J.; Ploetz, R.C.; Smith, J.A. (2017) No rest for the laurels: Symbioclone invader causes unprecedented damage to southern USA forests. Biological Invasions, in press.

Hulcr, J., \& Dunn, R. R. (2011). The sudden emergence of pathogenicity in insect-fungus symbioses threatens naive forest ecosystems. Proceedings of the Royal Society of London B: Biological Sciences, 278(1720), 2866-2873.

Hulcr, J., Mann, R., \& Stelinski, L. L. (2011). The scent of a partner: ambrosia beetles are attracted to volatiles from their fungal symbionts. Journal of Chemical Ecology, 37(12), 1374-1377.

Inch, S. A., \& Ploetz, R. C. (2012). Impact of laurel wilt, caused by Raffaelea lauricola, on xylem function in avocado, Persea americana. Forest Pathology, 42(3), 239-245.

Inch, S., Ploetz, R., Held, B., \& Blanchette, R. (2012). Histological and anatomical responses in avocado, Persea americana, induced by the vascular wilt pathogen, Raffaelea lauricola. Botany, 90(7), 627-635.

J. Deacon, Fungal Biology $4^{\text {th }}$ edition, Blackwell Publishing, 2006

Jeyaprakash, A., Davison, D. A., \& Schubert, T. S. (2014). Molecular detection of the laurel wilt fungus, Raffaelea lauricola. Plant Disease, 98(4), 559-564. 
Johnson, L. (2008). Iron and siderophores in fungal-host interactions. Mycological Research, 112(2), 170-183.

Macel, M., Van, D. A. M., Nicole, M., \& Keurentjes, J. J. (2010). Metabolomics: the chemistry between ecology and genetics. Molecular Ecology Resources, 10(4), 583-593.

Maor, R., \& Shirasu, K. (2005). The arms race continues: battle strategies between plants and fungal pathogens. Current Opinion in Microbiology, 8(4), 399-404.

Mayfield, A. E., \& Thomas, M. C. (2006). Pest alert: redbay ambrosia beetle, Xyleborus glabratus Eichhoff (Scolytinae: Curculionidae). Florida Department of Agriculture and Human Services, Division of Plant Industry, Gainesville, FL.

McCulloch, M., Jezierski, T., Broffman, M., Hubbard, A., Turner, K., \& Janecki, T. (2006). Diagnostic accuracy of canine scent detection in early-and late-stage lung and breast cancers. Integrative Cancer Therapies, 5(1), 30-39.

Moser, E., \& McCulloch, M. (2010). Canine scent detection of human cancers: a review of methods and accuracy. Journal of Veterinary Behavior: Clinical Applications and Research, 5(3), 145-152.

Niogret, J., Kendra, P. E., Epsky, N. D., \& Heath, R. R. (2011). Comparative analysis of terpenoid emissions from Florida host trees of the redbay ambrosia beetle, Xyleborus glabratus (Coleoptera: Curculionidae: Scolytinae). Florida Entomologist, 94(4), 10101017.

Nussear, K. E., Esque, T. C., Heaton, J. S., Cablk, M. E., Drake, K. K., Valentin, C., Lee, J. L., \& Medica, P. A. (2008). Are wildlife detector dogs or people better at finding desert tortoises (Gopherus agassizii)? Herpetological Conservation and Biology. (3), 103-115.

Philpott, C. C. (2006). Iron uptake in fungi: a system for every source. Biochimica et Biophysica Acta -Molecular Cell Research, 1763(7), 636-645.

Ploetz, R. C., Hulcr, J., Wingfield, M. J., \& de Beer, Z. W. (2013). Destructive tree diseases associated with ambrosia and bark beetles: black swan events in tree pathology? Plant Disease, 97(7), 856-872.

Ploetz, R. C., Pérez-Martínez, J. M., Evans, E. A., \& Inch, S. A. (2011). Toward fungicidal management of laurel wilt of avocado. Plant Disease, 95(8), 977-982.

Robert-Seilaniantz, A., Grant, M., \& Jones, J. D. (2011). Hormone crosstalk in plant disease and defense: more than just jasmonate-salicylate antagonism. Annual Review of Phytopathology, 49, 317-343. 
Savidge, J. A., Stanford, J. W., Reed, R. N., Haddock, G. R., \& Adams, A. A. Y. (2011). Canine detection of free-ranging brown tree snakes on Guam. New Zealand Journal of Ecology, 174-181.

Skoglund, P., Ersmark, E., Palkopoulou, E., \& Dalén, L. (2015). Ancient wolf genome reveals an early divergence of domestic dog ancestors and admixture into high-latitude breeds. Current Biology, 25(11), 1515-1519.

Weckwerth, W. (2003). Metabolomics in systems biology. Annual Review of Plant Biology, 54(1), 669-689.

Yadeta, K. A., \& Thomma, B. P. (2013). The xylem as battleground for plant hosts and vascular wilt pathogens. Frontiers in Plant Science 4(97). 


\title{
CHAPTER 2
}

\section{An evaluation of scent discriminating canines for rapid response to agricultural}

\author{
diseases \\ Julian Mendel ${ }^{1,2,4}$, Kenneth Furton ${ }^{1,3,4}$, DeEtta Mills ${ }^{1,2,3,4}$ \\ Florida International University ${ }^{1}$, Department of Biological Sciences ${ }^{2}$, Department of \\ Chemistry and Biochemistry ${ }^{3}$, International Forensic Research Institute ${ }^{4}$ \\ *Journal of Horticultural Technology: In review
}

\begin{abstract}
Laurel wilt disease, resulting from the invasive species of ambrosia beetle Xyleborus glabratus and its fungal partner Raffaelea lauricola, has resulted in the death of 300-500 million laurel trees since its arrival to the USA in 2002. First detected in Savannah, Georgia, the beetle species was routinely found associated with wild redbay trees afflicted by a systemic wilt disease, thus the beetle was given the common name, the redbay ambrosia beetle. Since then the beetle has spread throughout the state of Florida and the disease can infect all species in the family Lauraceae. One such tree is the commercially important avocado tree, the second largest tree crop in Florida other than citrus. This disease has been devastating the industry locally and larger avocado industries in Mexico and California have taken notice. The major problem with this disease is the rate at which it kills trees and the lack of viable treatments to save them. Trees succumb to the disease in as little as four weeks. Once symptoms are visually detected, is too late to treat or save that tree and the phytopathogen has already spread to adjacent trees via root grafting. Currently there is no viable, cost effective method of early diagnosis and treatment. The present study was undertaken to evaluate the use of
\end{abstract}


scent discriminating canines for detection of trees that were in the pre-symptomatic stages of disease and presents the first report of the ability of canines to detect infected avocado trees. Three canines, one Belgian Malinois and two Dutch Shepherds, were trained and studied over the course of a year for their ability to detect this disease. In addition, prevailing weather conditions were recorded and evaluated to determine their effect on canine performance. The results of the current evaluation suggest that canines are remarkably successful at detecting laurel wilt diseased trees and may provide a powerful tool in the defense of rapidly spreading crop diseases and pests in the near future.

\section{Introduction}

\section{Laurel Wilt Disease}

Laurel wilt disease is the consequence of an invasive species of ambrosia beetle, Xyleborus glabratus, which was introduced into the United States in untreated wooden packaging material. It was first detected in diseased redbay trees (Persea borbonia) in Georgia in 2002 (Mayfield and Thomas 2006). The beetle, originally from Asia, was found to be the vector of the disease in redbays and was thus named Redbay Ambrosia Beetle (RAB) (Fraedrich et al. 2008, Hanula et al. 2008, Mayfield III and Thomas 2006). The term ambrosia refers to an ecological relationship that these beetles share with fungal partners. These mutualistic partners have co-evolved to become dependent on one another for survival and dispersal. Ambrosia beetles belong to the sub-family Scolytinae and are some of the most common and the most devastating pests to plants known to date (Ploetz et al. 2013). 
Ambrosia beetles typically harbor fungal spores within specialized sacs known as mycangia. The location and form varies between species (Batra 1967) but in the case of $\mathrm{RAB}$, the female beetles possess paired mandibular mycangia which excrete fungal spores as they bore into host trees and inoculates the tree with the fungus. The beetle then actively cultivates or farms the fungal gardens within excavated galleries as a food source for itself and its developing larvae (Batra 1967, Ploetz et al. 2013). In laurel wilt disease, the particular fungal partner was identified as a new species of an asexual ascomycete--Raffaelea lauricola (Harrington et al. 2008, Harrington et al. 2011). Further studies on RABs captured in its native habitat, demonstrated the routine isolation of $R$. lauricola from mycangia confirming the pathogen also originated from Asia (Harrington et al. 2011). The name, laurel wilt disease, was coined when the fungal spores of $R$. lauricola were shown to infect and lead to wilt symptoms in many species of trees within the family Lauraceae (Harrington et al. 2008) including the commercially important avocado tree (Persea americana). The disease is systemic and is caused by the clogging of the xylem vessels through the tree's production of tyloses, phenolic, pectin, and lipid containing gums or gels as the tree tries to defend itself from the systemic infection (Inch et al. 2012). The result of blocked xylem vessels is compromised water and nutrient flow during evapotranspiration, visible wilting of the leaves, tissue necrosis and ultimately, the death of the tree. The presence of the fungus can be observed visually through black/brown stained sapwood (Fraedrich et al. 2008, Inch et al. 2012, Inch and Ploetz. 2012).

Laurel wilt disease is highly aggressive and it has been demonstrated that only a few spores (as low as 100 conidia) or a single beetle-boring event can be sufficient to 
elicit the systemic disease in avocado (Ploetz et al. 2013). Although previous suggestions indicated that once the Redbay trees were lost (the disease has killed approximately 300500 million Lauraceae trees in the Southeast coastal forests), the lack of a suitable host tree for breeding by RAB would stop the spread of the disease. However, since decimating the Redbay tree population, the beetle pair has jumped hosts and laurel wilt disease is now rapidly spreading through the South Florida avocado groves, a \$54 million a year industry (Ploetz and Pérez-Martínez 2011), with the cost of replacement of trees rising to $\$ 400$ million. The economic and ecological disaster will be even greater if this disease infects the larger avocado production areas such as California and Mexico.

This pathogen had not been previously described and therefore, very little is known about the fungus, especially the pathogenicity and disease progression. One peculiar factor is that ambrosia beetles typically prefer dead or dying trees (Batra 1967), but the new behavior seen in this invasive species is that it is targeting healthy laurel trees, causing their death. Currently the only preventative measure that exists is the fungistatic TILT ${ }^{\circ}$ which is a propiconazole formulation that suppresses the growth of the fungus but does not kill it. The formulation can provide 12-18 months of protection depending on the method of administration into the trees. However, to prophylactically treat all trees comes with a high cost that many small farmers simply cannot afford. To aid in the control of this disease, scent discriminating canines have been trained on laurel wilt affected avocado wood to enable earlier detection and a more focused cost effective treatment plan for farmers.

\section{Scent discriminating Canines}

The first documented use of canine scent detection comes from tomb evidence depicting 
them as useful hunting partners, a use that still persists today. Currently canines are extensively used in law enforcement and forensic science in the location of missing people, explosives, drugs, weapons, and ammunition (Furton and Myers 2001).

Furthermore, canines have demonstrated the ability to detect invasive species of plants (Goodwin et al. 2010), snakes (Savidge et al. 2011), tortoises (Cablk and Heaton 2006, Nussear et al. 2008), and various cancers (Godfrey 2014, McCulloch et al. 2006, Moser and McCulloch 2010) and even find use in bed bugs, termites, and mold detection (Brooks 2003, Pfiester 2008, Griffith et al. 2007). The highly sensitive canine olfactory system, roughly 10,000-100,000 times more sensitive than humans is capable of detecting odor concentrations at 1-2 parts per trillion. This ability is attributed to the size of the organ, density of neurons, the amount of functional receptors and the physical anatomy of the olfactory system (Craven et al. 2010). The present study represents the first of its kind, to this author's knowledge, evaluating the use of canine odor discrimination in the early detection of this plant disease.

\section{Materials \& Methods}

\section{Study location}

This study was conducted in a privately owned grove in the Redland agricultural district near Homestead, Florida, USA.

\section{Canine selection and training aids}

Canines with no prior training were acquired through the United States K-9 Academy and Police Dog Training Center (Hialeah FL, USA) (Figure 1) and trainers and handlers were provided with training aids containing laurel wilt diseased avocado wood. 


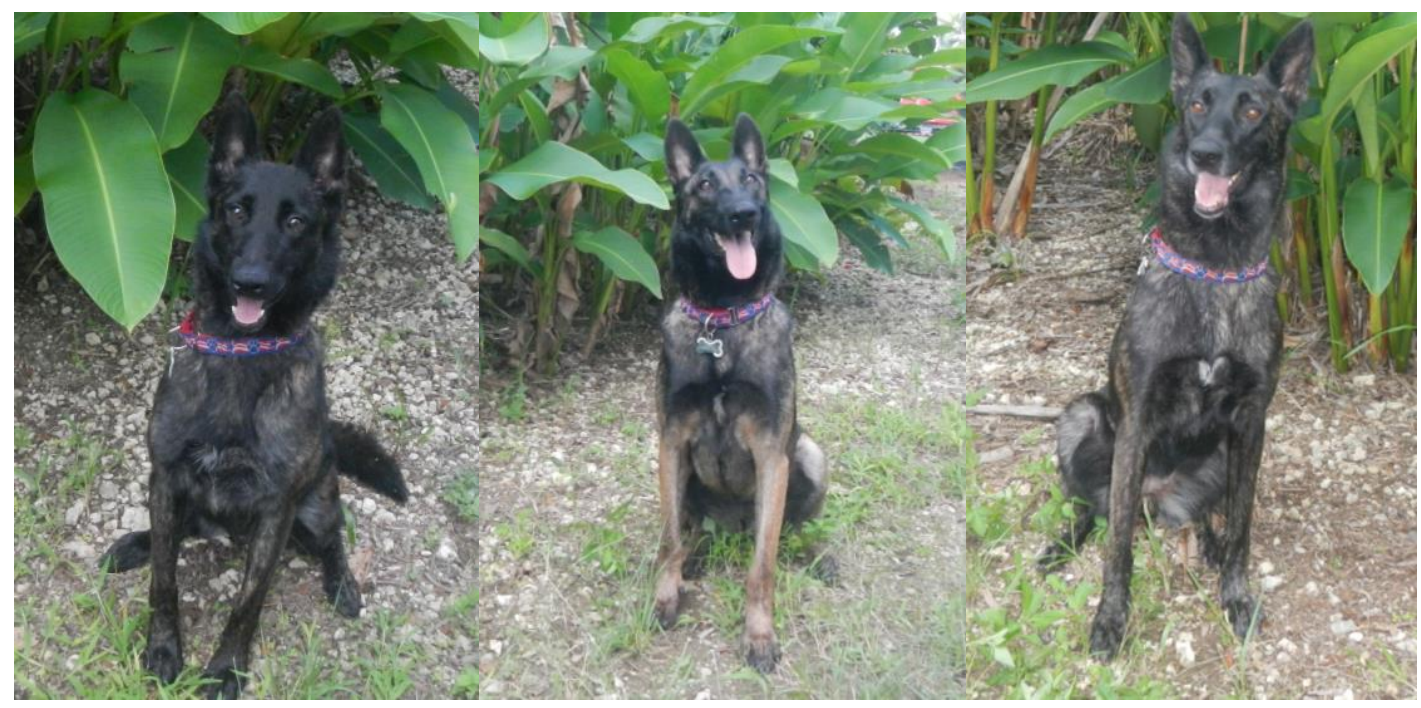

Figure 1. The three canines used in the present study, from left to right: Candy, Cobra and OneBetta

The training aids consist of infected avocado wood placed in Controlled Odor Mimic Permeation System (COMPS) (Figure 2) (United States patent\#: US20080295783 A1) polymer bags. The amount of plant material used was approximately 15-20 grams and was sealed within COMPS, stored in aluminum ziplock bags and allowed to equilibrate at least 24 hours prior to use.

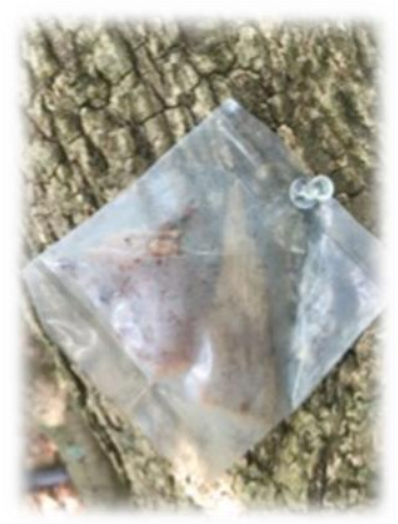

Figure 2. The controlled odor mimic permation system with infected avocado wood sealed inside 


\section{Canine training}

Briefly, canine training was performed in sequential stages. First, the canines were evaluated for their hunt drive or desire to work for reward. This evaluation was done with simple fetch exercises allowing the canines to hunt and locate their favorite chew toy in tall grasses, followed by "hide and seek" exercises in trees. Canines were then rewarded with their favorite chew toys, allowing them to play as a positive reinforcement tool, rather than using food rewards. The second phase of training involved the use of a universal detector calibrant (UDC) (United States patent\#: US9250222 B2), which is a synthetic compound with an odor found not to occur in nature. This began the process of odor association with reward and was done through the use of stainless steel odor boxes and the association of the toy with the UDC training aid. Once the canine proved successful at these two phases, the final step involved the substitution of the UDC for the target odor, laurel wilt disease infected avocado wood. The initial training process was completed in approximately one month followed by reinforcement training a minimum of three times a week thereafter; canines were monitored and evaluated over the course of a year and 229 training sessions.

\section{Evaluation of training success}

The evaluation of the canine performance was done within approximately 186 square meters planted with mango trees to ensure that, by chance, an actual pre-symptomatic, infected avocado tree would not be present at the training site. Training aids were placed 4-5 feet high on trees and were affixed to tree using a pushpin. The time in seconds from 
handler release to training aid location and alert (sitting at the base of the correct tree) was recorded. In addition to these data, the number of false alerts, failures to alert, as well as other observations regarding environmental and other distractors that seemed to affect the canine's accuracy in an agricultural setting were recorded.

\section{Evaluating the effect of weather conditions on canine performance}

Using a Kestrel 4500 weather \& environmental meter (Loftopia, LLC, Birmingham MI, USA) the temperature, relative humidity and wind speed was recorded at the start of each canine deployment.

\section{Three day controlled study}

In order to evaluate whether any differences were observed in canine performance when both the handler and the canine were blind to the placement of the training aids, a better simulation a real deployment scenario, a three day controlled study was also completed. Within a similar training area consisting of 25-30 trees, each tree was assigned a number. The COMPS training aids with healthy or infected avocado wood were prepared and the selection of trees in which to hide/place the training aids was performed using a random number generator. The evaluator then walked up and down each row, visiting each tree to ensure that the canines did not track the human scent but rather were searching for the training aid. After five minutes, the canine handler teams, blinded to the placement of the aids, worked their canines to locate the aids. This scenario was done at three different times, $0900 \mathrm{~h}, 1300 \mathrm{~h}$ and $1600 \mathrm{~h}$, and repeated on three different days with random placement using a random number generator, each time of the training aids. The time to alert on a positive aid was recorded. 


\section{Pathogen detection and negative control evaluation}

Training aids with only the laurel wilt pathogen, grown in pure culture (Ploetz and Pérez-Martínez 2011), were placed in sealed COMPS bags to determine if the canines were able to successfully detect and alert to just the fungus. All materials such as empty COMP bags as well as the media used to grow the pathogen were also set out as distractors during the three-day trial. A "positive pathogen" aid was placed within the training area as well as empty COMP bags and one growth media only sample sealed in a COMP. The dogs were then deployed and observations were made and alerts were recorded.

\section{Canine/handler Certification}

To ensure the training practices and performance of the canine handler teams was of a high standard, independent evaluators from The Scientific Working Group on Dogs and Orthogonal Detector Guidelines (SWGDOG), were used to certify the canines as being able to detect laurel wilt infected avocado wood. The SWGDOG is a committee formed to establish stringent guidelines and limitations for the use of detector dogs (Furton et al. 2010).

\section{Results}

Training Evaluation:

A total of 229 training sessions with three canines, Cobra (73), OneBetta (78) and Candy (78), were performed and the search-locate-alert time for canines was recorded. The averaged time to alert was: $40.82 \pm 3.8 \mathrm{sec}, 37.43 \pm 3.8 \mathrm{sec}$ and $48.50 \pm 4.4 \mathrm{sec}$ for Cobra, OneBetta and Candy, respectively. There was no significant difference between the times 
between canines (ANOVA p>0.05). There were a total of 12 false alerts in which the canines alerted to a tree not holding a positive training aid, 10 of which were attributed to OneBetta. There were also 12 failures to alert recorded, in which the canines did not locate the positive training aid during the session, with 10 being attributed to Candy. In order to evaluate canine performance, the Accuracy (ACC) and Positive Predictive Value (PPV) for each canine was calculated. The average ACC and PPV were determined to be 99.4\% and $94.8 \%$ respectively (Table 1.$)$. 
Table 1. Summary results of the canine searches ( $\mathrm{n}=229$, Candy(78), Cobra(73) OneBetta(78)) during the time period of September 2014 to April 2015.

There was no significant difference between the canines in terms of average time to alert correctly to a training aid (ANOVA p $>0.05$ ). The average accuracy of all three canines was $\sim 99.4 \%$

\begin{tabular}{lccccc}
\hline Canine Name & Canine Breed & $\begin{array}{c}\text { Average Time to Alert } \\
\text { (Seconds) }\end{array}$ & Failure to & False Alerts* & ACC/PPV** \\
& & Alert & $(\%)$ \\
\hline Candy & Dutch Shepherd & 48.50 & 10 & 0 & $99.5 / 100$ \\
OneBetta & Dutch Shepherd & 37.43 & 1 & 10 & $98.9 / 87.0$ \\
Cobra & Belgian Malinois & 40.82 & 2 & $99.7 / 97.3$ \\
\hline
\end{tabular}

* False alerts indicate when a canine sits on a tree that does not hold a training aid

** Accuracy(ACC) is calculated as the True Positive alerts + True Negative alerts divided by the Total Positives trees + Total Negative trees and Positive Predictive Value as the True Positive alerts divided by the sum of the True Positive alerts and False Positive alerts 


\section{Evaluation of weather conditions on performance:}

Scatterplots with trend lines (Figures 3-5) demonstrated shorter times to target location associated with temperature and wind speed, compared to longer search times associated with higher humidity. Linear regression revealed an $\mathrm{R}^{2}$ of 0.07 , with the only significant variable being temperature $(\mathrm{p}<0.05)$. It was observed during the study that false alerts were most often observed on trees downwind but near to the target tree. The analyses found that, with the exception of two alerts, false alerts were all observed when wind speeds were $\sim 5 \mathrm{~km} / \mathrm{h}$. or higher (Figure 6.) 

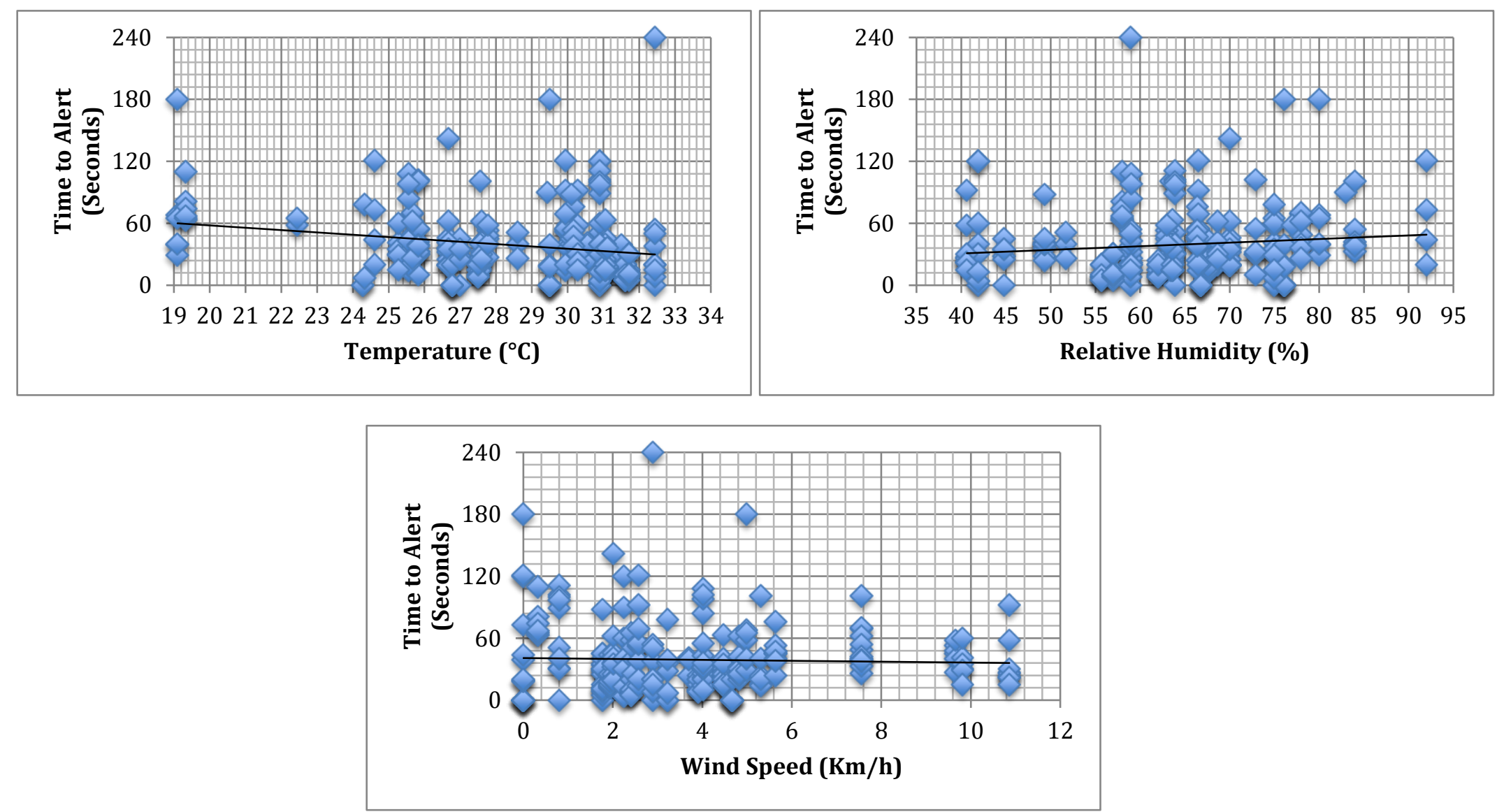

Figures 3-5. The canine data for the three canines with respect to temperature, relative humidity and wind speed. General trends indicate that while the canines are capable of performing well under all the conditions evaluated, increasing temperature $(\mathrm{p}<0.05)$ results in faster target location, with relative humidity $(\mathrm{P}>0.05)$ showing a reverse trend and wind speed showing a slight trend toward faster target location with lower speeds $(\mathrm{p}>0.05)$. 


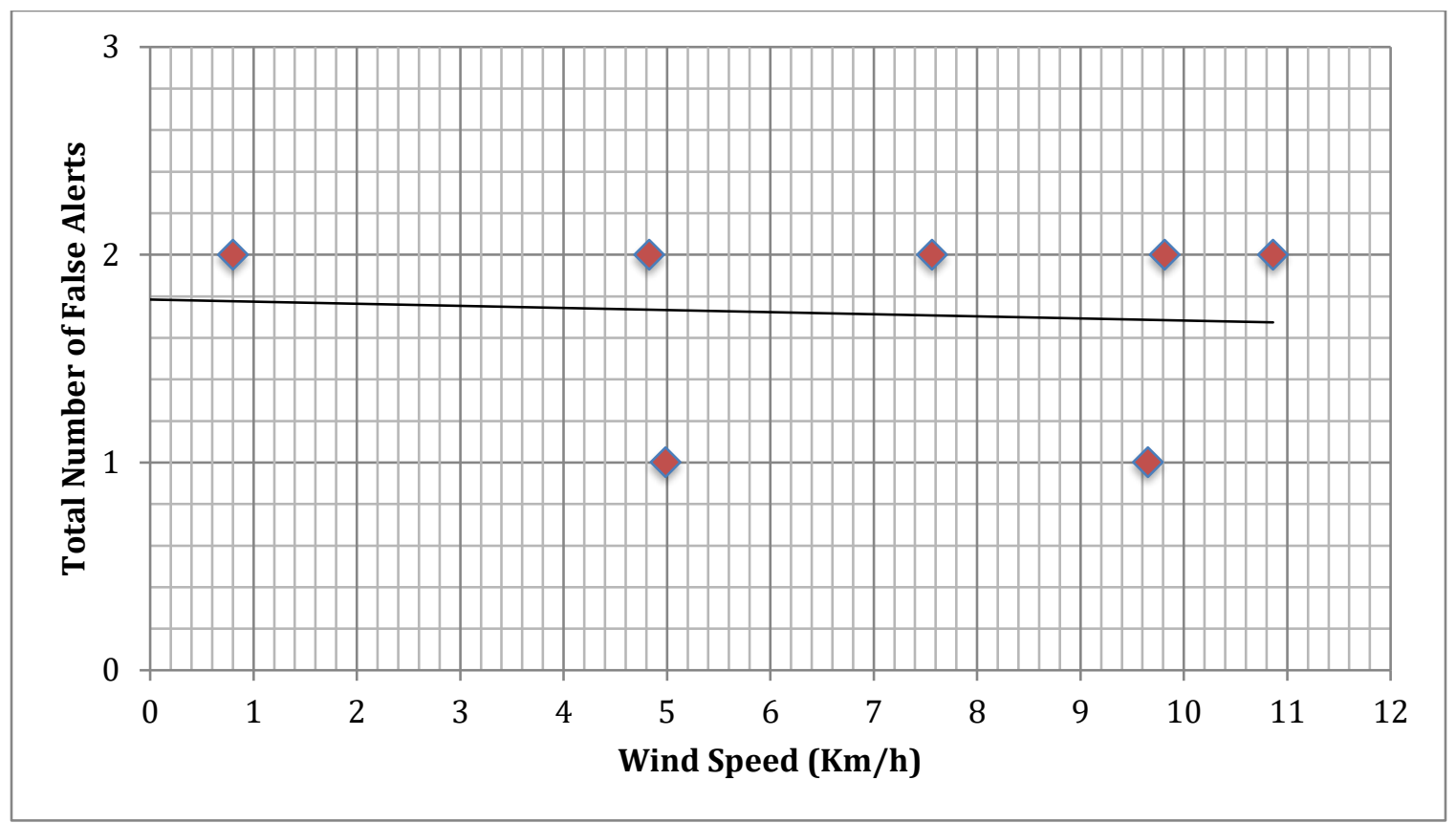

Figure 6. The graph is showing the relationship between total number of false alerts with increasing wind speed . Red indicates false alerts. With the exception of two false alerts by "OneBetta" at $\sim 0.8 \mathrm{Km} / \mathrm{h}$ all false alerts came when wind speed was $\sim 4.8 \mathrm{Km} / \mathrm{h}$ and higher. 


\section{Controlled studies/evaluations:}

A three day controlled study demonstrated high accuracy and precision by all three canines, ANOVA results showed no difference in the time to alert during different times of the day for deployment $(\mathrm{P}>0.05)$. When compared to the 229 canine training sessions it was observed that the randomized, the double-blind study led to significantly longer search times $(\mathrm{P}<0.05)$ (Table 2$)$. The second controlled study involving a variety of negative controls lead to only one false positive alert on growth media by OneBetta (Table 3.).

Table 2. A summary for the controlled three day evaluations with ANOVA results indicating no significant difference between canines as well as no significant difference between time of day ( $>>0.05)$. However, comparing the average from routine training to the more controlled randomized three day trial the average time to locate training aids was significantly higher in the three day trial $(\mathrm{p}<0.05)$.

\begin{tabular}{|c|c|c|c|c|c|}
\hline Canine & Training Time & T1 $($ sec $)$ & T2 $(\mathrm{sec})$ & T3 (sec) & Average \\
\hline Candy & D1- 9:00 AM & 43.54 & 45.01 & 71.2 & 53.25 \\
\hline Candy & D2- 1:00 PM & 60 & 50 & 43 & 51.00 \\
\hline Candy & D3- 4:00 PM & 150 & 25 & 32.9 & 69.30 \\
\hline Cobra & D1- 9:00 AM & 85 & 63 & 169 & 105.67 \\
\hline Cobra & D2- 1:00 PM & 40 & 43 & 80 & 54.33 \\
\hline Cobra & D3- 4:00 PM & 3.43 & 27.27 & 14.68 & 15.13 \\
\hline OneBetta & D1- 9:00 AM & 77 & 7.36 & 40.6 & 41.65 \\
\hline OneBetta & D2- 1:00 PM & 53 & 17 & 80 & 50.00 \\
\hline OneBetta & D3- 4:00 PM & 120 & 51 & 71 & 80.67 \\
\hline
\end{tabular}

- In each case healthy avocado wood was used as a negative control and no alerts were observed 
Table 3. The results of a two week trial with the laurel wilt pathogen cultures and negative control training aid materials for two canines, Cobra and OneBetta.

\begin{tabular}{ccccccc}
\hline Day & Canine & Pathogen & Empty & Empty COMP & Empty & Malt Agar Negative \\
& & & COMP & & NoMP & \\
\hline $\mathbf{1}$ & Cobra & Alert & No Alert & No Alert & No Alert & No Alert \\
$\mathbf{1}$ & OneBetta & Alert & No Alert & No Alert & No Alert & Alert \\
$\mathbf{2}$ & Cobra & Alert & No Alert & No Alert & No Alert & No Alert \\
$\mathbf{2}$ & OneBetta & Alert & No Alert & No Alert & No Alert & No Alert \\
$\mathbf{3}$ & Cobra & Alert & No Alert & No Alert & No Alert & No Alert \\
$\mathbf{3}$ & OneBetta & Alert & No Alert & No Alert & No Alert & No Alert \\
\hline
\end{tabular}




\section{Discussion}

This study demonstrated the ability of canines to detect an agricultural tree disease, laurel wilt. The goals of this study were to evaluate the success of canine training over an extended period, during the time period of September 2014 to July 2015 in Homestead Florida, USA. With an average time to locate a positive sample of infected avocado wood ranged between $~ 37-49$ seconds with the canines working approximately 25-30 trees in the study area, they proved to be not only an accurate detection option but also a truly rapid one. The high accuracy observed in this study was comparable to a study involving the detection of tethered tortoises (Cablk and Heaton 2006) which boasted >90 $\%$ accuracy in locating both surface and burrowed animals. Another study, with the same species of desert tortoise, evaluated detection accuracy in the wild with free roaming tortoises rather than those tethered to a specific location. They reported $70 \%$ accuracy (14).

A remarkably low number of false alerts, only 12, were detected and interestingly OneBetta was the canine responsible for 10 of those 12 alerts. This highlights an important point that each animal's behavior differs. It was noted by the handler and the trainer that OneBetta has a tendency to be eager to alert as soon as she picked up the odor field, but upon denial of her reward she then moves on to locate the point source.

Failures to locate a training aid during a deployment were also noted. A large number of these failed deployments, eleven of them, were due to fallen fruit in the grove, which distracted the canines and resulted in long and interrupted search times and were early in 
their training. Other distractions that resulted in longer times and failed deployments included the presence of other wild animals being flushed from the grasses that distracted the canines from their searches. Fine-tuning of obedience training proved to reduce these incidents over the course of the training, but highlights important factors to consider when deploying canines in an agricultural or uncontrolled environment. In Guam a study involving the location of brown tree snakes, reported a low 35\% success accuracy for the canine teams (Savidge et al. 2011). Perhaps the lower accuracy in that study can be attributed to the added difficulty in locating moving targets, given that in a separate study canines were $81 \%$ accurate locating the invasive plant Knapweed (Goodwin et al. 2010). The current study also calculated the positive predictive value or precision of canines in their detection of laurel wilt diseased avocado wood. The results were ranged between $87 \%-100 \%$ for the three canines. The high accuracy and precision in over 229 deployments coupled with the design of the training, using infected avocado wood and training in an agricultural setting, strongly supports the viability of utilizing canine detectors for laurel wilt disease detection.

The results of the controlled study in which both handlers and canines were blind to the placement of training aids, had an average time to alert of $\sim 58$ seconds which was found to be significantly higher, using a Students T-test $(\mathrm{p}<0.05)$, than the average of the 229 previous canine deployments ( 42 seconds). However, as a result of the substantially smaller number of deployments in the current experiment, it is unclear whether this was truly because of the additional controls and precautions being taken to mask the human trail or whether the difference would be significance with a comparable numbers of trials. During the controlled study, no alerts to healthy avocado wood COMPS were observed 
and in addition, no false alerts were observed to the blank COMPS or other distractors. There was no significant difference found using ANOVA between the accuracy of the three canines, or in deployments taking place at different times of day ( $p>0.05)$.

Another goal of the present study was to investigate the effect, if any, on canine performance in the often-harsh conditions such as high temperatures and humidity in South Florida's agricultural environments. A previous study by Nusser et al. (2008) examined whether the prevailing weather conditions (wind speed, temperature and relative humidity) affected the search times in canine handler teams in locating desert tortoises and found no relationship. Savidge et al. (2010) in the detection of snakes demonstrated increased success with decreasing wind speeds and increasing humidity. In an attempt to evaluate the predictive power of these variables on the time to alert a linear regression analysis was done and demonstrated a weak model with an $\mathrm{R}^{2}$ value of 0.07 ; however, temperature had a significant p-value (ANOVA) indicating it possibly has a greater effect on odor dispersal from COMPS allowing for faster detection times. It is known that high temperatures can adversely affect canines (Furton et al. 2010), so perhaps the small search area combined with higher temperatures led to greater odor dispersal and thus the faster detections observed. It is clear, however, that the canines are capable of performing at high levels under all the conditions observed during the course of the study. Interestingly it was observed that a higher number of false alerts were seen at higher wind speeds $(>4.8 \mathrm{~km} / \mathrm{h})$ (Figure 6), particularly for OneBetta who was responsible for 10 of the 12 false alerts over the course of the study (Table 1). False alerts were usually on a tree downwind of the target tree. Only two false alerts were observed at low wind speeds. It is known that wind can transport odors making higher winds ideal 
for tracking and location over long distances (Cablk and Heaton 2006); however, it can also result in pooling of odors away from the source and dispersal can make it difficult for the canines to pinpoint targets (Savidge et al. 2011). Canine performance was not affected by climate conditions in a previous study with desert tortoises (Nussear et al. 2008) while, with respect to brown tree snakes in Guam, increasing humidity had a positive effect with performance, while lower wind speeds increased success (Savidge et al. 2011).

Lastly, the canines after being presented with the laurel wilt pathogen, grown in pure culture, successfully demonstrated the ability to detect and alert to only the fungus (Table 3.). The fact that the canines were able to alert to and detect the pathogen in laboratory grown cultures, when they were primarily trained on the entire scent picture of the pathogen growing within avocado wood, is a testament to their specificity. This ability is not surprising as previous studies demonstrated this ability to detect lab cultures with canines trained on toxic mold species growing on wood (Griffith et al. 2007). The study on mold aimed to determine if through the use of analytical chemistry, they could identify volatile signature differences between closely related species of mold and whether detector dogs could distinguish between non toxic and toxic species. While canines demonstrated $>90 \%$ accuracy on toxic mold growing on wood, this translated to approximately $70 \%$ with lab-grown cultures (Griffith et al. 2007). This study also discussed the usefulness of analytical techniques to identify unique chemical signatures to improve training through more specific odor mimics as aids, and has also been investigated with explosives and drugs (Harper et al. 2005). 
Another interesting study by Waggoner et al. (1998), discussed the effect of extraneous odors on the ability of canines to detect target odors. This study involved the masking of the target with increasing concentrations of non-target odors (Waggoner et al. 1998). This is significant as most training takes place in controlled environments indoors with no extraneous odors. The results demonstrated a remarkable ability to alert correctly to the target in the presence of masking odors, but that in extremely high non-target odors environments, their detection capabilities can be reduced (Waggoner et al. 1998). In the current study, the method of training in outdoor agricultural settings was well thought out to enable the canines to be accustomed to as many possible interfering odors as possible as they would experience them in their intended deployment application. This study demonstrated successful training, usefulness, and evaluation of the detection capabilities of scent discriminating canines and provides a new tool in the arsenal in defense against plant diseases in an agricultural or outdoor, uncontrolled environment

\section{Conclusion}

This study demonstrated the ability of scent discriminating canines to locate laurel wilt diseased avocado wood with high accuracy and speed. During the course of the study 229 trials were performed and only 12 false alerts were observed and 12 failures to alert. It was observed that canines are capable of high levels of performance even in harsh weather conditions such as high heat and humidity.

This study provided the proof of principle that canines can detect agricultural diseases in planta and can be a powerful tool in disease detection and treatment if the disease is caught in its earliest stages. Laurel wilt disease is especially difficult and costly to manage. Once symptoms of this disease become visible to humans, it is already too late 
for treatment, and that tree must be removed, as it is highly likely that the pathogen has spread to adjacent trees, through root grafts. Analogous to early cancer detection in humans (Godfrey 2014, McCulloch et al. 2006, Moser and McCulloch 2010), the ability to detect trees at an earlier disease stage would provide a significant advantage in the battle to stop the spread of this deadly crop disease.

\section{References}

Batra, L. R. (1967). Ambrosia fungi: a taxonomic revision, and nutritional studies of some species. Mycologia, 59(6), 976-1017.

Brooks, S. E., Oi, F. M., \& Koehler, P. G. (2003). Ability of canine termite detectors to locate live termites and discriminate them from non-termite material. Journal of Economic Entomology, 96(4), 1259-1266.

Cablk, M. E., \& Heaton, J. S. (2006). Accuracy and reliability of dogs in surveying for desert tortoise (Gopherus agassizii). Ecological Applications, 16(5), 19261935.

Craven, B. A., Paterson, E. G., \& Settles, G. S. (2010). The fluid dynamics of canine olfaction: unique nasal airflow patterns as an explanation of macrosmia. Journal of The Royal Society Interface, 7(47) 933-943.

Fraedrich, S. W., Harrington, T. C., Rabaglia, R. J., Ulyshen, M. D., Mayfield III, A. E., Hanula, J. L., ... \& Miller, D. R. (2008). A fungal symbiont of the redbay ambrosia beetle causes a lethal wilt in redbay and other Lauraceae in the southeastern United States. Plant Disease, 92(2), 215-224.

Furton, K. G., \& Myers, L. J. (2001). The scientific foundation and efficacy of the use of canines as chemical detectors for explosives. Talanta, 54(3), 487-500.

Furton, K., Greb, J., \& Holness, H. (2010). The scientific working group on dog and orthogonal detector guidelines (SWGDOG). National Criminal Justice Reference Service, 155, U.S. Department of Justice, Rockville, MD.

Godfrey, A. (2014). Canine scent detection of human cancers: Is this a viable technique for detection? Veterinary Nursing Journal, 29(12), 392-394.

Goodwin, K. M., Engel, R. E., \& Weaver, D. K. (2010). Trained dogs outperform human surveyors in the detection of rare spotted knapweed (Centaurea stoebe). Invasive Plant Science and Management, 3(2), 113-121. 
Griffith, R. T., Jayachandran, K., Whitstine, W., \& Furton, K. G. (2007).

Differentiation of toxic molds via headspace SPME-GC/MS and canine detection. Sensors, 7(8), 1496-1508.

Hanula, J. L., Mayfield, A. E., Fraedrich, S. W., \& Rabaglia, R. J. (2008). Biology and host associations of redbay ambrosia beetle (Coleoptera: Curculionidae: Scolytinae), exotic vector of laurel wilt killing redbay trees in the southeastern United States. Journal of Economic Entomology, 101(4), 1276-1286.

Harper, R. J., Almirall, J. R., \& Furton, K. G. (2005). Identification of dominant odor chemicals emanating from explosives for use in developing optimal training aid combinations and mimics for canine detection. Talanta, 67(2), 313-327.

Harrington, T. C., Fraedrich, S. W., \& Aghayeva, D. N. (2008). Raffaelea lauricola, a new ambrosia beetle symbiont and pathogen on the Lauraceae. Mycotaxon, 104(2), 399-404.

Harrington, T. C., Yun, H. Y., Lu, S. S., Goto, H., Aghayeva, D. N., \& Fraedrich, S. W. (2011). Isolations from the redbay ambrosia beetle, Xyleborus glabratus, confirm that the laurel wilt pathogen, Raffaelea lauricola, originated in Asia. Mycologia, 103(5), 1028-1036.

Inch, S. A., \& Ploetz, R. C. (2012). Impact of laurel wilt, caused by Raffaelea lauricola, on xylem function in avocado, Persea americana. Forest Pathology, 42(3), 239-245.

Inch, S., Ploetz, R., Held, B., \& Blanchette, R. (2012). Histological and anatomical responses in avocado, Persea americana, induced by the vascular wilt pathogen, Raffaelea lauricola. Botany, 90(7), 627-635.

Mayfield III, A. E., \& Thomas, M. C. (2006). The Redbay Ambrosia Beetle, Xyleborus glabratus Eichhoff (Scolytinae: Curculionidae). Florida Department of Agriculture \& Consumer Services, Pest Alert. p1-2.

McCulloch, M., Jezierski, T., Broffman, M., Hubbard, A., Turner, K., \& Janecki, T. (2006). Diagnostic accuracy of canine scent detection in early-and late-stage lung and breast cancers. Integrative Cancer Therapies, 5(1), 30-39.

Moser, E., \& McCulloch, M. (2010). Canine scent detection of human cancers: a review of methods and accuracy. Journal of Veterinary Behavior: Clinical Applications and Research, 5(3), 145-152.

Nussear, K. E., Esque, T. C., Heaton, J. S., Cablk, M. E., Drake, K. K., Valentin, C., Lee, J. L., \& Medica, P. A. (2008). Are wildlife detector dogs or people better 
at finding desert tortoises (Gopherus agassizii)? Herpetological Conservation and Biology. (3), 103-115.

Pfiester, M., Koehler, P. G., \& Pereira, R. M. (2008). Ability of bed bug-detecting canines to locate live bed bugs and viable bed bug eggs. Journal of Economic Entomology, 101(4), 1389-1396.

Ploetz, R. C., Hulcr, J., Wingfield, M. J., \& de Beer, Z. W. (2013). Destructive tree diseases associated with ambrosia and bark beetles: black swan events in tree pathology? Plant Disease, 97(7), 856-872.

Ploetz, R. C., Pérez-Martínez, J. M., Evans, E. A., \& Inch, S. A. (2011). Toward fungicidal management of laurel wilt of avocado. Plant Disease, 95(8), 977-982.

Savidge, J. A., Stanford, J. W., Reed, R. N., Haddock, G. R., \& Adams, A. A. Y. (2011). Canine detection of free-ranging brown tree snakes on Guam. New Zealand Journal of Ecology, 174-181.

Waggoner, L. P., Jones, M. H., Williams, M., Johnston, J. M., Edge, C. C., \& Petrousky, J. A. (1998, December). Effects of extraneous odors on canine detection. In Enabling Technologies for Law Enforcement and Security (pp. 355362). International Society for Optics and Photonics. 


\title{
CHAPTER 3
}

\section{Agri-Dogs: Using canines for earlier detection of laurel wilt disease affecting avocado trees (Persea americana) in South Florida}

\author{
Julian Mendel ${ }^{1,2,4}$, Christina Burns ${ }^{1,2,4}$, Beatrice Kallifatidis ${ }^{1,2,4}$, Edward Evans ${ }^{5}$, \\ Jonathan Crane ${ }^{5}$, Kenneth G. Furton ${ }^{1,3,4}$ DeEtta Mills ${ }^{1,2,3,4}$ \\ *Journal of Horticultural Technology: In review
}

\begin{abstract}
:
\end{abstract}
The invasive ambrosia beetle, Xyleborus glabratus, was first detected in Savannah Georgia, USA in 2002. This tiny beetle has since led to one of the most devastating new plant diseases in recent times. The beetle together with a symbiotic fungal partner, Raffaelea lauricola, a phytopathogen, infects trees of the family Lauraceae. In Florida, this devastating disease has affected the agriculturally important Persea americana (avocado) and once symptoms are visible, i.e., wilting leaves, it is too late to save the infected tree. However, prophylactic systemic treatment with propiconazole can provide some depression of fungal growth for approximately 12-18 months. The present study evaluated the novel approach of using scent discriminating canines trained on the volatiles of laurel wilt pathogen as a proactive management tool for grove owners. Canine deployments in groves resulted in the detection of 265 pre-symptomatic avocado trees during two trials. In trial 1, the detected 155 pre-symptomatic trees were all treated with propiconazole and, over the subsequent 14-month monitoring period, $97 \%$ remained asymptomatic. In trial 2, the canines detected 100 pre-symptomatic trees. But, the trees 
were not treated and the majority succumbed to the disease in $2-5$ weeks. The canines have proven to be an effective proactive management tool.

Introduction:

Laurel wilt disease is a systemic wilt affecting trees belonging to the Lauraceae (Fraedrich et al. 2008, Mayfield III and Thomas 2006). The disease is caused by a fungal pathogen Raffaelea lauricola (Raf) that is now vectored by several ambrosia beetle species in addition to its original host Xyleborus glabratus (Carillo et al. 2014, Fraedrich et al. 2008, Hanula et al. 2008, Harrington et al. 2008, Mayfield and Thomas 2006). Originating from Asia, this new pathogen made entry into the United States through the transport of untreated wooden products used in shipping that contained the invasive redbay ambrosia beetle, Xyleborus glabratus (Harrington et al. 2011). The introduction in 2002 in Georgia led to extreme devastation and the loss of half a billion native woody Lauraceae along the coastal forests from North Carolina to Florida (J. Smith, personal communication). It has spread rapidly over the last 15 years south through all but six counties of Florida and as far west as Texas and Louisiana. In Florida, native Lauraceae and the commercially important avocado Persea americana Mills are hosts of this lethal disease and now poses a serious threat to the avocado industry (Crane et al. 2013, Crane et al. 2015). Current estimates attribute the loss of approximately 25,000 avocado trees ( 250 acres) to laurel wilt (D. Pybas and J.H. Crane, personal communication). 
Ambrosia beetles are a unique clade due to their highly specialized relationship with their symbiotic fungi. Adult female beetles harbor fungal symbionts within specialized sacs known as mycangia and inoculate host trees with this fungus as they bore inside and excavate breeding galleries where they actively cultivate their fungal symbionts for food (Batra 1967). Currently, at least three ambrosia beetle species have been shown capable of transmitting the laurel wilt pathogen (Carillo et al. 2014). The phytopathogen subsequently colonizes and disperses through the xylem vessels, activating the tree's immune response. Host trees begin occluding xylem vessels in an attempt to quarantine and block the spread of the fungus (Inch et al. 2012, Inch and Ploetz 2012). The hypersensitive reaction essentially leads to the tree's death as it completely shuts down its xylem transport of water and nutrients.

The management of this disease has proven to be difficult. A healthy adult tree may be killed within 4-8 weeks and once symptoms are visible, it is too late to save the tree. Early symptoms of laurel wilt include wilting of part or the entire tree canopy, quickly followed by leaf desiccation and browning. As the disease progresses, stems and limbs dieback until eventually the entire tree dies. There is no fungicide currently approved capable of curing an infected tree and only a one, propiconazole $\left(\mathrm{Tilt}^{\circledR}\right)$ can be injected or infused prophylactically into trees that may provide 12-18 months of protection (Mayfield III et al. 2008, Ploetz and Pérez-Martínez 2011).

To complicate the control and spread of the disease, the laurel wilt pathogen can be transmitted by three methods: (a) transmission of the pathogen from tree to tree through 
root grafting among adjacent trees; (b) inoculation of the galleries with the pathogen during other native ambrosia beetle boring; and (c) by anthropogenic movement of ambrosia beetle (pathogen contaminated) infested wood products. If laurel wilt affected trees are not detected and removed quickly one affected tree in a grove may lead to three to five additional diseased trees per month (R. Ploetz, personal communication). This spread significantly increases any treatment or removal costs. If non-symptomatic trees but infected with Raf could be identified efficaciously, these trees could be removed immediately reducing or eliminating the spread of the pathogen from tree-to-tree root graft transmission. This increased detection capability could reduce control costs significantly and improve the efficacy of treating healthy avocado trees with fungicides adjacent to laurel wilt-affected trees. While more effective fungicide treatments and disease resistant avocado cultivars are long-term goals of ongoing research, the best defense available today is to improve the early detection of laurel wilt and to reduce the root transmitted spread of the disease and costs of control.

Scent discriminating canines have been used by man very early in history as evidenced by tomb drawings depicting them as hunting partners, a use that still persists (Furton and Myers 2001). Canines have an incredible sense of smell as a result of the large size and physical structure of the olfactory organs, density of neurons as well as vast numbers of functional receptors (Craven et al. 2009, Furton and Myers 2001). These factors make canines capable of detecting volatiles at concentrations as low as 1-2 parts per trillion. Law enforcement agencies and the military have used canines in the detection of drugs, explosives, money, weapons, as well as missing persons (Furton and Myers 2001). The 
USDA and Border Control have used canines to detect illegal food products, invasive plants and pests (Goodwin et al. 2010), snakes (Savidge et al. 2011), and tortoises (Cablk and Heaton 2006, Nussear et al. 2008) at the borders and ports of entry. Canines have also been used to detect various cancers (Godfrey 2014, McCulloch et al. 2006, Moser and McCulloch 2010) and even for the detection of mold, bedbugs and termites (Brooks et al. 2003, Griffith et al. 2007, Pfiester et al. 2008). The current study reports on the use of canines trained on the scent of laurel wilt pathogen as an early detection tool for farmers to enable more cost effective options for management of pre-symptomatic trees and as an additional tool for overall disease management. The potential for successfully treating non-symptomatic but Raf infected trees with systemic fungicide to maintain tree health and production is discussed.

\section{Materials \& Methods:}

\section{Trial 1: Canine grove deployment and detection}

Two canines were consistently used throughout the duration of this investigation, Cobra, a Belgian Malinois, and One Betta, a Dutch Shepherd. These dogs were trained to detect odors associated with Raf infected avocado wood or the fungal culture through positive reinforcement techniques similar to methods used for law enforcement canine training. The dogs were certified following the practices published by the Scientific Working Group on Dogs and Orthogonal Detector Guidelines (SWGDOG)(SWGDOG.ORG) 
Laurel wilt outbreaks in nine commercial avocado groves (20 to 60 acres in area) in Homestead, Florida, were used to investigate the capability of canine detection of the laurel wilt pathogen. Trees ranged in age from 15 to 85 years old and were spaced from $20 \mathrm{ft}$ to $25 \mathrm{ft}$ in-row and $20 \mathrm{ft}$ to $25 \mathrm{ft}$ between rows. In groves already visibly infected laurel wilt trees, the canines searches led to 165 non-symptomatic trees as potentially positive for Raf but non-symptomatic. Trees alerted to by both dogs during a deployment were tagged and roots were sampled for DNA testing for the presence of the pathogen. One hundred and fifty-five of the 165 laurel wilt suspect trees were infused with Tilt ${ }^{\circledR}$. Ten were left un-treated. With grove owner's permissions, follow up canine visits and monitoring of the health and status of previously tagged trees were done over a 14-month period. Any trees that succumbed to disease were noted.

\section{Root sampling}

Because of the nature of this disease and the fact that this study was done primarily in privately owned groves, sampling for Raf by cutting through the bark and into the sapwood of the trees was not feasible. This was because damaged trees resulted in increased beetle recruitment and could spread the disease. Thus, in trees showing no visible signs of disease, root samples were collected to determine their $R a f$ status. Raffaelea lauricola has been isolated from the roots of container-grown and field avocado trees (Hughes et al. 2015). Fifteen to 30 root sections ranging in diameter of 0.2 $\mathrm{cm}$ to $3.0 \mathrm{~cm}$ and $0.1 \mathrm{~m}$ to $2 \mathrm{~m}$ from the base of the tree trunks were collected from the soil underneath the canopy of the trees identified by the canines. 
Root samples were surface sterilized by washing and removing excess soil with water, followed by a series of washes using 10\% bleach for 1 min followed by brief soak in $70 \%$ ethyl alcohol. Samples were then homogenized with a Micro-Mill ${ }^{\circledR}$ grinder (Bel-Art-SP Scienceware Wayne, NJ) to generate a mixture of consistent small particles/chips. These samples were then used for DNA extraction or for fungal culturing. The DNA extraction from homogenized root samples and fungal cultures was performed using the Fast DNA $^{\mathrm{TM}}$ Spin Kit for Soil (MP Bio, Solon, OH) and FastPrep-24 ${ }^{\mathrm{TM}}$ System homogenizer per manufacturer's protocols. Homogenized root samples were also used to isolate Raffaelea lauricola for DNA testing using a semi selective media CSMA+ (cyclohexamide streptomycin malt agar with additional antibiotics) as described previously (Ploetz and Pérez-Martínez 2011).

The DNA extracts were amplified using qPCR by two previously described techniques. A FAM-labeled Taqman probe for the 28S rDNA species- specific DNA region of interest and LW28S-F1 and LW28S-R1 primers were used (Jeyaprakash et al. 2014). Amplification was performed using the MJ-Mini Opticon Thermal Cycler (Bio-Rad Hercules, CA). DNA extracted from fungal isolates obtained from roots was also amplified using previously published multi-locus microsatellite PCR protocol (Dreaden et al. 2014). Briefly, each reaction contained $1 \mathrm{ng} / \mu$ l template DNA, $1 \mathrm{X}$ Immomix $^{\mathrm{TM}}$ (Bioline, Taunton, MA), 0.4 uM of each primer (Integrated DNA Technologies, 
Coralville, IA) and DEPC water to a final volume of $25 \mu 1$. PCR parameters were: initial denaturation step of $95^{\circ} \mathrm{C}$ for $10 \mathrm{~min}, 40$ cycles of $95^{\circ} \mathrm{C}$ for $35 \mathrm{sec}, 65^{\circ} \mathrm{C}$ for $30 \mathrm{sec}$ and $72^{\circ} \mathrm{C}$ for $30 \mathrm{sec}$. Amplification products were separated on an Applied Biosystems 3130xl Genetic Analyzer using POP-7, Module DS 30, filter D and GeneScan ROX $500^{\mathrm{TM}}$ internal size standard (Thermo Fisher Scientific, Grand Islands, NY). The injection was for $23 \mathrm{sec}$ and subsequent analyses used GeneMapper ${ }^{\circledR}$ v3.7 (Applied Biosystems by Thermo Fisher Scientific, Grand Islands, NY).

\section{Trial 2: Grove monitoring for laurel wilt}

An observational trial was conducted within a 40-50-year old 25-acre grove where several hundred trees were visibly affected with, or had been removed due to laurel wilt. The owner opted to not treat any infected trees with systemic fungicide and instead decided to remove all trees in the near future (Figure 1). Before the grove was to be bulldozed, the owner granted permission to work canines and tag trees for disease monitoring over a six-week period. Canines detected 100 pre-symptomatic trees out of an approximately 800-tree area in the grove within a week. The trees were tagged and their GPS coordinates recorded. Trees were then routinely checked bi-weekly for visible signs (e.g., wilting, leaf desiccation, stem dieback, etc.) of the disease. Since the grove was known to be affected by laurel wilt, DNA testing was not a priority, as there is no other known avocado disease that under dry soil conditions in south Florida kills avocado trees (J.H. Crane, personal communication). The study was run for a period of six weeks 
before the grove was bulldozed; because of the time constraint, the fate of all 100 trees could not be followed.

\section{Economic analysis}

A simple economic feasibility analysis was performed through calculating the costs of canine deployment and treatment of pre-symptomatic trees and comparing the total with the value of a mature fruit bearing avocado tree. This was done utilizing an interactive Tree Value Calculator tool from the agricultural economics extension website at the University of Florida (Evans 2009, Evans and Crane 2016). The analysis model had the following assumptions: assume a five acre canine search area, trees are eight years or older, detected trees showing no visible signs of disease, and successful professional treatment of trees with TILT $^{\circledR}$ was done within five days of canine detection. Additionally, follow up monitoring and, at the grove owner's discretion, fungicide treatments every 12-18 months must be performed to maintain protection of trees. $\underline{\text { Results }}$

\section{Trail 1: Canine grove deployment and laurel wilt detection}

During the course of this study, certified scent discriminating canines were deployed to nine commercial avocado groves affected by laurel wilt disease. Two canines were deployed in each grove and the canines alerted to a 165 trees that were potentially positive for Raf; these trees were classified as pre-symptomatic for laurel wilt--no visible 
disease symptoms. Only trees that both canines independently alerted to in separate deployments were considered positive alerts. Of those 165 trees, 155 were subsequently treated with Tilt ${ }^{\circledR}$ within 1-5 days of canine alert and, over a monitoring period $\geq 14$ months, 151 of these trees remained healthy (97\%) with no visible disease symptoms. Four trees succumbed to laurel wilt one year after the initial treatment. Ten trees that were potentially infected by $R a f$ (i.e., canines alerted) and were not treated (decision of the grove owner). Of those, seven of them succumbed to laurel wilt (70\%) and were removed.

DNA detection indicated that of the 165 trees the canines alerted to $96(58 \%)$ tested positive for Raf, using the $28 \mathrm{~S}$ probe on DNA extracted from the roots. In addition, seven samples were positive using microsatellites and sequenced to confirm identity for isolates grown in culture (Table 1). Since the laurel wilt pathogen is unevenly distributed within trees, sampling roots of the detected trees may not indicate the presence of the pathogen (i.e., false negative) (Crane 2013, Hughes et al. 2015, Inch et al. 2012, Ploetz and PérezMartínez 2011) if the fungus had not trans-located to the roots at the time of sampling. These data suggest that prompt fungicide treatment of pre-symptomatic but Raf positive trees, allows the maintenance of health and production providing that follow up treatments are applied as recommended (Table 1 and 2).

\section{Trial 2: Grove monitoring for laurel wilt}

The observational study resulted in the canines identifying 100 pre-symptomatic trees, of which 22 progressed to full wilt within the 6-week period. An additional nine trees 
showed signs of early disease. Four trees progressed to wilt within 2-3 weeks while the remainder began showing signs of disease four to six weeks post canine alert (Figure 2). It should be noted that trees not alerted to by the canines, but within the search area were also observed and wilt was observed in only four of those trees. Two of which were directly adjacent to an alerted tree. Unfortunately, all 100 trees could not be observed before the complete grove was bulldozed and all trees destroyed.

\section{Laurel wilt management potential}

Out of the nine groves surveyed in trial 1, three owners specifically chose to follow all recommended laurel wilt sanitation guidelines (Crane 2013) using the canine alerts. The sanitation guidelines included the immediate removal of laurel wilt affected trees,

chipping and burning the wood followed by the systemic treatment with Tilt $^{\circledR}$ of a minimum of two to three rings of healthy trees surrounding the removed tree. Over the course of my investigation, 151 of the 155 canine alerted, pre-symptomatic trees were treated with Tilt ${ }^{\circledR}$. These 151 treated trees have remained healthy over 14 -month period. After 14 months, only 4 trees in grove 1 began showing signs of wilt (Table 3).

\section{Economic analysis}

To evaluate the financial cost and benefits of early detection of laurel wilt affected with canines to local avocado growers, calculations and projections were done utilizing data obtained through the Food and Resource Economics Department, at the University of Florida. The calculations indicate a potential savings per 5 acres ranging from $\$ 300$ $\$ 4350$ dollars depending on the number of pre-symptomatic trees detected and treated 
(Table 4).

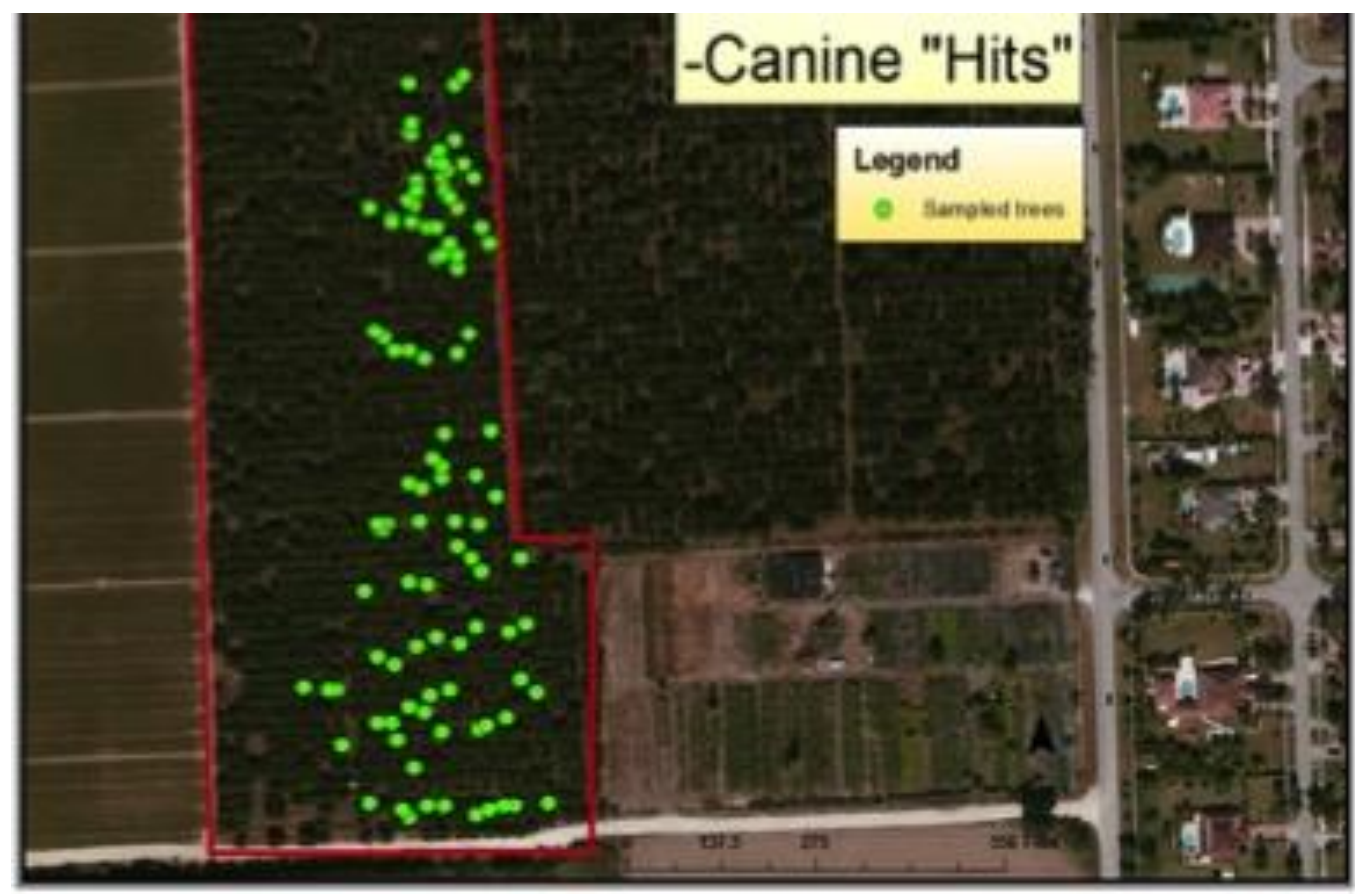

Figure 1. A map showing the trees canines alerted to as pre-symptomatic for the laurel wilt pathogen during trial 2. Trees were visually monitored for six-weeks before the grove was bulldozed. Of the 100 trees with canine alerts, 22 trees progressed to laurel wilt with all the visible symptoms, nine more showed early signs of the disease before the grove was bulldozed. 
Table 1. Laurel wilt DNA results for trees canines identified as pre-symptomatic for laurel wilt disease using root samples.

\begin{tabular}{|l|c|c|c|}
\hline \multicolumn{1}{|c|}{ Trees detected } & \multicolumn{1}{|c|}{$\begin{array}{c}\text { DNA positive for } \\
\text { Raffaelea lauricola }\end{array}$} & $\begin{array}{c}\text { LSU probe positive for } \\
\text { Raffaelea lauricola }\end{array}$ & $\begin{array}{c}\text { Microsatellite PCR } \\
\text { positives of isolates } \\
\text { grown in culture }^{\mathrm{x}}\end{array}$ \\
\hline \multicolumn{2}{|c|}{96} & 92 & $7^{\mathrm{z}}\left(4+3^{\mathrm{x}}\right)$ \\
\hline $\begin{array}{l}\mathrm{z} \text {, Trees were sampled for the laurel wilt pathogen, Raffaelea lauricola, prior to fungicide treatment. } \\
\text { y, DNA results displayed show the total number of LSU probe PCR (direct from root extraction) and }\end{array}$ \\
$\begin{array}{l}\text { Microsatellite positives (from isolates) } \\
\text { x, Four samples were confirmed positive for Raffaelea lauricola } \text { with microsatellites after culturing from } \\
\text { root samples and an additional three samples were negative for the probe but positive upon culturing. }\end{array}$ \\
\hline
\end{tabular}

Table 2. The number of commercial avocado trees canines detected as laurel wilt suspects, number of suspect trees treated with TILT ${ }^{\circledR}$ fungicide and number of trees dead 14 months after fungicide treatment.

\begin{tabular}{|c|c|c|c|c|c|}
\hline $\begin{array}{c}\text { \# trees } \\
\text { canines } \\
\text { detected }\end{array}$ & $\begin{array}{c}\text { Infusion } \\
\text { treatment }\end{array}$ & $\begin{array}{c}\text { \# trees healthy } \\
\text { after } 14 \text { mo }\end{array}$ & $\begin{array}{c}\% \text { trees } \\
\text { remaining } \\
\text { healthy }\end{array}$ & $\begin{array}{c}\text { \# trees } \\
\text { progressed to } \\
\text { wilt }\end{array}$ & $\begin{array}{c}\text { \% progressed } \\
\text { to wilt }\end{array}$ \\
\hline 155 & $\begin{array}{c}\text { Treated with } \\
\text { Tilt }\end{array}$ & 151 & 97 & 4 & 3 \\
\hline 10 & Non-treated & 3 & 30 & 7 & 70 \\
\hline
\end{tabular}




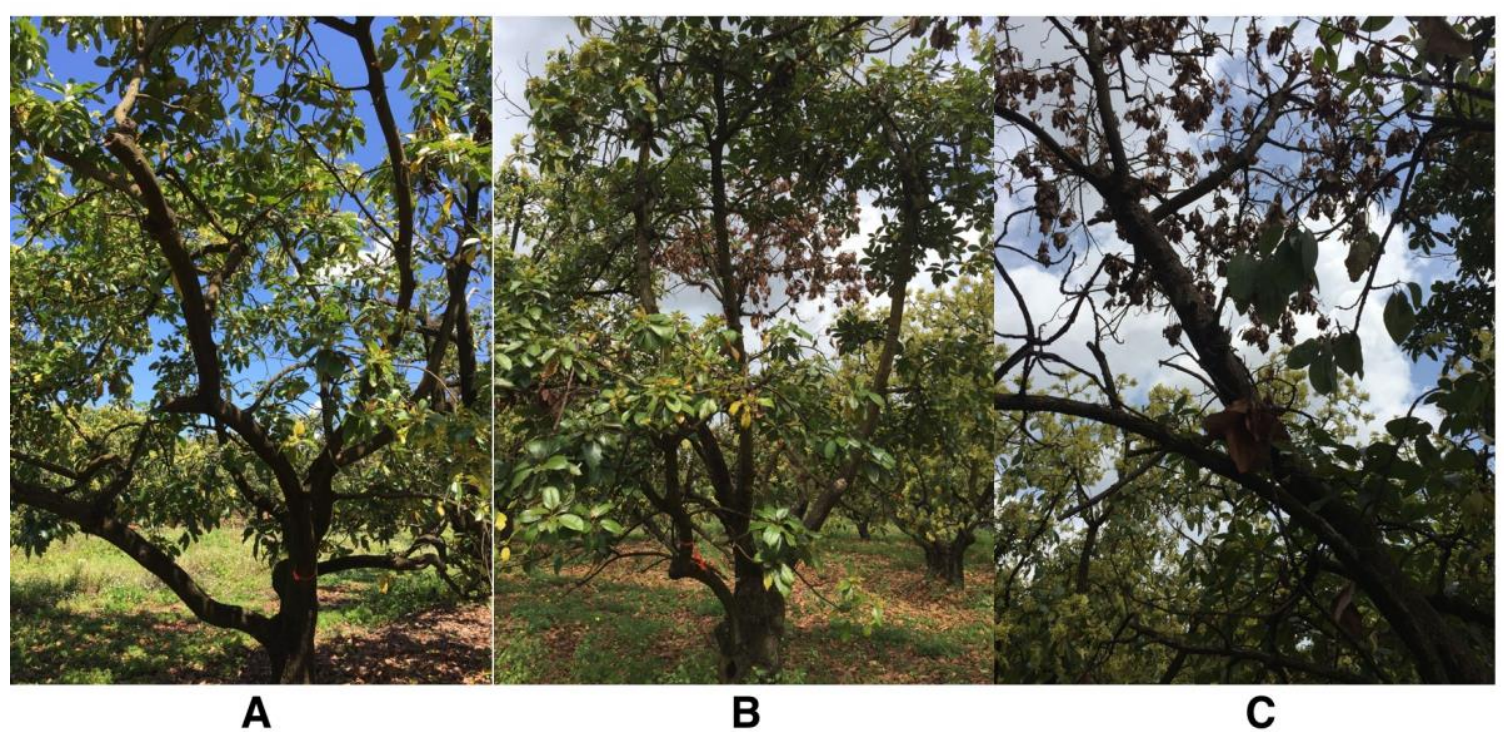

Figure 2. Image taken of an avocado tree in a commercial grove at the time of the canine alerts (A), and two weeks post canine alert (B and C), showing symptoms of laurel wilt, during Trial 2. 
Table 3. Disease management results for three individual avocado groves where grove owners followed recommended prophylactic propiconazole $\left(\right.$ TILT $\left.^{\circledR}\right)$ treatment and guidelines based on canine alerts.

\begin{tabular}{|c|c|c|c|c|c|}
\hline $\begin{array}{l}\text { Grove } \\
\text { ID }\end{array}$ & $\begin{array}{l}\text { Number } \\
\text { of trees in } \\
\text { grove }\end{array}$ & $\begin{array}{l}\text { Number of pre- } \\
\text { symptomatic trees } \\
\text { detected by canines }\end{array}$ & $\begin{array}{l}\text { Number of } \\
\text { Tilt }{ }^{\circledR} \text { treated } \\
\text { trees }\end{array}$ & $\begin{array}{l}\text { Number of treated } \\
\text { trees that progressed to } \\
\text { wilt }\end{array}$ & $\begin{array}{l}\text { Protection } \\
\text { period } \\
\text { (months) }\end{array}$ \\
\hline 1 & 2250 & 35 & 342 & 4 & 14 \\
\hline 2 & 1200 & 49 & 281 & 0 & 16 \\
\hline 3 & 1000 & 23 & 62 & 0 & 9 \\
\hline
\end{tabular}

Table 4. Cost and simple economic feasibility analysis of canines as an early detection tool for laurel wilt disease in a five-acre commercial grove.

\begin{tabular}{|l|c|c|c|c|c|c|}
\hline Activity & $\begin{array}{l}1 \text { Tree } \\
\text { detected }\end{array}$ & $\begin{array}{l}2 \text { Trees } \\
\text { detected }\end{array}$ & $\begin{array}{l}3 \text { Trees } \\
\text { detected }\end{array}$ & $\begin{array}{l}4 \text { trees } \\
\text { detected }\end{array}$ & $\begin{array}{l}5 \text { trees } \\
\text { detected }\end{array}$ & $\begin{array}{l}10 \text { trees } \\
\text { detected }\end{array}$ \\
\hline $\begin{array}{l}\text { Canine } \\
\text { deployment }\end{array}$ & $\$ 150$ & $\$ 150$ & $\$ 150$ & $\$ 150$ & $\$ 150$ & $\$ 150$ \\
\hline $\begin{array}{l}\text { TILT }^{\circledR} \\
\text { treatment }^{\mathrm{x}}\end{array}$ & $\$ 25$ & $\$ 50$ & $\$ 75$ & $\$ 100$ & $\$ 125$ & $\$ 250$ \\
\hline Sum & $\$ 175$ & $\$ 200$ & $\$ 225$ & $\$ 250$ & $\$ 275$ & $\$ 400$ \\
\hline $\begin{array}{l}\text { Value of saved } \\
\text { trees }^{\mathrm{z}}\end{array}$ & $\$ 475$ & $\$ 950$ & $\$ 1425$ & $\$ 1900$ & $\$ 2375$ & $\$ 4750$ \\
\hline
\end{tabular}

$\mathrm{X}$, Cost of infusion with Tilt ${ }^{\circledR}$ fungicide.

$\mathrm{y}$, Cost to deploy canines on a 5- acre grove.

z, This simplified analysis sets deployment costs at $\$ 150$ for 5 acres. The value of a lost tree is calculated utilizing the University of Florida Agricultural

Economics Extension interactive Tree Value Analysis tool. Assumptions and factors considered are the age of the bearing tree (mature at 8 years or more), interest rates, the farm gate price of avocado fruit per pound, the cost of stump removal if tree succumbs to laurel wilt and the replant costs of a new tree. 


\section{Discussion:}

Invasive species due to their very nature tend to be major problems in the non-native ecosystems they invade. With extensive global trade and travel, the rate of new introductions of insects and diseases has continued to grow and has become a significant problem (Batra 1967). A naïve host, when faced with a novel pathogen is at a great disadvantage and if the host is of significant economic or ecological value the impacts on the ecosystem and commercial interests can be catastrophic (Griffith et al 2007, Ploetz et al. 2013). Generally, indigenous and exotic ambrosia beetles are not significant environmental or agricultural pests (Ploetz et al. 2013). In their native habitats, they usually attack dead and decaying wood, or compromised trees, but recent ambrosia beetle introductions have become invasive and the redbay ambrosia beetle attacks healthy trees possibly due to olfactory mismatch (Hulcr and Dunn 2011,Ploetz et al. 2013). In addition, other ambrosia beetles that normally attack stressed trees that are contaminated with the laurel wilt pathogen are now the primary vectors for laurel wilt in commercial avocado groves (Carillo et al. 2014). Laurel wilt disease has killed over half a billion native laurel trees throughout the southeastern U.S. and in many cases, has completely restructured critical ecosystems and coastal forests. To add to the problem, the disease has spread to the agriculturally important avocado production area of south Florida. This extends the problem beyond an ecological disaster and now impacts the economy of the state of Florida and has the potential to be the causal agent of thousands of job losses. This industry generates \$54M/year annually (Evans et al. 2010, Ploetz et al. 2011) and 
the economic impact of this disease on the avocado industry is estimated to be $\$ 400 \mathrm{M}$ (Evans et al. 2010) The rapid spread of this disease could result in even greater disaster should it reach Mexico, California and Central and South America.

Historically, other well-studied tree diseases such as Chestnut blight and Dutch elm disease are similar to the laurel wilt. Chestnut blight caused by a fungal ascomycete Chryphonetria parasitica, which originated from a shipment of nursery trees from Asia (Gruenwald 2012). It was discovered that there were two forms of the pathogen, one possessing viral RNA sequences that lead to a loss of pathogenicity. This phenomenon, termed hypo-virulence by attenuation (Nuss 1992, Peever et al. 2000), lead to the successful bio-control of the disease. Dutch elm disease was caused by another invasive ascomycete vectored by a bark beetle, and similar to laurel wilt, also originated from Asia (Brasier 1991, Harwood et al. 2011). The management of this disease involved pruning trees and removing debris for burning and sanitation, followed by the infamous use of DDT, a pesticide used to combat beetles that subsequently had devastating effects on the environment (Harwood et al. 2011). Fungicides were used as well as beetle traps. Resistance to the disease through biological agents was successful where a species of non-pathogenic fungi was applied to trees to stimulate immunity and resistance. Finally, the best-case scenario for management of tree diseases is development of resistant cultivars, however, this is a long-term approach. Indeed the breeding programs leading to hybrids have lead to disease resistant elms (Harwood et al. 2011). 
What can be learned from these classic examples is that management of new invasive tree disease is a daunting task and a costly one. Chemical control without due diligence can lead to unintended consequences and while biological control and breeding programs for disease resistant trees are ideal, they require significant research and funding and usually are long term solutions. The case of laurel wilt is no different, and the best solution available at the current time involves reactive versus proactive approaches.

In an effort to provide a more rapid response and aid the farmers in this difficult situation, scent discriminating canines were trained on the scent of $R a f$ and deployed in a number of groves to determine their ability to improve rapid disease detection and subsequent management. It appears that visually non-symptomatic but $R a f$ affected avocado trees if detected prior to visual disease symptoms (i.e., wilting, desiccation, etc.) and immediately treated with systemic fungicide may survive for up to 14 months. This approach represents a significant leap in the proactive monitoring and early detection capabilities of the farmer. The goal of early detection and treatment with canines is to significantly reduce the spread laurel wilt outbreaks, delineate the hot spots of disease and to reduce the costs to the grove owner.

The canines used in the present study were trained on the scent of laurel wilt infected avocado wood over a period of one year and reinforcement training was done weekly. Independent evaluators following the Scientific Working Group on Dogs and Orthogonal Detector Guidelines (SWGDOG) certified these canines as being capable of detecting laurel wilt diseased avocado wood with $>95 \%$ accuracy. The present study is the first 
documented investigation to evaluate the use of canines to detect a xylem based, vascular wilt disease in trees. Previous studies have demonstrated good accuracy and capabilities with canines used in the conservation of animal species such as the desert tortoise and brown tree snakes (Cablk and Heaton 2006, Nussear et al. 2008, Savidge et al. 2011) and also demonstrated an ability to outperform human surveyors in locating the rare spotted knapweed, a problematic invasive plant (Goodwin et al. 2010).

During the course of the present study an opportunity was presented to monitor the visual progression of pre-symptomatic trees in a private, laurel wilt affected grove (Trial 2). This study resulted in the detection of 100 pre-symptomatic trees within a 3-day period and while the grove was bulldozed after only 6 weeks of monitoring, 22 trees with positive canine alert progressed to wilt and an additional four demonstrated some sign of possible wilt with green leaves beginning to wilt. Nonetheless, the results suggest that the canines have the ability to alert to Raf infected trees as far as 40 to 46 days before any visual symptoms developed.

Finally, of the nine groves where canine deployments were routine (Trial 1), three owners followed the recommended guidelines for sanitation and also treated pre-symptomatic trees identified by the canine alerts plus 1-2 rings of trees around the infected tree with Tilt $^{\circledR}$ (Table 4). These three groves were all affected by chronic laurel wilt infections prior to the canine detection and systemic application of Tilt ${ }^{\circledR}$ to these pre-symptomatic trees. Over the period of 14 months, canine alerts lead to the treatment of $342(\sim 15 \%)$ trees in grove 1, $281(\sim 23 \%)$ in grove 2 and $62(\sim 6 \%)$ in grove 3 . Of the trees treated 
only four succumbed to wilt and only did so after 14 months after the initial treatment with TILT $^{\circledR}$ in grove 1 . This demonstrated the importance of being vigilant and early treatment but also showed the necessity to possibly re-deploying the canines to monitor even after fungicide infusions and perhaps the need for repeated treatment to maintain protection. These three groves demonstrate the validity and success of using canines as a management tool specifically for early detection. It is of special importance that grove 1 had lost in excess of 100 trees to wilt prior to this approach and only 4 since deployment (after $12+$ months post treatment). Also, the cost of treating every tree in a grove is prohibitive for the vast majority of growers and the approach resulted in successful management with only proactively treating hot spots or a small fraction of the total number of trees.

To further evaluate the financial benefits of early detection an economic analysis was done. With the cost of deployment for canines was set at $\$ 150$ for 5 acres (approximately 500 trees) and the cost of treatment at $\$ 25$ per tree. The result indicated that depending on the number of pre-symptomatic trees detected the potential avoided losses ranged from approximately $\$ 300$ to $\$ 4350$ depending on the number of trees identified. The ability of canines to detect these trees before symptoms greatly enhances the ability to stop the spread of infections, reducing losses and saving money over the long term. It is also important to note that when a tree is lost and a new one planted, it takes six years before it bears fruit, and a total of seven years until they are considered mature (Braulia et al. 2014). Even then that tree will likely not produce more than half the product as the previously lost older tree. Therefore, this type of proactive approach using canines is an 
economically worthy effort in the fight against laurel wilt disease. Canine detection provides a rapid response to managing the spread of infection and proved to be cost effective in both the short term and the long run.

\section{$\underline{\text { Conclusion }}$}

World trade today has no physical borders and thousands of miles of ocean are irrelevant with respect to the movement and establishment of invasive species. Global commerce and trade has led to the introduction of devastating diseases and disturbances to native and naïve ecosystems and the frequency of these events is only expected to increase. The options for management and protection are often very limited because of the simple fact that, by nature, these events are spontaneous and new. A common factor in the treatment of any disease is that early detection will significantly improve the prognosis and the potential to prevent, treat, or reduce the spread. Therefore innovative, and rapid deployment methods are key. Canines provide a highly sensitive bio-detector system for virtually anything with an odor and this study demonstrated their capabilities as an additional management tool in an agricultural setting. In conclusion this study demonstrates that canines can be critical as an early detection tool for the monitoring of both new and existing diseases and of pests on important commercial crops. In the case of laurel wilt, being able to detect up to 46 days before symptoms appear, opens a window to save trees that previously would have been lost. 


\section{Acknowledgements}

The Florida Department of Agriculture and Consumer Services (FDACS) supported this research through a Specialty Crop Block Grant (\#020731) to Dr. DeEtta Mills. Julian Mendel was supported in part during this research through the MBRS-RISE program (NIH/NIGMS R25 GM061347). The presented content is solely the responsibility of the authors and does not necessarily represent the official views of the National Institutes of Health. We thank Innovative Detection Concepts (iDC) for providing the canines used in this project, as well as canine trainers Peter Nunez and Lourdes Eldin for training and handling the canines. Special thanks also to Dr. Jennifer Gebelein and Carlos Pulido as well as Alison Simon.

\section{References}

Batra, L. R. (1967). Ambrosia fungi: a taxonomic revision, and nutritional studies of some species. Mycologia, 59(6), 976-1017.

Brasier, C. M. (1991). Ophiostoma novo-ulmi sp. nov., causative agent of current Dutch elm disease pandemics. Mycopathologia, 115(3), 151-161.

Braulia De Oleo, Edward A. Evans, and J. H. Crane. Establishment cost of avocados in South Florida. EDIS New Publications RSS. Food and Resource Economics, Oct. 2014. Web. 06 Dec. 2016

Brooks, S. E., Oi, F. M., \& Koehler, P. G. (2003). Ability of canine termite detectors to locate live termites and discriminate them from non-termite material. Journal of Economic Entomology, 96(4), 1259-1266.

Cablk, M. E., \& Heaton, J. S. (2006). Accuracy and reliability of dogs in surveying for desert tortoise (Gopherus agassizii). Ecological Applications, 16(5), 1926-1935.

Carrillo, D., Duncan, R. E., Ploetz, J. N., Campbell, A. F., Ploetz, R. C., \& Peña, J. E. (2014). Lateral transfer of a phytopathogenic symbiont among native and exotic ambrosia beetles. Plant Pathology, 63(1), 54-62.

Crane J. (2013, April 11). Retrieved October 5, 2016, from http://trec.ifas.ufl.edu/RAB-LW-2/pdfs/Current status and recommendations for control of LW and RAB 4-10-13 pdf version.pdf

Crane, J.H., E.A. Evans, D. Carrillo, R.C. Ploetz, and A.J. Palmateer. 2015. The potential for laurel wilt to threaten avocado production is real. Proc. VIII World Avocado Congress, Lima, Perú (Sept. 13-18, 2015) p.9-16. [Accessed 12-23-15; http://www.avocadosource.com/WAC8/WAC8_TOC.htm]. 
Crane, J.H., J. Peña, and J.L. Osborne. 2013. Redbay ambrosia beetle-laurel wilt pathogen: a potential major problem for the Florida avocado industry. Hort. Sci. Dept., UF/IFAS Extension. [http://edis.ifas.ufl.edu/pdffiles/HS/HS37900.pdf].

Craven, B. A., Paterson, E. G., \& Settles, G. S. (2009). The fluid dynamics of canine olfaction: unique nasal airflow patterns as an explanation of macrosmia. Journal of The Royal Society Interface, (7) 933-943.

Dreaden, T. J., Davis, J. M., Harmon, C. L., Ploetz, R. C., Palmateer, A. J., Soltis, P. S., \& Smith, J. A. (2014). Development of multilocus PCR assays for Raffaelea lauricola, causal agent of laurel wilt disease. Plant Disease, 98(3), 379-383.

Evans, E. A., Crane, J., Hodges, A., \& Osborne, J. L. (2010). Potential economic impact of laurel wilt disease on the Florida avocado industry. Horticulture Technology, 20(1), 234-238.

Evans, E.A. and J.H. Crane. 2016. Estimates of the replacement costs of commercial and backyard avocado trees in south Florida. Food and Resource Econ. Sept., UF/IFAS Extension. 3 pages [accessed 2-2-17; http://edis.ifas.ufl.edu/fe825].

Evans, E.A., (2009, June 8). Tree Value Analysis Tool. Retrieved February 14, 2017, from http://agecon.centers.ufl.edu/TreeCostAvocado.htm

Fraedrich, S. W., Harrington, T. C., Rabaglia, R. J., Ulyshen, M. D., Mayfield Iii, A. E., Hanula, J. L., ... \& Miller, D. R. (2008). A fungal symbiont of the redbay ambrosia beetle causes a lethal wilt in redbay and other Lauraceae in the southeastern United States. Plant Disease, 92(2), 215-224.

Furton, K. G., \& Myers, L. J. (2001). The scientific foundation and efficacy of the use of canines as chemical detectors for explosives. Talanta, 54(3), 487-500.

Godfrey. A. BSc (Hons) RVN (2014) Canine scent detection of human cancers, Veterinary Nursing Journal, 29:12, 392-394, DOI: 10.1111/vnj.12200

Goodwin, K. M., Engel, R. E., \& Weaver, D. K. (2010). Trained dogs outperform human surveyors in the detection of rare spotted knapweed (Centaurea stoebe). Invasive Plant Science and Management, 3(2), 113-121.

Griffith, R. T., Jayachandran, K., Whitstine, W., \& Furton, K. G. (2007).

Differentiation of toxic molds via headspace SPME-GC/MS and canine detection. Sensors, 7(8), 1496-1508.

Gruenwald, N. J. (2012). Novel insights into the emergence of pathogens: the case of chestnut blight. Molecular Ecology, 21(16), 3896-3897. 
Hanula, J. L., Mayfield, A. E., Fraedrich, S. W., \& Rabaglia, R. J. (2008). Biology and host associations of redbay ambrosia beetle (Coleoptera: Curculionidae:

Scolytinae), exotic vector of laurel wilt killing redbay trees in the southeastern United States. Journal of Economic Entomology, 101(4), 1276-1286.

Harrington, T. C., Fraedrich, S. W., \& Aghayeva, D. N. (2008). Raffaelea lauricola, a new ambrosia beetle symbiont and pathogen on the Lauraceae. Mycotaxon, 104(2), 399-404.

Harrington, T. C., Yun, H. Y., Lu, S. S., Goto, H., Aghayeva, D. N., \& Fraedrich, S. W. (2011). Isolations from the redbay ambrosia beetle, Xyleborus glabratus, confirm that the laurel wilt pathogen, Raffaelea lauricola, originated in Asia. Mycologia, 103(5), 1028-1036.

Harwood, T. D., Tomlinson, I., Potter, C. A., \& Knight, J. D. (2011). Dutch elm disease revisited: past, present and future management in Great Britain. Plant Pathology, 60(3), 545-555.

Hughes, M. A., Inch, S. A., Ploetz, R. C., Er, H. L., Bruggen, A. H. C., \& Smith, J. A. (2015). Responses of swamp bay, Persea palustris, and avocado, Persea americana, to various concentrations of the laurel wilt pathogen, Raffaelea lauricola. Forest Pathology, 45(2), 111-119.

Hulcr, J., \& Dunn, R. R. (2011). The sudden emergence of pathogenicity in insectfungus symbioses threatens naive forest ecosystems. Proceedings of the Royal Society of London B: Biological Sciences, 278(1720), 2866-2873.

Inch, S. A., \& Ploetz, R. C. (2012). Impact of laurel wilt, caused by Raffaelea lauricola, on xylem function in avocado, Persea americana. Forest Pathology, 42(3), 239-245.

Inch, S. A., Ploetz, R., Held, B., \& Blanchette, R. (2012). Histological and anatomical responses in avocado, Persea americana, induced by the vascular wilt pathogen, Raffaelea lauricola. Botany, 90(7), 627-635.

Jeyaprakash, A., Davison, D. A., \& Schubert, T. S. (2014). Molecular detection of the laurel wilt fungus, Raffaelea lauricola. Plant Disease, 98(4), 559-564.

Mayfield III, A. E., \& Thomas, M. C. (2006). The Redbay Ambrosia Beetle, Xyleborus glabratus Eichhoff (Scolytinae: Curculionidae). Pest Alert. Florida Department of Agriculture \& Consumer Services.

Mayfield III, A. E., Barnard, E. L., Smith, J. A., Bernick, S. C., Eickwort, J. M., \& Dreaden, T. J. (2008). Effect of propiconazole on laurel wilt disease development in 
redbay trees and on the pathogen in vitro. Arboriculture \& Urban Forestry, 34(5), 317-324.

McCulloch, M., Jezierski, T., Broffman, M., Hubbard, A., Turner, K., \& Janecki, T. (2006). Diagnostic accuracy of canine scent detection in early-and late-stage lung and breast cancers. Integrative Cancer Therapies, 5(1), 30-39.

Moser, E., \& McCulloch, M. (2010). Canine scent detection of human cancers: a review of methods and accuracy. Journal of Veterinary Behavior: Clinical Applications and Research, 5(3), 145-152.

Nuss, D. L. (1992). Biological control of chestnut blight: an example of virusmediated attenuation of fungal pathogenesis. Microbiological Reviews, 56(4), 561576.

Nussear, K. E., Esque, T. C., Heaton, J. S., Cablk, M. E., Drake, K. K., Valentin, C., Lee, J. L., \& Medica, P. A. (2008). Are wildlife detector dogs or people better at finding desert tortoises (Gopherus agassizii)? Herpetological Conservation and Biology. (3), 103-115.

Peever, T. L., Liu, Y. C., Cortesi, P., \& Milgroom, M. G. (2000). Variation in tolerance and virulence in the chestnut blight fungus-hypovirus interaction. Applied and Environmental Microbiology, 66(11), 4863-4869.

Pfiester, M., Koehler, P. G., \& Pereira, R. M. (2008). Ability of bed bug-detecting canines to locate live bed bugs and viable bed bug eggs. Journal of Economic Entomology, 101(4), 1389-1396.

Ploetz, R. C., Hulcr, J., Wingfield, M. J., \& de Beer, Z. W. (2013). Destructive tree diseases associated with ambrosia and bark beetles: black swan events in tree pathology?. Plant Disease, 97(7), 856-872.

Ploetz, R. C., Pérez-Martínez, J. M., Evans, E. A., \& Inch, S. A. (2011). Toward fungicidal management of laurel wilt of avocado. Plant Disease, 95(8), 977-982.

Savidge, J. A., Stanford, J. W., Reed, R. N., Haddock, G. R., \& Adams, A. A. Y. (2011). Canine detection of free-ranging brown tree snakes on Guam. New Zealand Journal of Ecology, 174-181. 


\title{
CHAPTER 4
}

\section{Enhancing sample collection for the diagnosis and profiling of laurel wilt disease}

\begin{abstract}
Laurel wilt disease continues to be difficult to detect, manage, and diagnose by conventional means. One issue with this disease, as well as other similar beetle vectored diseases, is the sampling methods available for diagnosis or study. Currently, the practice is to hack into the tree with a cutting tool, such as a hatchet, and remove pieces of wood to be sent back to the diagnostic lab to test for the phytopathogen. This method is extremely destructive, causing damage to a tree that can likely lead to additional problems, such as enhanced beetle recruitment. In addition to that, often, as is the case with laurel wilt disease, the pathogen is not evenly distributed within the tree so sampling one location on the plant produces false negative results. To this end a non-invasive vacuum device previously developed in the field of forensics has been repurposed for the collection of microbial communities and externally secreted metabolites from the inside of a tree without the need to chop into it. The device has demonstrated successful results in recovering touch/trace DNA such as epithelial cells, pollen grains from fabric and, in the current study, microbial communities and fungal spores from beetle galleries within a tree. From laurel wilt infected trees, the Venturi vacuum device (VVD) provided noninvasive samples of the pathogenic fungi, Raffaelea lauricola, without including plant host material.
\end{abstract}


Introduction

Sample collection is an important first step in most scientific investigations. In some cases sample collection can be simple and some techniques can be applied to a variety of sample types. Often it can also be the opposite, where most traditional sampling techniques simply do not fulfill the needs of a particular investigation. The fungal pathogen of laurel wilt disease grows within the xylem and excavated ambrosia beetle galleries of trees in the family Lauraceae (Inch et al. 2012, Inch and Ploetz 2012). Because these portions of the plant host are very difficult to access, sampling for positive pathogen identification, diagnosis or research typically involves chopping out a relatively large piece of the plant with a hatchet. Drawbacks to using this method are a high rate of false negative detection of the pathogen, because it is unevenly distributed in the tree, and the large wound causing increased beetle attack (personal communication, Jonathan Crane).

The objective of this study was to test the use of a modified version of the Venturi vacuum device (VVD), developed for the collection of touch DNA forensic samples, as a more reliable and less destructive method for detecting laurel wilt disease in avocado trees.

Materials \& Methods:

Venturi Vacuum Device (VVD):

The VVD is portable and electricity free. It utilizes a Venturi pump (Vaccon Company, Inc. Medway, MA) that generates suction through the action of high speed compressed 
$\mathrm{CO}_{2}$. This lack of dependence on electricity through the use of a Venturi pump to generate suction enables varying sizes of compressed air tanks to be used making it fully capable of field deployment (Figure 1, Patent pending, Serial No. 15/007,501).

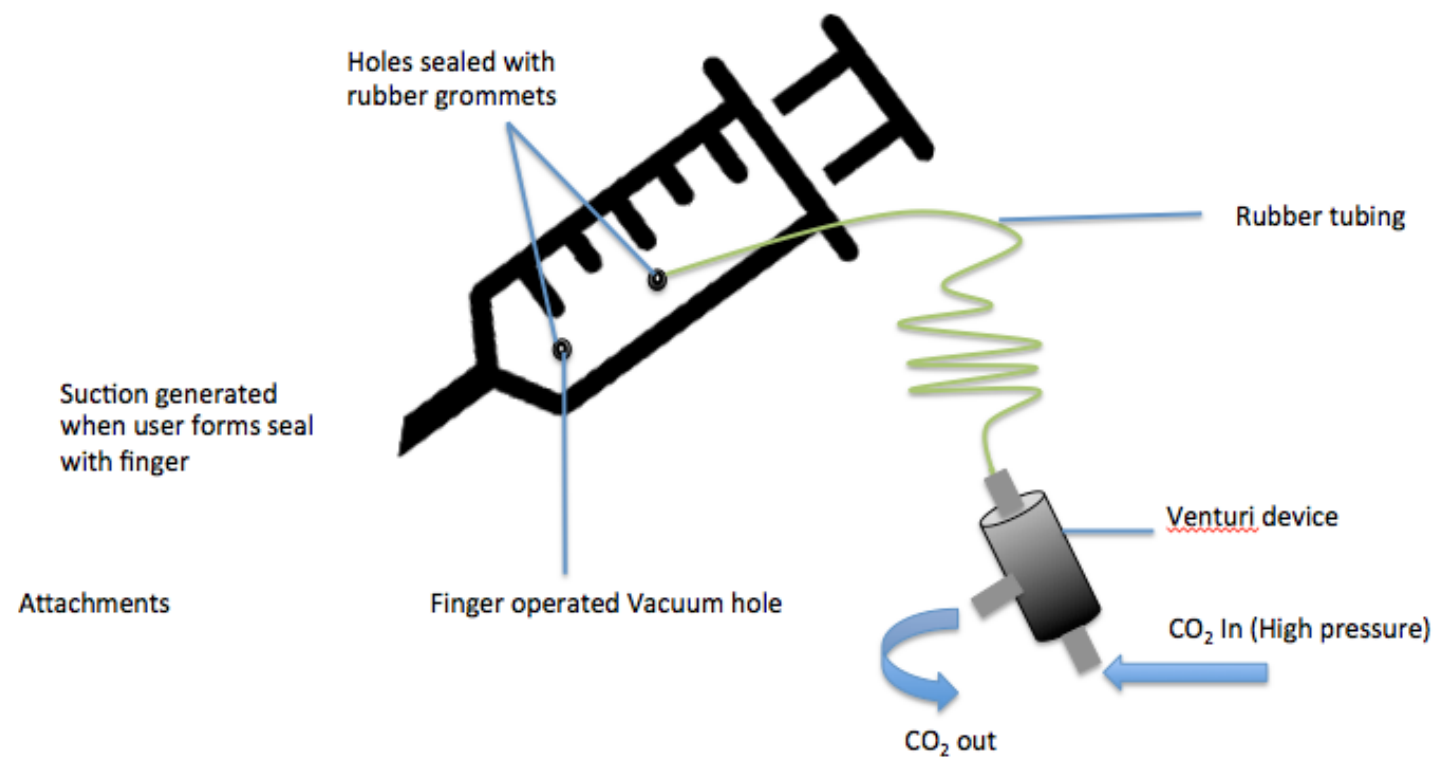

Figure 1. The prototype syringe modified Venturi vacuum device used to collect gallery samples.

\section{Gallery Flushes}

The vacuum device was applied to the collection of fungal spores from avocado trees demonstrating symptoms of laurel wilt disease. If no beetle burrow entry was obvious, a minimal piece of the outer bark was carefully stripped away to reveal the inner xylem sapwood where the beetle galleries are located and the fungus thrives. A solution of $1 \mathrm{x}$ PBS was used to flush beetle canals and the sapwood to dislodge fungal spores. The VVD was used to simultaneously collect spores on polycarbonate filters. In order to determine whether spores were successfully collected, the filters were shredded and placed onto malt extract agar plates and monitored for fungal growth at room temperature 
for 10 days. Finally, DNA analysis was used to confirm the presence of the pathogen. DNA extraction

The DNA extraction was performed using the Fast DNA ${ }^{\mathrm{TM}}$ Spin Kit for Soil (MP Bio, Solon, $\mathrm{OH}$ ) and FastPrep-24 ${ }^{\mathrm{TM}}$ System homogenizer per manufacturer's protocols. Raffaelea lauricola DNA analysis

As described in previous work a FAM-labeled Taqman probe for the $28 \mathrm{~S}$ rDNA speciesspecific DNA region of interest and LW28S-F1 and LW28S-R1 primers were used (Jeyaprakash et al. 2014). Amplification was performed using the MJ-Mini Opticon Thermal Cycler (Bio-Rad Hercules, CA).

Results:

Attempts to recover fungal communities from within beetle galleries using the vacuum device also proved successful as seen in the resulting growth on malt extract plates (Figure 2). In addition DNA results from gallery flushes and isolations indicated the presence of Raffaelea lauricola. 


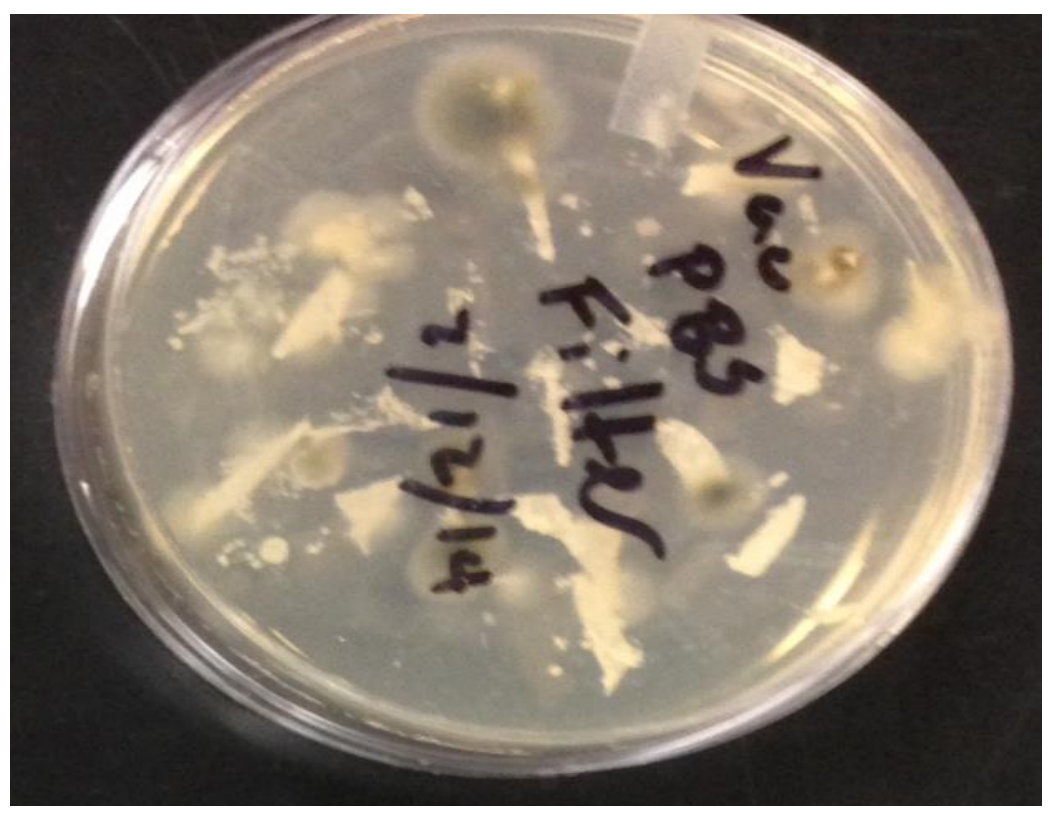

Figure 2. Photograph of fungal growth from polycarbonate filters used on avocado trees with vacuum collection from beetle galleries. Fungal growth was observed on malt extract plates indicating that fungal spores were successfully collected using the vacuum device. This application can prove useful in the diagnosis of various plant pathogens that are not easily accessible by other means.

\section{Discussion:}

Sample collection is a critical part of any biological investigation. In the field of forensic DNA analysis and more specifically touch sample collection this is even more important as the integrity of sampling affects the admissibility of evidence in a courtroom. There have been studies that demonstrate clearly the lack of innovation in sample collection as well as others that compare techniques such as tape lifts and swabs which provide strong evidence that techniques vary in efficiency and usefulness as sample types and locations are different (Pang and Cheung 2007, Kenna et al. 2011). Others have demonstrated the usefulness of vacuum technology in more efficient sample collection. In recent times the M-Vac wet vacuum collection device has shown some promise in crime scene evidence 
collection but key downfalls were the size and complexity of the instrument limiting its wide spread use and also deployment in the field (Hedman et al. 2015). In addition it was not ideal for fabrics. In the case of the Venturi prototype developed for use in the current study, many of these issues have been addressed. The compressed air-fed Venturi pump is hand-held, sterile and portable, and the air tank size is variable depending on the need for portability. The device is not run with electricity, enabling field deployment for sample collection. In addition, the simple design enables various front-end tip modifications such as suction cups fitted with filters, or needle applicators, all of which can be easily switched to tackle an array of sample types and access to difficult locations. In previous work, the device successfully collected various forensic samples such as epithelial cells for forensic DNA profiling, and pollen from fabric. The present work demonstrated the success in collecting microbial communities from within beetleexcavated tunnels within avocado trees. The modified syringe/needle applicator enabled the flushing of galleries with simultaneous collection of material for metabolic profiling, the results of which will be discussed in the next chapter of this dissertation. With respect to laurel wilt disease and similar vascular wilt pathogens, as mentioned previously, sampling is often done through the cutting of trees to remove wood for culturing in the lab but often the pathogen is not evenly distributed throughout the tree and false negatives can occur (Crane 2013, Hughes et al. 2015, Inch et al. 2012, Ploetz and Pérez-Martínez 2011). The Venturi vacuum device greatly reduces this risk as it enables direct sampling of beetle galleries, which harbor gardens of the fungal pathogen. Utilizing this method represents a great innovation in sampling technique, a non- 
destructive approach, which enables the targeted study of microbial communities in hard to reach, in situ environments.

\section{References}

Crane, J.H., J. Peña, and J.L. Osborne. 2013. Redbay ambrosia beetle-laurel wilt pathogen: a potential major problem for the Florida avocado industry. Hort. Sci. Dept., UF/IFAS Extension. [http://edis.ifas.ufl.edu/pdffiles/HS/HS37900.pdf].

Hedman, J., Ågren, J., \& Ansell, R. (2015). Crime scene DNA sampling by wetvacuum applying M-Vac. Forensic Science International: Genetics Supplement Series, 5, e89-e90.

Hughes, M. A., Inch, S. A., Ploetz, R. C., Er, H. L., Bruggen, A. H. C., \& Smith, J. A. (2015). Responses of swamp bay, Persea palustris, and avocado, Persea americana, to various concentrations of the laurel wilt pathogen, Raffaelea lauricola. Forest Pathology, 45(2), 111-119.

Inch, S. A., \& Ploetz, R. C. (2012). Impact of laurel wilt, caused by Raffaelea lauricola, on xylem function in avocado, Persea americana. Forest Pathology, 42(3), 239-245.

Inch, S. A., Ploetz, R., Held, B., \& Blanchette, R. (2012). Histological and anatomical responses in avocado, Persea americana, induced by the vascular wilt pathogen, Raffaelea lauricola. Botany, 90(7), 627-635.

Jeyaprakash, A., Davison, D. A., \& Schubert, T. S. (2014). Molecular detection of the laurel wilt fungus, Raffaelea lauricola. Plant Disease, 98(4), 559-564.

Kenna, J., Smyth, M., McKenna, L., Dockery, C., \& McDermott, S. D. (2011). The recovery and persistence of salivary DNA on human skin. Journal of Forensic Sciences, 56(1), 170-175.

Pang, B. C. M., \& Cheung, B. K. K. (2007). Double swab technique for collecting touched evidence. Legal Medicine, 9(4), 181-184.

Ploetz, R. C., Pérez-Martínez, J. M., Evans, E. A., \& Inch, S. A. (2011). Toward fungicidal management of laurel wilt of avocado. Plant Disease, 95(8), 977-982. 


\section{CHAPTER 5}

\section{The laurel wilt metabolome: A non-targeted UPLC-HRMS approach reveals significant changes in disease biochemistry}

Introduction

Laurel wilt disease, since its introduction in 2002 in Port Wentworth, Georgia, has lead to severe devastation of the wild laurel forests. It is estimated that over 300-500 million redbay trees have been lost in the southeastern United States (Hughes et al. 2017). Since spreading to S Florida in 2012, it has posed and continues to pose a significant and growing threat to the avocado industry (Crane et al. 2015, Evans et al. 2010, Ploetz et al. 2011). (The reader is directed to a thorough review on the current status, goals and challenges involved with management and control of this disease by Ploetz et al. (2017)). Of significant concern is the general lack of knowledge on how Raffaelea lauricola (Raf/RL), the fungal pathogen that causes laurel wilt disease, causes the rapid and systemic death of its host tree. Current work involves searching for resistant cultivars for breeding programs, new fungicides, improved beetle control and grove sanitation. Plantpathogen interactions are difficult to elucidate and with a lack of basic knowledge of this new invasive species and disease, it becomes all the more difficult. As genomic and transcriptomic analyses are the main focus within the laurel wilt research community, this study aimed to shed light on the disease dynamics through a non-targeted metabolomics approach.

Metabolomics is considered to be the highest level of post genome analysis (Allwood et. al 2008). This becomes especially powerful as small even sometimes-undetectable changes in gene expression can lead to large changes in metabolism. Plant metabolomics 
generally aims to identify and quantify chemical compounds that are present and can be system wide, localized or phenotype based. Metabolomics is fast becoming a natural complement to traditional genetic expression investigations and has been used extensively in the exploration of plant microbe interactions. Investigations into general fungal interactions (Allwood et al. 2008, Draper et al. 2011, Mazid et al. 2011, Pusztahelyi et al. 2015, Tenenboim and Brotman 2016), parasitic (Lee et al. 2016) and pathogenic fungal interactions (Kumar et al. 2014, Parker et al. 2009, Pasquet et al. 2014, Thatcher et al. 2009) have revealed insightful information on disease biochemistry, plant defenses, and resistance. This study involved the non-targeted metabolite profiling of mature avocado trees, both healthy and diseased, found in commercial groves in Homestead Florida, USA. In addition, mock inoculation samples of young avocado were collected to monitor disease progression within the host tree, as well in vitro metabolite detection of the fungal pathogen in culture. The results and comparisons revealed significant differences between infected and healthy avocado trees, sufficient enough for discrimination and classification of the two phenotypes. Discriminate analysis revealed potential biomarkers for disease and using Random Forest analysis, successful and accurate diagnoses of diseased trees was possible.

Materials \& Methods:

\section{Sample types and collection:}

The sample types used in this study involved xylem/wood samples (experiment 1) as well as beetle gallery/canal flushes (experiment 2) and the phytopathogen grown in culture (experiment 3). 
Experiment 1, xylem samples: Samples of healthy xylem from six trees, and infected xylem from 18 trees were collected and processed as described below. Infected xylem samples were taken from areas surrounding and including beetle inoculation points to represent a sample consisting of both host and pathogen/microbial metabolites. To sample, a small portion of the outer bark of the trees was removed, approximately $5 \mathrm{ft}$ above ground, to reveal the inner xylem surface of the trunk. Two to three strips of xylem tissue, $1 \mathrm{~cm} \times 3 \mathrm{~cm}$, were then removed using surface sterilized cutting tools. Samples were placed in $2 \mathrm{~mL}$ cryo-tubes (Thermo Fisher Scientific, Grand Islands, NY) and placed on dry-ice/acetone for flash freezing followed by storage at $-80^{\circ} \mathrm{C}$ until shipped on dry ice for metabolomic processing.

Experiment 2: Beetle gallery flush samples from 21 infected trees were collected in the field using the VVD, and processed for metabolomics as described in the next section. Briefly, beetle galleries and the artificial inoculated galleries in the greenhouse experiments (described below) were sampled directly using $1 \mathrm{~mL}$ of $1 \mathrm{X}$ phosphate buffered saline (PBS) (Thermo Fisher Scientific, Grand Islands, NY) and a sterile VVD. Galleries were flushed with PBS while simultaneously applying a vacuum for the collection of samples. The liquid collected was then expelled into $2 \mathrm{~mL}$ cryo-tubes, flash frozen and stored at $-80^{\circ} \mathrm{C}$.

Four young avocado trees of the variety Lula were purchased and placed in a greenhouse facility and allowed to acclimate to the conditions for 3 weeks. The trees were 1 to 1.5 meters in height with a main stem diameter of approximately $4 \mathrm{~cm}$. Fungal inoculation was performed using a sterilized $2 \mathrm{~mm}$ diameter drill bit to make four, 45 -degree, angled downward, canals, staggered around the main stem of the trees. The holes were made 
about $10 \mathrm{~cm}$ above the graft union. Using sterile syringes, suspensions of approximately 5000-7000 Raffaelea lauricola spores were injected into each of the holes, then sealed and wrapped with parafilm wax. Using the VVD, the artificial galleries were sampled prior to inoculation, and then one hole was sampled per week upon the onset of visual symptoms. The samples were flash frozen, stored, and processed as described above. Experiment 3: In vitro temporal xylem strip colonization by the phytopathogen:

In order to evaluate the immediate and initial changes during the colonization of xylem by $R$. lauricola, $1-2 \mathrm{~cm}$ long, thin strips of freshly cut healthy xylem were placed directly on top of the pathogen growing in a semi-selective media (Ploetz and Pérez-Martínez 2011) for 10 days. Triplicate xylem strips were then removed at 3, 24, 48, 72, and $120 \mathrm{hr}$ for processing. In order to establish the resting metabolic profile of the pathogen, triplicate samples of the pure culture biomass were also collected and served as a baseline. The samples were flash frozen and stored as described above.

\section{Sample preparation and analyses:}

All samples were sent to collaborators at the University of Tennessee Knoxville for metabolite extraction, identification, and quantification.

Experiment 1, Wood: Wood fractions were manually ground under liquid nitrogen using a mortar and pestle. Weights were recorded for normalization-to-mass. A 1,300 $\mu \mathrm{L}$ aliquot of extraction solvent ( $0.1 \%$ formic acid in 2:2:1 acetonitrile:water:methanol) was added to each sample, followed by a 20 min incubation period at $-20^{\circ} \mathrm{C}$. Samples were centrifuged at 13,000 rpm for $5 \mathrm{~min}$, where after the supernatant was collected. Pellets were washed with $200 \mu \mathrm{L}$ of extraction solvent, incubated, and then centrifuged. The 
supernatant fractions were combined and dried under nitrogen. Samples were resuspended with $300 \mu \mathrm{L}$ of milliQ water.

Experiment 2, Flush: Gallery flush fractions were centrifuged (13,000 rpm for $5 \mathrm{~min})$ then dried under nitrogen, followed by re-suspension with $300 \mu \mathrm{L}$ of milliQ water. Experiment 3, temporal, in culture: The temporal samples were processed the same as wood samples described above and the $R a f$ samples were treated as gallery flush samples.

\section{Metabolomics parameters and analyses:}

Ultra-high performance liquid chromatography coupled with high-resolution mass spectrometry (UPLC-HRMS): UPLC-HRMS was completed using an Ultimate 3000 LC pump coupled with an Exactive Plus Orbitrap ${ }^{\mathrm{TM}}$ MS (Thermo Fisher Scientific, Waltham, MA). All solvents were HPLC grade and purchased from Thermo Fisher Scientific (Atlanta, GA). Solvent A (97:3 water:methanol containing $10 \mathrm{mM}$ tributylamine, and 15 $\mathrm{mM}$ acetic acid) and solvent $\mathrm{B}$ (methanol), were set to use a multi-step gradient as follows; 0 to $5 \mathrm{~min}, 0 \% \mathrm{~B} ; 5$ to $13 \mathrm{~min}, 20 \% \mathrm{~B}$; 13 to $15.5 \mathrm{~min}, 55 \% \mathrm{~B} ; 15.5$ to $19 \mathrm{~min}$, $95 \% \mathrm{~B}$; and 19 to $25 \mathrm{~min}, 0 \% \mathrm{~B}$. With a flow rate of $0.2 \mathrm{~mL} / \mathrm{min}$, a $10 \mu \mathrm{L}$ injection passed through a Synergi Hydro-RP $(100 \times 2.0 \mathrm{~mm}, 2.5 \mu \mathrm{m})$ LC column (Phenomenex) maintained at $25^{\circ} \mathrm{C}$. While running full scan in negative mode, the eluent was introduced to the MS by an electrospray ionization source (Lu et al., 2010). Samples were analyzed with a resolving power of 140,000 and a scan window of 72 to $800 \mathrm{~m} / \mathrm{z}$ from 0 to $9 \mathrm{~min}$, and 100 to $1,000 \mathrm{~m} / \mathrm{z}$ from 9 to $25 \mathrm{~min}$. Samples were injected in a randomized order to reduce instrumental error. 
Data Processing: Using MAVEN (Melamud et al., 2010), metabolites were selected from a pre-existing list of 270 known compounds with annotated biological activity. All retention times were confirmed using standards, or based on previously established chromatography (Lu et al., 2010). Integration of the area under the curve provided each metabolite with a total ion count that can be considered the relative concentration of the metabolite within a single sample.

Statistical Analysis: Heat maps were generated to visualize differences between sample types healthy versus infected, diseased xylem versus diseased gallery flushes and gallery flushes versus the pathogen in pure culture. This was performed first by using Cluster (http://bonsai.hgc.jp/ mdehoon/software/cluster/software.htm) to $\log _{2}$ transform the data, and then it was clustered using an average linkage function. Next using JTree software (http://jtreeview.sourceforge.net) maps were generated.

Further analyses were performed using MetaboAnalyst 3.0 (www.metaboanalyst.ca), a comprehensive data analysis web tool suite of statistical software built for metabolomics analysis (Xia et al.2015, Xia and Wishart, 2016). The data were pre-processed including transformation and scaling of the data to reduce technical/experimental variations and improve performance of downstream analysis. Multivariate analysis in the form of partial least squares discriminate analysis (PLS-DA) was used for classification and identification of important feature selection.

In order to determine the predictive ability or the ability of the data to diagnose/discriminate between diseased and healthy samples, the machine learning algorithm Random Forest analysis using "randomForest" R-Package (https://CRAN.Rproject.org/package=randomForest) was employed. The Random forest analysis was 
performed in two separate trials: The first trial used only xylem samples (healthy and infected) where two-thirds of the data were used for training the model and the remaining data were used to test its classification accuracy. The second trial used the entire xylem data set (healthy and infected) and tested the model using gallery flushes from infected trees to determine whether they would classify correctly as infected trees. Finally, using the Kyoto Encyclopedia of Genes and Genomes metabolome informatics (KEGG compound) database (http://www.genome.jp/kegg/compound/), metabolites were mapped to relevant existing pathways for biological significance assignment and comparison. Results \& Discussion:

This experiment represents the first of its kind to investigate the biochemical changes in laurel wilt disease. As discussed in the previous chapter, current sampling techniques for diagnosis of laurel wilt disease involves an unrefined process of chopping into trees followed by lengthy lab culture times and then DNA analysis to identify the causative agent. This approach is not ideal as it leads to damaged trees and increased recruitment of beetles, as more tree volatiles are released in response to the wounding (Kendra et al. 2011, Nigoret et al. 2011), which could possibly enhance disease progression as the tree activates different biochemical pathways to cope with the wounding. The use of the VVD also described in the previous chapter enabled the non-invasive sampling of beetle galleries directly. This approach was successful in generating metabolic profiles directly associated with each disease state environment.

\section{Experiment 1}

Healthy versus infected samples: Sampling of the xylem of mature avocado trees in the groves lead to the identification of 171 metabolites. When comparing healthy xylem to 
infected xylem, profiles revealed 104 significantly up-regulated metabolites $(\mathrm{p}<0.05) 11$

of which were exclusively found in the infection. There were an additional 10

compounds that were significantly down regulated $(\mathrm{p}<0.05)$ in infected xylem when

compared to healthy xylem. The significance of the changes was determined through a

\section{Students T-test (Table 1).}

Table 1. Showing the significantly different compounds observed when comparing healthy to infected xylem samples. Significance was determined with a Students T-test $(\mathrm{p}<0.05)$.

\begin{tabular}{|c|c|c|}
\hline \multicolumn{2}{|c|}{ Increased During infection* } & Reduced During Infection \\
\hline 3-Methylthiopropionate & Homovanillic acid (HVA) & Allantoate \\
\hline $\begin{array}{l}\text { 5-Hydroxyindoleacetic acid (5- } \\
\text { HIAA) }\end{array}$ & N-Acetylglucosamine 1/6-phosphate & Uridine \\
\hline $\mathrm{IMP}$ & Sulfolactate & Lipoate \\
\hline 1-Methyladenosine & Phenyllactic acid & Fumarate \\
\hline Glutathione & Uric acid & 4-Aminobutyrate (GABA) \\
\hline Glucosamine & Pyroglutamic acid & Geranyl diphosphate \\
\hline 2-Oxo-4-methylthiobutanoate & Hydroxyphenylacetate & 3-Hydroxyisovaleric acid-1 \\
\hline Homocysteic acid & 3-Hydroxyisovaleric acid & Hypoxanthine-1 \\
\hline FMN & Pantothenate & Allantoin \\
\hline Ornithine & Uridine_2.8 & Kynurenine \\
\hline Acetyllysine & Ascorbate & \\
\hline Thymine & Salicylate & \\
\hline Cysteate & Gluconolactone & \\
\hline Thymidine & Citraconate & \\
\hline Xanthurenic acid & sn-Glycerol 3-phosphate & \\
\hline D-Erythrose 4-phosphate & Hydroxyisocaproic acid & \\
\hline N-Acetylornithine & 2-Hydroxy-2-methylsuccinate & \\
\hline Lysine & Aspartate & \\
\hline Dipicolinate & Leucine/Isoleucine & \\
\hline Uridine 1.8 & D-Glucarate & \\
\hline Taurine & Glucose 1-phosphate & \\
\hline N-Acetylglutamine & Shikimate & \\
\hline Kynurenic acid & 2-Isopropylmalate & \\
\hline NAD+ & D-Gluconate & \\
\hline Trehalose 6-phosphate & myo-Inositol & \\
\hline Prephenate & Succinate/Methylmalonate & \\
\hline Guanine & 6-Phospho-D-gluconolactone & \\
\hline Histidine & 3_4-Dihydroxyphenylacetate (DOPAC) & \\
\hline
\end{tabular}




\begin{tabular}{|l|l|} 
Arginine & 3-Methylphenylacetic acid \\
\hline 6-Phospho-D-gluconate & N-Acetylglutamate \\
\hline Cytidine & UDP-N-acetylglucosamine \\
\hline Adenosine & Glutamine \\
\hline Nicotinate & Hypoxanthine \\
\hline Deoxyuridine & N-Acetyl-beta-alanine \\
\hline N-Acetylglucosamine & 4-Pyridoxate \\
\hline Orotate & Phenylalanine \\
\hline Glycerone phosphate & Tyrosine \\
\hline Proline & Hydroxybenzoate \\
\hline Guanosine & Valine \\
\hline Serine & Phenylpyruvate \\
\hline Uracil & Abscisate \\
\hline Octulose 8/1P & UDP-glucose \\
\hline 2_3-Dihydroxybenzoate & Hydroxyphenylpyruvate \\
\hline AMP/dGMP & Xanthine \\
\hline UMP & Sedoheptulose 1/7-phosphate \\
\hline Deoxyribose phosphate & Homoserine/Threonine \\
\hline Indole-3-carboxylate & Vanillin \\
\hline 2-Aminoadipate & Adenine \\
\hline Ribose phosphate & 2-Oxoglutaric acid \\
\hline 2-Oxoisovalerate & 2-Dehydro-D-gluconate \\
\hline Glutamate & Aconitate \\
\hline Xylitol & Citrate/isocitrate \\
\hline & \\
\hline & \\
\hline
\end{tabular}

* Compounds in red indicate exclusive presence in infected trees

Heat maps were used to visualize the data as a preliminary tool for discrimination (Supplementary Figure 1) and PLSDA revealed significant differences between healthy xylem and infected xylem samples enabling accurate classification between the two groups $\left(\mathrm{R}^{2} / \mathrm{Q}^{2}>0.8\right)$ and indicated the compounds of highest importance in contributing to the separation between the two groups (Figures 1a \&1b). 


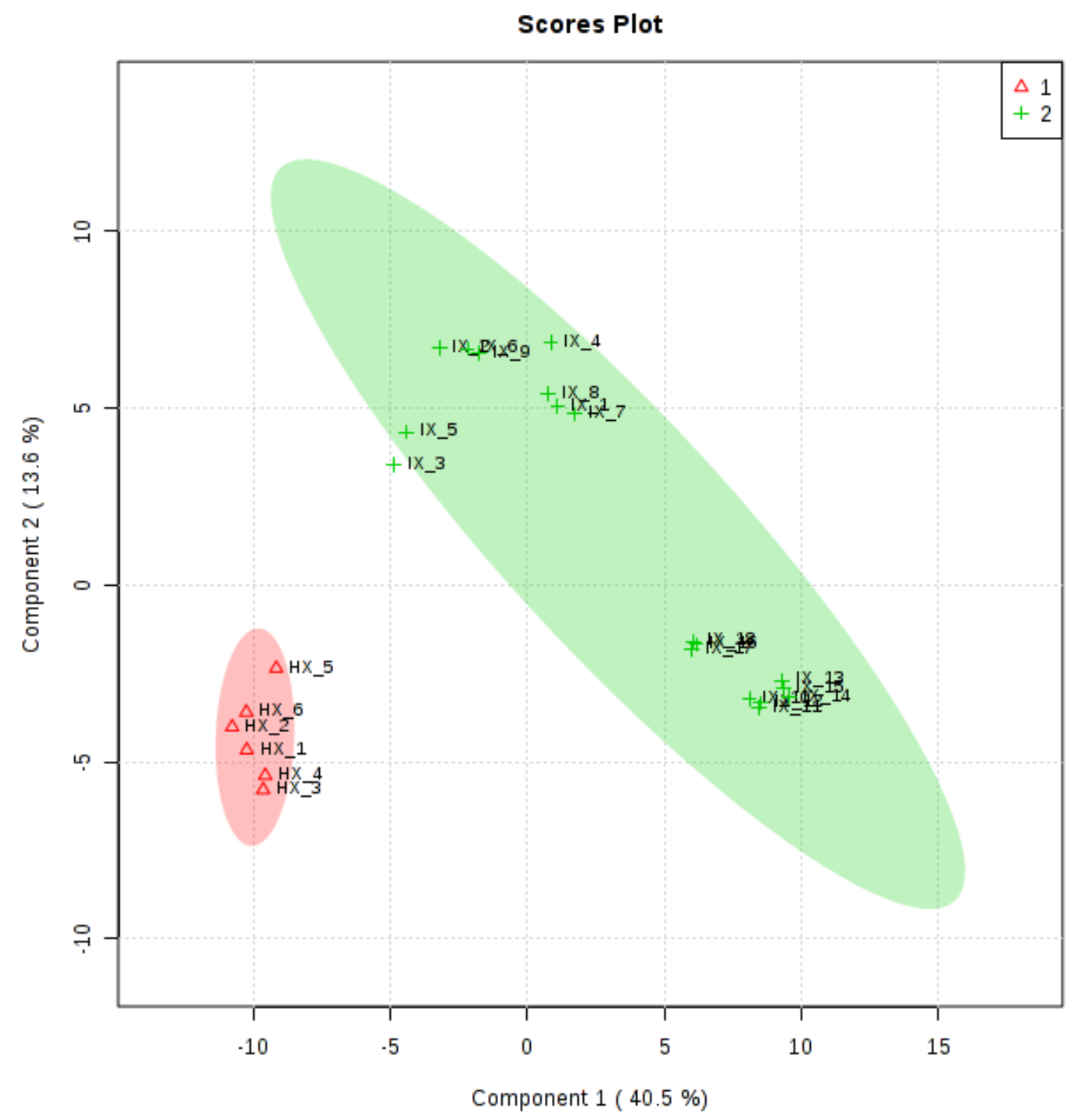

Figure 1a. A 2D-PLSDA plot for the metabolites in healthy xylem versus laurel wilt infected xylem in avocado trees. (Group 1:Healthy (red), Group 2: Infected (green)). $\left(\mathrm{R}^{2} / \mathrm{Q}^{2}\right.$ ratio $\left.>0.8\right)$. The clear clusters formed by each sample type or group indicates success in class separation. The high $\mathrm{R}^{2} / \mathrm{Q}^{2}$ validates the model as being due to the data variations rather than over fitting. 


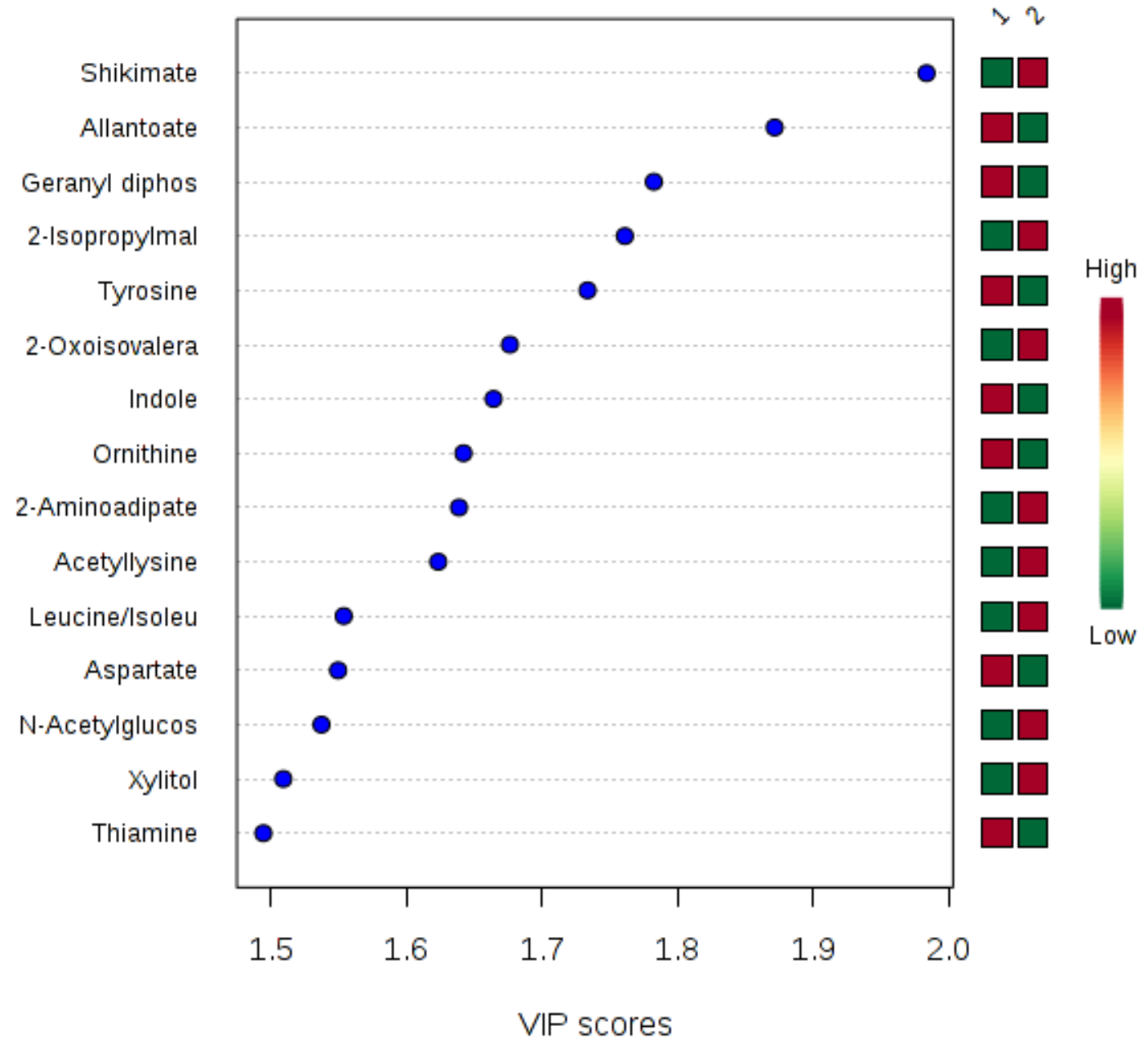

Figure $1 \mathrm{~b}$. The top 15 classifying compounds between the two sample types. Group 1:Healthy (red), Group 2: Infected (green). PLSDA variable importance (VIP) scores above 1.5 are considered of high significance in the separation of classes. The colored boxes to the right represent the relative concentrations of the compounds in the two sample types.

The top compounds involved in classifying healthy vs infected trees as determined by the PLSDA (Figure 1b) included the up regulation of shikimate, a key host precursor to the formation of polyphenols involved with defense mechanisms such as the formation of gums and gels as well as many being toxic to pathogens (Yadeta \& Thomma 2013).

Allantoate, which is involved in jasmonic acid signaling, a hormone involved in systemic 
host immune responses, was decreased upon infection (Tagaki et al. 2016). Geranyl diphosphate, a precursor to monoterpenes, was decreased during infection suggesting the possible conversion of the monoterpenes to volatiles, not measured using these methods, and released by the tree during infection (Dudareva et al 2004). Additionally, the increased concentration of xylitol in infected plants could suggest cell wall degradation by the pathogen.

Though some potential insight can be gained from the compounds provided by PLSDA, it is important to remember that most, if not all compounds, play multiple roles in multiple pathways and as such, when taken in isolation, conclusions are limited. Therefore to further elucidate the biological significance of the data, all compounds that were found in the KEGG database were mapped to various biochemical pathways. The pathways with the greatest instances of compounds are shown in Table 2.

Table 2. The top mapped pathways in the KEGG compound database associated with differentially expressed compounds in healthy xylem (HX) and infected xylem (IX) as well as those found exclusively in infected xylem.

\begin{tabular}{|c|c|c|c|}
\hline KEGG Mapped Pathway & $\square$ in $\mathbf{H X}$ & $\square$ in IX & IX only \\
\hline Biosynthesis of secondary metabolites & 6 & 58 & 7 \\
\hline Biosynthesis of antibiotics & 4 & 45 & 5 \\
\hline Microbial metabolism in diverse environments & 6 & 41 & 4 \\
\hline Biosynthesis of plant secondary metabolites & 4 & 38 & 3 \\
\hline Biosynthesis of amino acids & 2 & 33 & 2 \\
\hline 2-oxocarboxylic acid metabolism & $\mathbf{0}$ & 21 & $\mathbf{0}$ \\
\hline Carbon metabolism & 3 & 19 & 2 \\
\hline ABC transporters & 1 & 18 & $\mathbf{0}$ \\
\hline Biosynthesis of plant hormones & 2 & 18 & $\mathbf{0}$ \\
\hline Biosynthesis of alkaloids & 7 & 65 & 5 \\
\hline Carbon fixation in photosynthetic organisms & 2 & 10 & $\mathbf{0}$ \\
\hline Biosynthesis of terpenes and steroids & 3 & 9 & $\mathbf{0}$ \\
\hline Aminoacyl-tRNA biosynthesis & 1 & 15 & 1 \\
\hline
\end{tabular}


This metabolomic data revealed significant disturbances in plant metabolism. Primary metabolites were significantly perturbed, some of which have been visualized (S. Figures 3-6), specifically starch, sucrose, and fructose metabolism, which lead to increases in metabolites like lactate and glucose. In addition, amino acid synthesis was affected with thirty-three related compounds and amino acids being detected in infected samples. This was expected as sugars are utilized for energy generation and the generation of secondary metabolites critical to defense, as was also found in similar studies with soybean and tobacco (Aliferis et al. 2014, Scharte et al. 2005). Secondary metabolism was also affected in diseased trees with many compounds increasing in concentration and associated to pathways such as Aminoacyl-tRNA synthesis, terpene, alkaloid, and plant hormone synthesis, among others. Many compounds were associated with antibiotic biosynthesis indicating microbial metabolism and possibly competition among the microbial communities associated with the disease. The indications are in line with expected host defense mechanisms, such increased activation of resistance $(\mathrm{R})$ genes, terpenes, and alkaloids, and are important in herbivore defense and anti-microbial activity (Cushnie et al. 2014) that may be produced locally versus systemically as a direct response to the beetle attacks.

Of particular interest was the up regulation of plant defense hormones salicylic acid (SA) and abscisic acid (ABA) as well as the absence of jasmonates (JA) (S. Figure 6). Compounds involved with polyphenols and antifungals such as hydroxyisocaproic acid (Sakko et al. 2013) were also found. Plant hormones play a significant role in the defense against various pathogens and are known to involve intricate cross talk and antagonistic 
relationships (Robert-Seilaniantz et al. 2011). For example, salicylic acid is known to have an antagonistic relationship with jasmonic acid (JA). The high increase in SA could explain the absence of JA in the profiles obtained. JA is required for the activation of key defense mechanism involved with necrotrophic pathogens, but is also involved with other defense responses (Robert-Seilaniantz et al. 2011).

Interestingly, there was an increased production of Abscisic acid in infected plants. It has been shown that this hormone, key in environmental and abiotic stress responses, can lead to the suppression of the tree's defenses and increases susceptibility to many pathogens (Asselbergh et al. 2007, Robert-Seilaniantz et al. 2011). In one study that examined the xylem vessel defense against vascular wilt pathogens, there was production and accumulation of peroxidases, leading to the production of reactive oxygen species (ROS) that are toxic to pathogens (Yadeta and Thomma 2013). This is a mechanism that is a common response to many pathogens (Mair and Teige 2012, Taqi et al. 2011) and results in a hypersensitive host response (HR), a type of programmed cell death (PCD). The ROS reaction is also harmful to host cells and important antioxidant compounds are produced to scavenge ROS and detoxify before harming itself. The increased presence of Xanthine and its oxidation product uric acid in infected trees indicated the generation of ROS (Sharma 2012).

The data also show modified glutamate metabolism (S. Figure 4) with higher levels of succinate and reduction in $\gamma$-amino-butyric-acid (GABA), indicating Citric acid (TCA) cycle replenishment through the GABA shunt. This mode of glutamate metabolism is 
indicative of an "endurance" pathway taken to avoid cellular damage from ROS (Seifi et al. 2013). Glutamate, glutathione and ascorbate, compounds with well-known antioxidant activity, were increased (Taqi et al. 2011). This "endurance" mode is said to be a defense against necrotrophs that seek to destroy host tissue and absorb nutrients. However, as with most things involved in defense, the resistance to one mode of attack results in susceptibility to another. Indeed, this approach results in the enhanced susceptibility to biotrophic and hemi-biotrophic pathogens and may be key to allowing Raf to successfully colonize the xylem.

Experiment 2: Gallery flush versus infected wood: The purpose of the gallery flush samples was to minimize the amount of the host wood present in the sample, thus reflecting the fungal pathogen and its accompanying microbial community's metabolites. The same data analyses were used to determine the differences between the infected xylem and gallery flushes. When comparing gallery samples to infected xylem, it was observed that 66 compounds were significantly higher in galleries than xylem, while 25 were significantly higher in xylem tissue. It was also found that ten compounds were exclusive to the galleries and 16 were exclusive to xylem tissue and six to beetle gallery flushes. KEGG pathway mapping also revealed differences in the biological activities between the two sample types (Table 3). All compound identified were considered for completeness of pathway mapping regardless of significance. 
Table 3. The top mapped pathways in the KEGG compound database associated with differentially expressed compounds in infected xylem (IX) and Gallery flush samples (GF) as well as those found exclusively in only one sample type (IX only or GF only).

\begin{tabular}{|c|c|c|c|c|}
\hline Pathway & $\square$ in IX & $\square$ in GF & IX only & GF only \\
\hline Biosynthesis of secondary metabolites & 20 & 47 & 8 & 3 \\
\hline $\begin{array}{l}\text { Microbial metabolism in diverse } \\
\text { environments }\end{array}$ & 15 & 34 & 8 & 1 \\
\hline Biosynthesis of antibiotics & 13 & 37 & 5 & 1 \\
\hline $\begin{array}{l}\text { Biosynthesis of plant secondary } \\
\text { metabolites }\end{array}$ & 11 & 32 & 3 & 2 \\
\hline Carbon metabolism & 7 & 16 & 4 & 1 \\
\hline Biosynthesis of plant hormones & 6 & 14 & 2 & 1 \\
\hline Biosynthesis of amino acids & 5 & 31 & 2 & 2 \\
\hline 2-oxocarboxylic acid metabolism & 1 & 20 & 1 & $\mathbf{0}$ \\
\hline Protein digestion and absorption & 2 & 16 & 2 & 1 \\
\hline $\begin{array}{l}\text { Biosynthesis of alkaloids derived from } \\
\text { histidine and purine }\end{array}$ & 6 & 12 & 2 & 1 \\
\hline Biosynthesis of terpines and steroids & 4 & 8 & 2 & 1 \\
\hline
\end{tabular}

-Increased

Although both samples were from infected trees, the analyses revealed significant differences as well as what the most influential compounds were involved in classification (Figures $2 \mathrm{a} \& 2 \mathrm{~b}$ ). Of the compounds identified by PLSDA as important in distinguishing gallery samples from infected xylem, most seemed innocuous and were involved in normal metabolic pathways, such as the increase of 6-phospho-D-gluconate in gallery flushes that can indicate increased microbial metabolism, which would be expected. Histamine production in galleries could be associated with increased microbial biomass while CMP, dTMP, Quinolinate and Nicotinate are all up regulated in gallery flush samples, indicative of NAD+ synthesis. This important co-factor is essential in redox reactions, energy transactions and synthesis as well as cell-signaling. While not 
necessarily related to the diseased host, the increase in microbial biomass in beetle galleries is a plausible explanation for these changes.

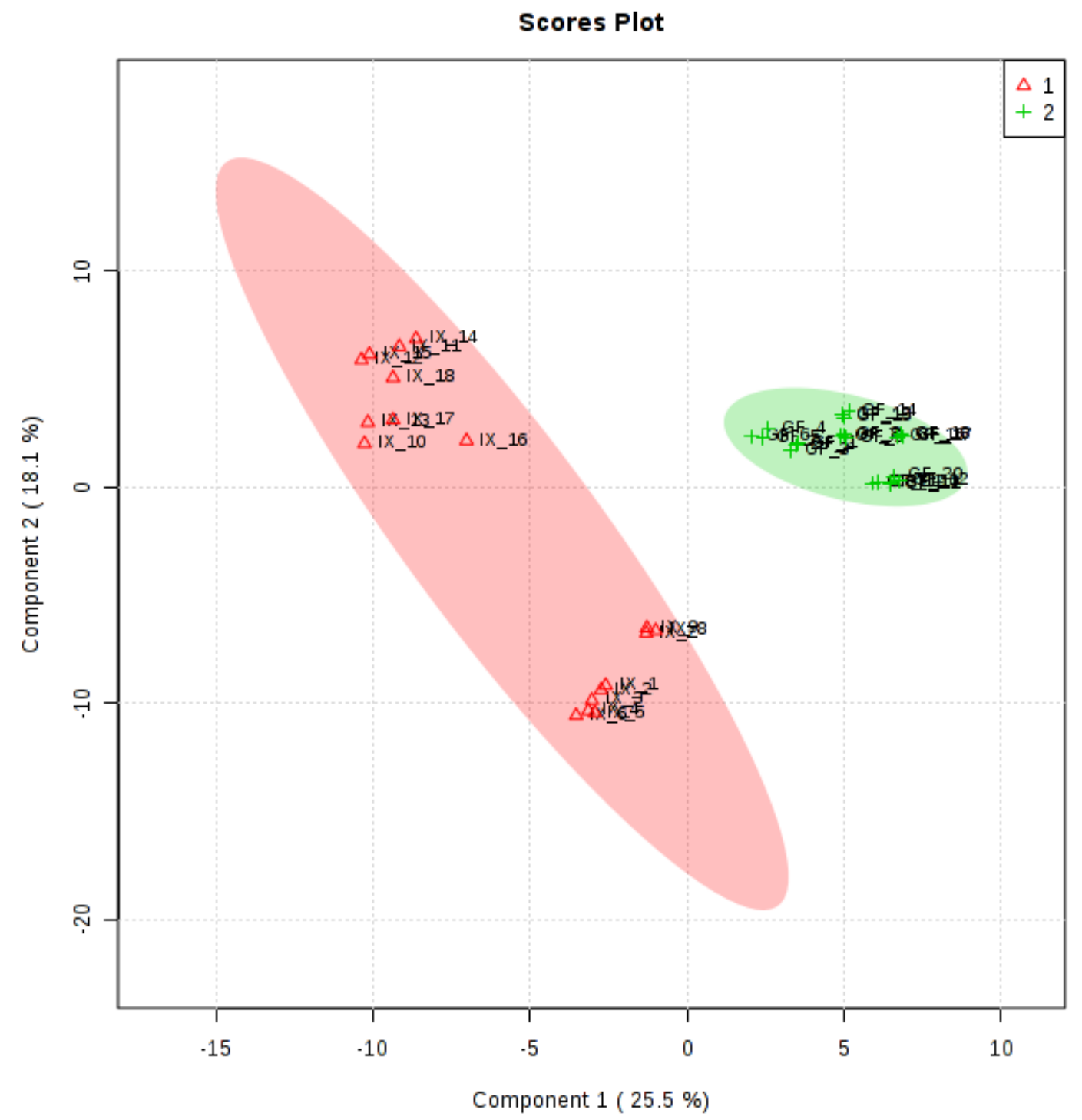

Figure 2a. A 2D-PLSDA plot for infected xylem tissue and beetle gallery flushes from laurel wilt infected avocado trees (Group 1:Xylem (red), Group 2: Gallery (green)). $\left(\mathrm{R}^{2} / \mathrm{Q}^{2}\right.$ ratio $\left.>0.7\right)$. The clear clusters formed by each sample type or group indicates success in class separation. The high $\mathrm{R}^{2} / \mathrm{Q}^{2}$ validates the model and group separation as being due to the data variations rather than over fitting. 


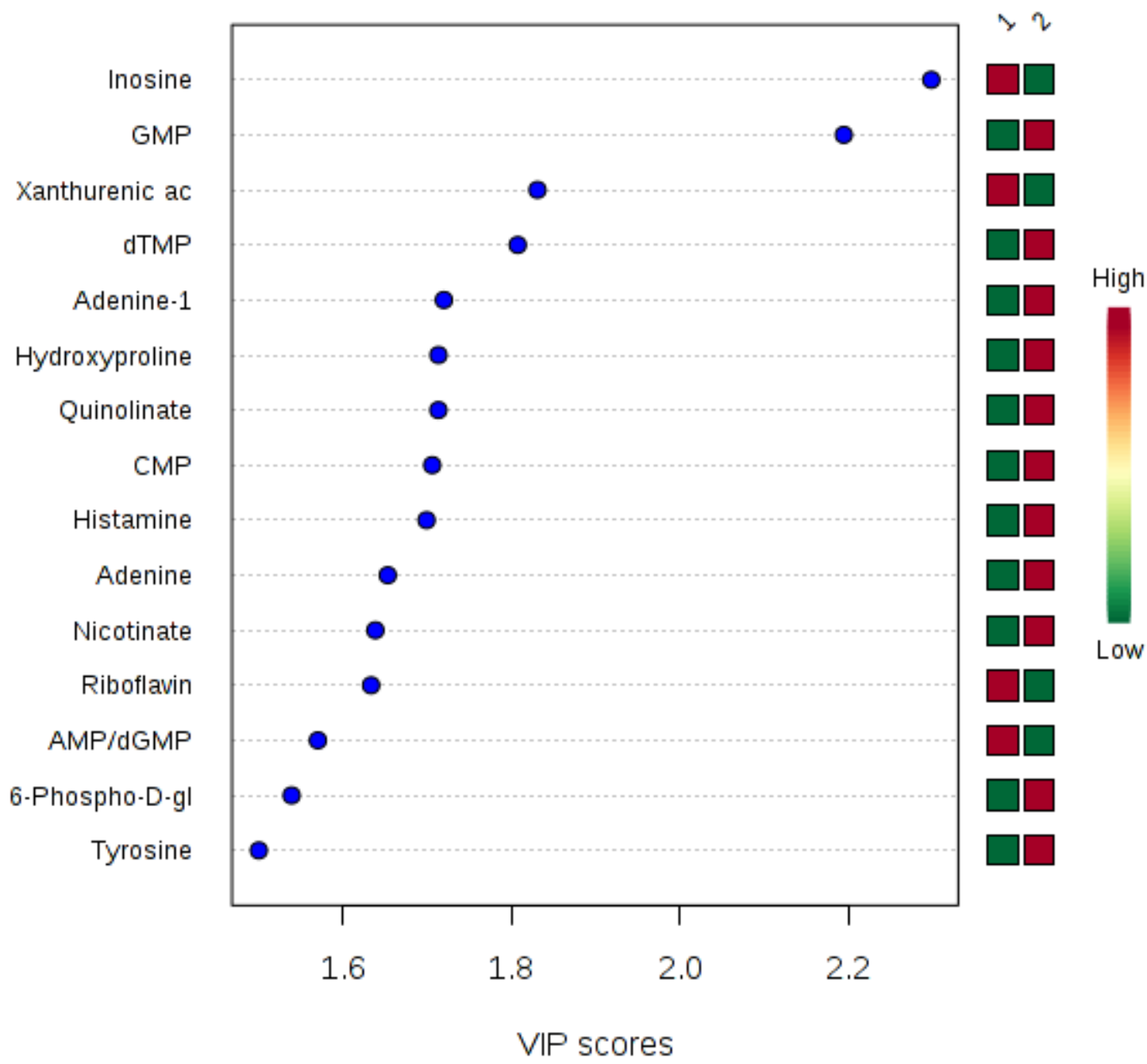

Figure $2 \mathrm{~b}$. The top 15 classifying compounds between the two sample types. (Group 1:Xylem (red), Group 2: Gallery (green)). PLSDA variable importance (VIP) scores above 1.5 are considered of high significance in the separation of classes. The colored boxes to the right represent the relative concentrations of the compounds in the two sample types.

Overall, the data suggest increased metabolism associated with microbial metabolism such as antibiotic production, NAD+ synthesis and histamine production. Changes in concentration of compounds in gallery flushes are likely due to the presence of microbial 
communities associated with Raf, in addition to being "hotspots" for local metabolic responses.

Random Forest algorithm: The results thus far in addition to providing insight into disease dynamics, have revealed that there are significant differences between healthy and infected samples enabling classification. Indeed other studies have also found similar results highlighting significant changes in metabolite profiles between diseased and healthy states in plants such as chickpea, barley, rice and soybean (Aliferis et al. 2014, Kumar et. al 2014, Parker et al. 2009). These differences were visualized well through heat maps and PLSDA-2Dplots. PLSDA enables the increased separation between groups through rotating principal components until maximum discrimination is achieved. A recent paper discussing the use of classification and predictive tools with metabolomics highlighted the usefulness of PSLDA as being good for visualizing differences, reducing dimensions, and its ability to rank variables or compounds importance. However, random forest analysis outperforms PLSDA in its ability to handle missing or zero values, outliers, in its predictive power and its resistance to over-fitting (Gromski et al. 2015). Most importantly, random forests analysis allows training a model using some of the data, and then the classification of unknown samples based on the model database. In trial 1 , the ability distinguish between healthy and infected xylem was high with $\sim 98 \%$ accuracy in the test data. Trial 2 was set up to mimic a real life sampling and diagnosis scenario. Therefore all healthy and infected xylem samples were used to train the model, and gallery flush samples were entered as unknowns. All of the 
gallery flush samples classified correctly as being from infected trees (100\% accuracy)

(Table 4).

Table 4 . The classification accuracy of healthy versus infected trees using the machine learning algorithm Random Forest. Trial 1 involved building the model with $2 / 3$ of the total healthy and infected xylem samples $(\mathrm{N}=24)$ and testing for classification with the remaining samples. Trial 2 involved training with the entire data set of healthy and infected samples followed by testing with gallery flush samples from infected trees $(\mathrm{N}=45)$.

\begin{tabular}{cc}
\hline Random Forest & Percent Accuracy \\
\hline Trial 1* & $98 \pm 3.5 \%$ \\
Trial 2 & $100 \%$ \\
\hline
\end{tabular}

* Trial 1 was done three times with different randomly selected training/testing sets to enable an average accuracy to be calculated

In the case of the first trial, a single healthy sample classified as being infected. This may be due to a manipulation or labeling error, but it is also possible that the tree may have been in early stages of infection that were not yet visible or under some other stress. These results demonstrate the power of bioinformatics in tandem with metabolomics data in providing an alternative method of diagnosis of laurel wilt disease, other than long culture times or DNA-based testing. The implications of this method can apply not only to laurel wilt but any novel disease where DNA diagnoses may prove difficult.

Metabolomics and informatics tools such as random forest could potentially enable rapid highly accurate diagnosis of disease.

Experiment 2: Artificial inoculation of young avocado trees: This experiment involved the artificial fungal inoculation of four young avocado trees in a controlled greenhouse setting. The purpose was to track the metabolic profile changes in only the pathogen, without its associated microbial community members, over time as symptoms developed, 
which could not be done in mature trees

in groves for obvious reasons. Of the four trees inoculated, only one progressed to disease (Figure 3).

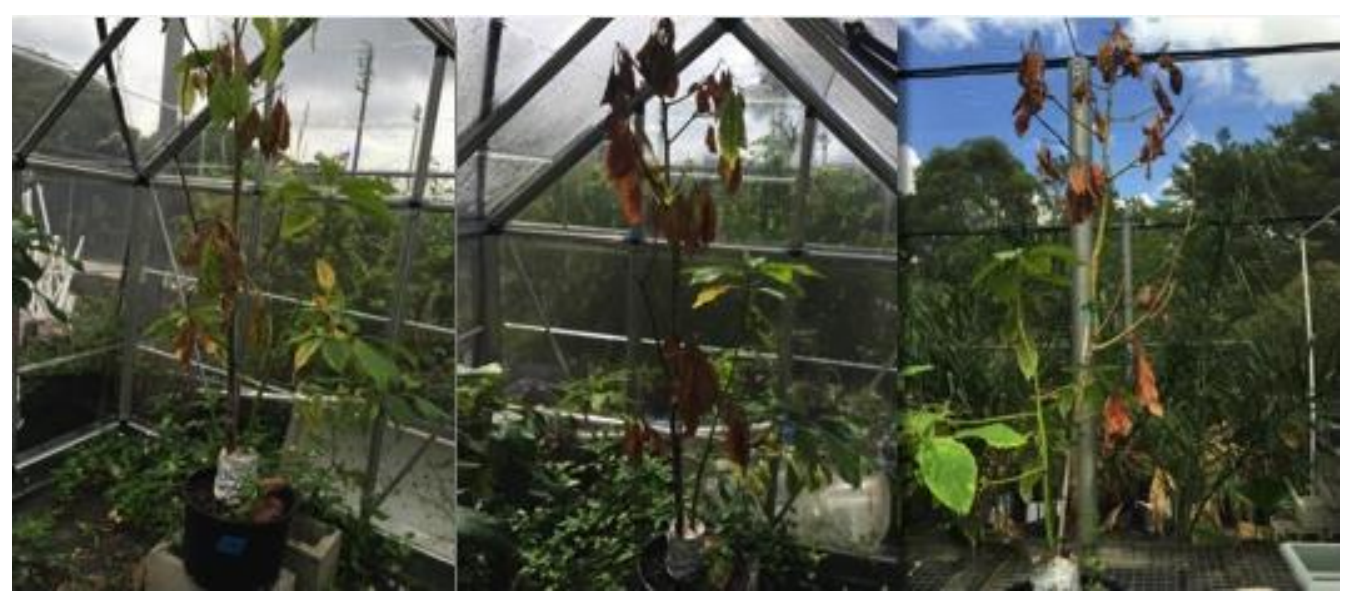

Figure 3. The disease progression in artificially inoculated avocado trees. Days 60, 65 and 72, respectively from left to right shows the early progression of symptoms from early leaf curling to brown leaves and ultimately complete wilt.

Unfortunately, it was discovered after beginning the trial that young plants that are already more resistant to disease naturally, and that Lula, the variety used in this experiment, happened to display some resistance to infection (personal communication, $\mathrm{J}$. Crane UF-TREC) when compared with other varieties. The trees had to be inoculated twice; the second time two months after the first. Even then symptoms did not develop until another two months and not in all trees. Other complications with this study were the size of the trees being too small to allow for many replicate samples as making that many holes in the tree would cause excessive stress and hinder the results. The initial plan was to sample one hole, from one of the four trees per time point, allowing for the monitoring of disease progression in the fungus over time without removing too much of the inoculum each sampling event. This would serve as a pilot study to be replicated 
with more trees. However, as described above only one tree developed symptoms and as such only one pre-symptomatic sample was taken and three symptomatic samples. While the sample size was small, the results of this study indicated very similar changes as those observed in mature avocado with shifting metabolic profiles observed throughout disease progression, whereby many pathways are up regulated (Table 5). Alternatively, additional microbes may need to be present in the galleries other than $R a f$. It is often the case where a disease is a polymicrobial phenomenon with a community as a whole supporting disease development, rather than just a pathogen monoculture. Inoculating with just the fungus could also explain why disease development took so long. The results of the KEGG pathway mapping revealed a sharp increase in biochemical activity post inoculation when compared to healthy samples, further increases are seen as symptoms develop and through to the tree's death (Table 5).

Table 5. The biological activity associated with compound increasing temporally during the artificial inoculation experiment in a young avocado tree. The top mapped compounds show increases from preinoculation through disease progression.

\begin{tabular}{|c|c|c|c|c|}
\hline Pathway & $\begin{array}{c}\text { Day } \\
19\end{array}$ & $\begin{array}{c}\text { Day } \\
\text { 60* }\end{array}$ & $\square$ Day 65 & $\square$ Day 72 \\
\hline Biosynthesis of secondary metabolites & 33 & 48 & 13 & 30 \\
\hline $\begin{array}{c}\text { Microbial metabolism in diverse } \\
\text { environments }\end{array}$ & 29 & 34 & 11 & 22 \\
\hline Biosynthesis of antibiotics & 28 & 38 & 10 & 23 \\
\hline Biosynthesis of amino acids & 20 & 38 & 11 & 22 \\
\hline 2-oxocarboxylic acid metabolism & 14 & 17 & 4 & 13 \\
\hline Carbon metabolism & 14 & 16 & 7 & 11 \\
\hline $\begin{array}{l}\text { Phenylalanine, tyrosine and tryptophan } \\
\text { biosynthesis }\end{array}$ & 6 & 9 & 3 & 7 \\
\hline Protein digestion and absorption & 7 & 15 & 2 & 13 \\
\hline
\end{tabular}

Increased- Day 19 was compared to pre-inoculation samples, and each subsequent time point was compared to the previous one.

* Visible symptoms were observed on this day 
In order to determine what compounds were important at the various stages of disease a PLSDA-VIP plot was utilized (Figure 4.) Perhaps the most interesting result is that the healthy control xylem had higher concentrations of SA (salicylate), which gradually depleted as the tree succumbed to disease. It is well known that SA plays a role in plant development and growth and this may help to confer resistance to younger plants such as the ones used in this study. As disease severity increased, and likely fungal biomass, so did the compounds like Xanthine and Indole-3-Carboxylate, which are known to be fungicidal. Signs of cellulose degradation were also evident with the presence of xylitol, glucose derivatives and the most significant classifier, gluconolactone. In addition to being antioxidant, this compound stimulates cellulase production (Kou et al. 2014) and its high concentration at plant death could be indicative of a switch in lifestyle from biotroph to necrotroph by the pathogen. 


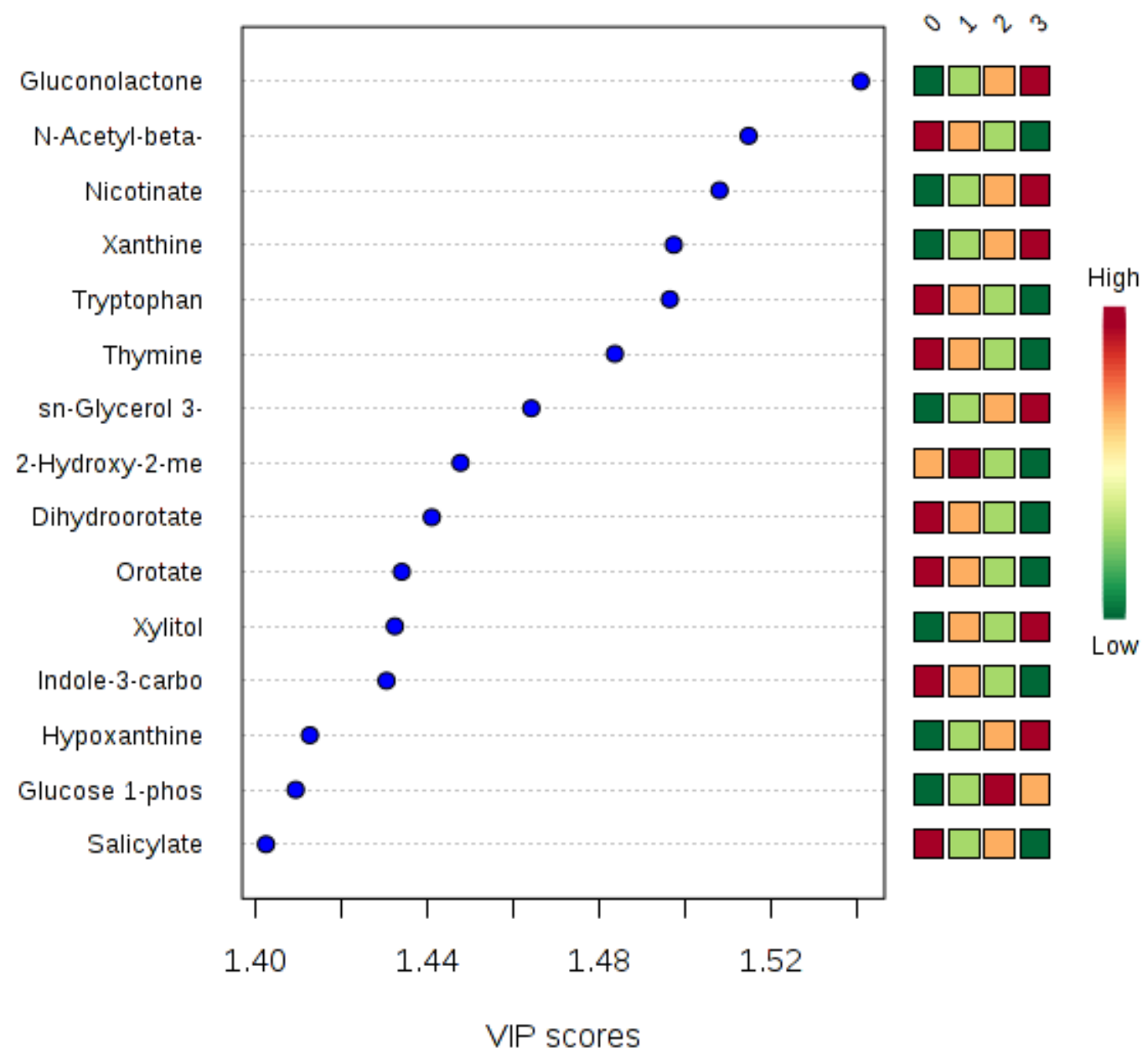

Figure 4. The top 15 compounds across time in the artificial inoculation study in a young avocado plant (Group 0: Healthy Xylem control, Groups 1-3: gallery flushes at early mid and late stage infection).

PLSDA variable importance (VIP) scores above 1.5 are considered of high significance in the separation of classes. The colored boxes to the right represent the relative concentrations of the compounds in the two sample types.

Experiment 3, in situ analysis of Raf during growth on avocado wood: In an attempt to further elucidate the changes that may occur with respect to the pathogen during disease development, the third experiment utilized thin strips of freshly cut, healthy avocado xylem placed atop growing cultures of Raf. Triplicate samples were taken at each time 
point over a five-day period at 3,24, 48, 72 and $120 \mathrm{hr}$ post contact. These results also revealed similar pathways were affected as previously described and detectable changes were observed at the very first time point (3 hours). In general, the compounds associated with the mapped pathways gradually increased from day to day (Table 6).

Table 6. The KEGG pathway mapping of compounds present in Raffaelea lauricola (RL) in pure culture and the number of compounds that increased over time upon contact with healthy xylem tissue.

\begin{tabular}{ccccccc}
\hline Pathway & RL baseline & $\square \mathbf{3 h}$ & $\square \mathbf{2 4} \mathbf{h}$ & $\square \mathbf{4 8 ~ h}$ & $\square 72 \mathrm{~h}$ & $\square \mathbf{1 2 0 h}$ \\
\hline $\begin{array}{c}\text { Biosynthesis of } \\
\text { secondary metabolites }\end{array}$ & 52 & 11 & 24 & 27 & 39 & $\mathbf{3}$ \\
$\begin{array}{c}\text { Microbial metabolism } \\
\text { in diverse environments }\end{array}$ & 38 & 9 & 15 & 24 & 24 & 5 \\
\hline $\begin{array}{c}\text { Biosynthesis of } \\
\text { antibiotics }\end{array}$ & 38 & 11 & 19 & 21 & 29 & 3 \\
$\begin{array}{c}\text { 2-oxocarboxylic acid } \\
\text { metabolism }\end{array}$ & 32 & 1 & 0 & 11 & 9 & 0 \\
\hline $\begin{array}{c}\text { Biosynthesis of amino } \\
\text { acids }\end{array}$ & 20 & 4 & 15 & 20 & 19 & 0 \\
\hline $\begin{array}{c}\text { Carbon metabolism } \\
\text { Aminoacyl-tRNA } \\
\text { biosynthesis }\end{array}$ & 17 & 4 & 9 & 13 & 13 & 1 \\
\hline
\end{tabular}

$\square$-Increased: $3 \mathrm{hr}$ compared to RL and each subsequent time point to the previous one.

PLSDA showed changes over time with some overlap between the groups. Raf, at baseline, however, showed clear separation from other temporal measures. The variable importance plot also demonstrated the top compounds for classification (Figure 5a \& 5b). 


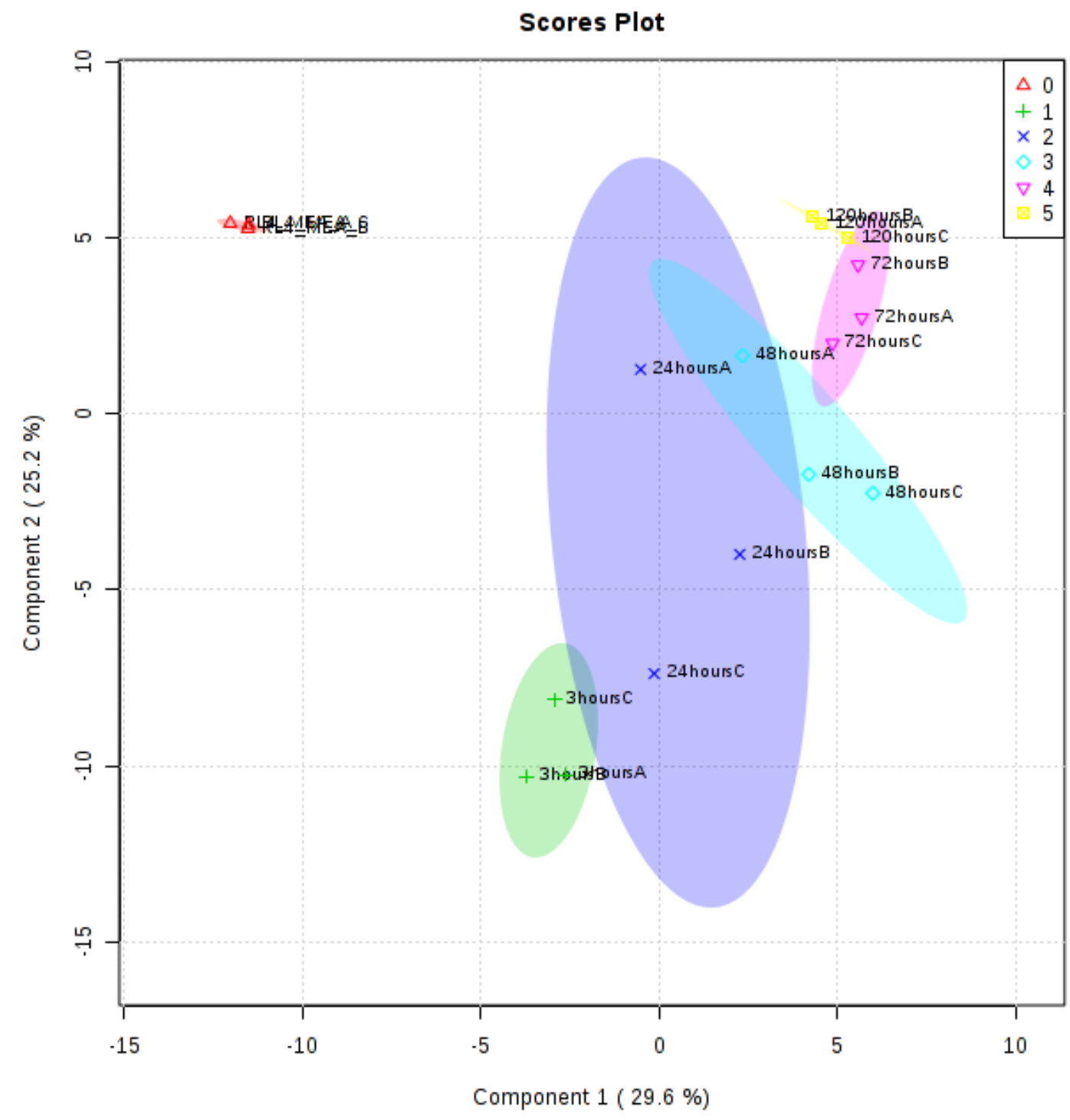

Figure 5a. A 2D-PLSDA plot for the in situ time series experiment showing changes in Raffaelea lauricola over 120 hours after coming in contact with xylem tissue. Key: Red-Pathogen (0), Green (1)- 3h, Purple (2)-24h, Blue (3)-48h Pink (4)-72h and yellow (5)-120h. 


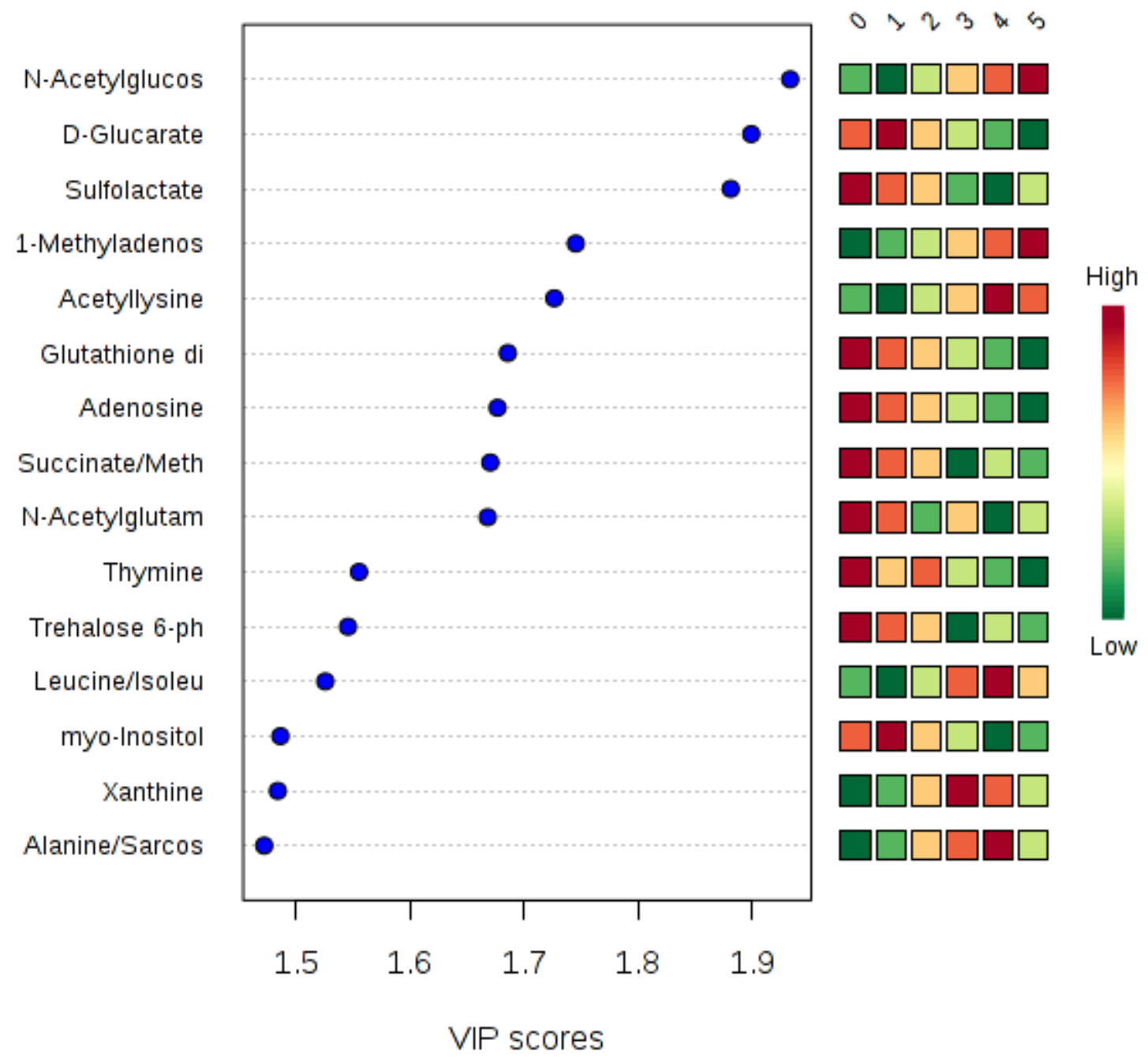

Figure 5b. Important compounds involved in classification/discrimination of each time point. Key: RedPathogen (0), Green (1)- 3h, Purple (2)-24h, Blue (3)-48h Pink (4)-72h and yellow (5)-120h. PLSDA variable importance (VIP) scores above 1.5 are considered of high significance in the separation of classes. The colored boxes to the right represent the relative concentrations of the compounds in the two sample types.

Interestingly, the baseline metabolome of the pathogen in pure culture revealed the presence of plant hormones, $\mathrm{SA}$ and $\mathrm{ABA}$. This is of particular interest as pathogenic fungi and bacteria have been shown to hijack plant defenses through the secretion of plant hormones and hormone mimics (de Torres-Zabala et al. 2007, Robert-Seilaniantz et 
al. 2011, Thatcher et al. 2009). SA production will limit immediate herbivore response and antimicrobial defense through the suppression of JA signaling. One particular beetle predator on tomato plants utilizes SA secretions from a bacterial symbiont to avoid activating some plant defenses (Chung et al. 2013, Maor and Shirasu 2005). This finding could have significant implications for disease development in laurel wilt. Salicylic acid is known to be involved in both local and systemic responses to pathogens and is geared towards defense against biotrophic or hemibiotrophic pathogens. This, therefore, indicates an unusual response by the pathogen to secrete SA. However. if you consider that Raf is beetle-vectored, the first line of defense by the tree would be JA-mediated herbivore defenses to stop the beetle. It is therefore possible that this is a coevolved strategy to enhance the chances of inoculation through the SA-mediated suppression of JA. The role of ABA secretion as previously described could be an attempt to attenuate the defenses of the host tree, in spite of increased SA production. This information provides potential for genetic intervention of pathways that lead to the production of plant hormones in Raf to determine if virulence is affected.

\section{Conclusion}

This study was the first metabolomic investigation into laurel wilt disease in avocado trees. Diseased trees display significant changes in multiple pathways involved in both primary and secondary metabolism that enable healthy and diseased plants to be successfully classified and random forest analysis demonstrated the ability of metabolomics, perhaps to be used in place of DNA confirmation, for a more rapid and cost effective diagnosis. In infected trees, increased SA production, an expected response 
to pathogens such as Raf, was observed. However glutamate metabolism changes revealed increased ROS scavenging through the "endurance" pathway, which, on the contrary, favors Raf establishment. Metabolic profiling of Raf in culture revealed the presence of the plant hormones SA and ABA, which may play a role in circumventing plant defenses. The in situ culturing experiment revealed observable changes in metabolism as early as $3 \mathrm{~h}$ post contact with the xylem. While metabolomics is a growing field with increasingly useful applications, there still remains many limitations such as a lack of standardization across instruments, software deficiencies, and small number of species-specific databases. The lack of identity information for the vast majority of metabolites in plant and pathogen interactions is also a problem. Standalone metabolomics studies are also limited in interpretations and most studies combine data with other "Omics" fields for maximum information. Nonetheless, this study expands the knowledge of plant pathogen interaction within the scope of laurel wilt disease, and as others in the research community advance in other aspects of this disease, these data could prove useful in combination with additional 'omics' data sets.

\section{References}

Aliferis, K. A., Faubert, D., \& Jabaji, S. (2014). A metabolic profiling strategy for the dissection of plant defense against fungal pathogens. PLoS One, 9(11), e111930.

Allwood, J. W., Ellis, D. I., \& Goodacre, R. (2008). Metabolomic technologies and their application to the study of plants and plant-host interactions. Physiologia Plantarum, 132(2), 117-135.

Asselbergh, B., Curvers, K., França, S. C., Audenaert, K., Vuylsteke, M., Van Breusegem, F., \& Höfte, M. (2007). Resistance to Botrytis cinerea in sitiens, an 
abscisic acid-deficient tomato mutant, involves timely production of hydrogen peroxide and cell wall modifications in the epidermis. Plant Physiology, 144(4), 1863-1877.

Chung, S. H., Rosa, C., Scully, E. D., Peiffer, M., Tooker, J. F., Hoover, K., ... \& Felton, G. W. (2013). Herbivore exploits orally secreted bacteria to suppress plant defenses. Proceedings of the National Academy of Sciences, 110(39), 15728-15733.

Crane, J.H., E.A. Evans, D. Carrillo, R.C. Ploetz, and A.J. Palmateer. 2015. The potential for laurel wilt to threaten avocado production is real. Proc. VIII World Avocado Congress, Lima, Perú (Sept. 13-18, 2015) p.9-16. [Accessed 12-23-15; http://www.avocadosource.com/WAC8/WAC8_TOC.htm].

Cushnie, T. T., Cushnie, B., \& Lamb, A. J. (2014). Alkaloids: an overview of their antibacterial, antibiotic-enhancing and antivirulence activities. International Journal of Antimicrobial Agents, 44(5), 377-386.

de Torres-Zabala, M., Truman, W., Bennett, M. H., Lafforgue, G., Mansfield, J. W., Egea, P. R., ... \& Grant, M. (2007). Pseudomonas syringae pv. tomato hijacks the Arabidopsis abscisic acid signalling pathway to cause disease. The EMBO Journal, 26(5), 1434-1443.

Draper, J., Rasmussen, S., \& Zubair, H. (2011). Metabolite analysis and metabolomics in the study of biotrophic interactions between plants and microbes. Annual Plant Reviews, 43.

Dudareva, N., Pichersky, E., \& Gershenzon, J. (2004). Biochemistry of plant volatiles. Plant Physiology, 135(4), 1893-1902.

Evans, E. A., Crane, J., Hodges, A., \& Osborne, J. L. (2010). Potential economic impact of laurel wilt disease on the Florida avocado industry. Horticulture Technology, 20(1), 234-238.

Gromski, P. S., Muhamadali, H., Ellis, D. I., Xu, Y., Correa, E., Turner, M. L., \& Goodacre, R. (2015). A tutorial review: Metabolomics and partial least squaresdiscriminant analysis-a marriage of convenience or a shotgun wedding. Analytica Chimica Acta, 879, 10-23.

Hughes, M.A.; Riggins, J.J.; Koch, F.H.; Cognato, A.I.; Anderson, C.; Formby, J.P.; Dreaden, T.J.; Ploetz, R.C.; Smith, J.A. (2017) No rest for the laurels: Symbioclone invader causes unprecedented damage to southern USA forests. Biological Invasions, in press.

Kendra, P. E., Montgomery, W. S., Niogret, J., Pena, J. E., Capinera, J. L., Brar, G., ... \& Heath, R. R. (2011). Attraction of redbay ambrosia beetle (Coleoptera: 
Curculionidae: Scolytinae) to avocado, lychee, and essential oil lures. Journal of Chemical Ecology, 37, 932-942.

Kou, Y., Xu, J., Cao, Y., Lv, X., Zhao, G., Chen, G., \& Zhang, W. (2014).

Gluconolactone induces cellulase gene expression in cellulolytic filamentous fungus

Trichoderma reesei. Royal Society of Chemistry Advances, 4(68), 36057-36063.

Kumar, Y., Dholakia, B. B., Panigrahi, P., Kadoo, N. Y., Giri, A. P., \& Gupta, V. S. (2015). Metabolic profiling of chickpea-Fusarium interaction identifies differential modulation of disease resistance pathways. Phytochemistry, 116, 120-129.

Lee, D. K., Ahn, S., Cho, H. Y., Yun, H. Y., Park, J. H., Lim, J., ... \& Kwon, S. W. (2016). Metabolic response induced by parasitic plant-fungus interactions hinder amino sugar and nucleotide sugar metabolism in the host. Scientific Reports, 6.

Lu, W., Clasquin, M. F., Melamud, E., Amador-Noguez, D., Caudy, A. A., \& Rabinowitz, J. D. (2010). Metabolomic analysis via reversed-phase ion-pairing liquid chromatography coupled to a stand alone orbitrap mass spectrometer. Analytical Chemistry, 82(8), 3212-3221. doi: 10.1021/ac902837x.

Mair A. and Teige M. (2012) Shaping the pathogen response by protein kinase triggered oxidative burst. New Phytologist, 196: 4-6.

Maor, R., \& Shirasu, K. (2005). The arms race continues: battle strategies between plants and fungal pathogens. Current Opinion in Microbiology, 8(4), 399-404.

Mazid, M., Khan, T. A., \& Mohammad, F. (2011). Role of secondary metabolites in defense mechanisms of plants. Biology and Medicine, 3(2), 232-249.

Melamud, E., Vastag, L., \& Rabinowitz, J. D. (2010). Metabolomic analysis and visualization engine for LC- MS data. Analytical Chemistry, 82(23), 9818-9826.

Niogret, J., Kendra, P. E., Epsky, N. D., \& Heath, R. R. (2011). Comparative analysis of terpenoid emissions from Florida host trees of the redbay ambrosia beetle, Xyleborus glabratus (Coleoptera: Curculionidae: Scolytinae). Florida Entomologist, 94(4), 1010-1017.

Parker, D., Beckmann, M., Zubair, H., Enot, D. P., Caracuel-Rios, Z., Overy, D. P., ... \& Draper, J. (2009). Metabolomic analysis reveals a common pattern of metabolic reprogramming during invasion of three host plant species by Magnaporthe grisea. The Plant Journal, 59(5), 723-737.

Pasquet, J. C., Chaouch, S., Macadré, C., Balzergue, S., Huguet, S., MartinMagniette, M. L., ... \& Saindrenan, P. (2014). Differential gene expression and metabolomic analyses of Brachypodium distachyon infected by deoxynivalenol 
producing and non-producing strains of Fusarium graminearum. BMC Genomics, 15(1), 629.

Ploetz, R. C., Harrington, T., Hulcr, J., Fraedrich, S., Smith, J. A., Inch, S., \& Palmateer, A. (2011). Recovery plan for laurel wilt of avocado (caused by Raffaelea lauricola). National Plant Disease Recovery System. Homeland Security Presidential Directive Number 9 (HSPD-9).

Ploetz, R. C., Kendra, P. E., Choudhury, R. A., Rollins, J. A., Campbell, A., Garrett, K., \& Dreaden, T. (2017). Laurel wilt in natural and agricultural ecosystems: understanding the drivers and scales of complex pathosystems. Forests, 8(2), 48.

Ploetz, R. C., Pérez-Martínez, J. M., Evans, E. A., \& Inch, S. A. (2011). Toward fungicidal management of laurel wilt of avocado. Plant Disease, 95(8), 977-982.

Pusztahelyi, T., Holb, I. J., \& Pócsi, I. (2015). Secondary metabolites in fungus-plant interactions. Frontiers in Plant Science, 6, 573.

Robert-Seilaniantz, A., Grant, M., \& Jones, J. D. (2011). Hormone crosstalk in plant disease and defense: more than just jasmonate-salicylate antagonism. Annual Review of Phytopathology, 49, 317-343.

Sakko, M., Moore, C., Novak-Frazer, L., Rautemaa, V., Sorsa, T., Hietala, P., ... \& Rautemaa, R. (2014). 2-hydroxyisocaproic acid is fungicidal for Candida and Aspergillus species. Mycoses, 57(4), 214-221.

Scharte J, Scho“n H, Weis E (2005) Photosynthesis and carbohydrate metabolism in tobacco leaves during an incompatible interaction with Phytophthora nicotianae. Plant Cell \& Environment 28: 1421-1435.

Seifi, H. S., Van Bockhaven, J., Angenon, G., \& Höfte, M. (2013). Glutamate metabolism in plant disease and defense: friend or foe? Molecular Plant-Microbe Interactions, 26(5), 475-485.

Sharma, P., Jha, A. B., Dubey, R. S., \& Pessarakli, M. (2012). Reactive oxygen species, oxidative damage, and antioxidative defense mechanism in plants under stressful conditions. Journal of Botany. 2012: 1-6

Takagi, H., Ishiga, Y., Watanabe, S., Konishi, T., Egusa, M., Akiyoshi, N., ... \& Shimada, H. (2016). Allantoin, a stress-related purine metabolite, can activate jasmonate signaling in a MYC2-regulated and abscisic acid-dependent manner. Journal of Experimental Botany, 67(8), 2519-2532.

Taqi, A. K., Mohd, M., \& Firoz, M. (2011). Role of ascorbic acid against pathogenesis in plants. Journal of Stress Physiology \& Biochemistry, 7(3). 
Tenenboim, H., \& Brotman, Y. (2016). Omic relief for the biotically stressed: metabolomics of plant biotic interactions. Trends in Plant Science, 21(9), 781-791.

Thatcher, L. F., Manners, J. M., \& Kazan, K. (2009). Fusarium oxysporum hijacks COI1-mediated jasmonate signaling to promote disease development in Arabidopsis. The Plant Journal, 58(6), 927-939.

Xia, J. and Wishart, D.S. (2016) Using MetaboAnalyst 3.0 for Comprehensive metabolomics data analysis. Current Protocols in Bioinformatics, 55:14.10.114.10.91.

Xia, J., Sinelnikov, I., Han, B., and Wishart, D.S. (2015) MetaboAnalyst 3.0 - making metabolomics more meaningful . Nucleic Acids Research 43, W251-257.

Yadeta, K. A., \& Thomma, B. P. (2013). The xylem as battleground for plant hosts and vascular wilt pathogens. Frontiers in Plant Science 4(97). 
Supplementary data:

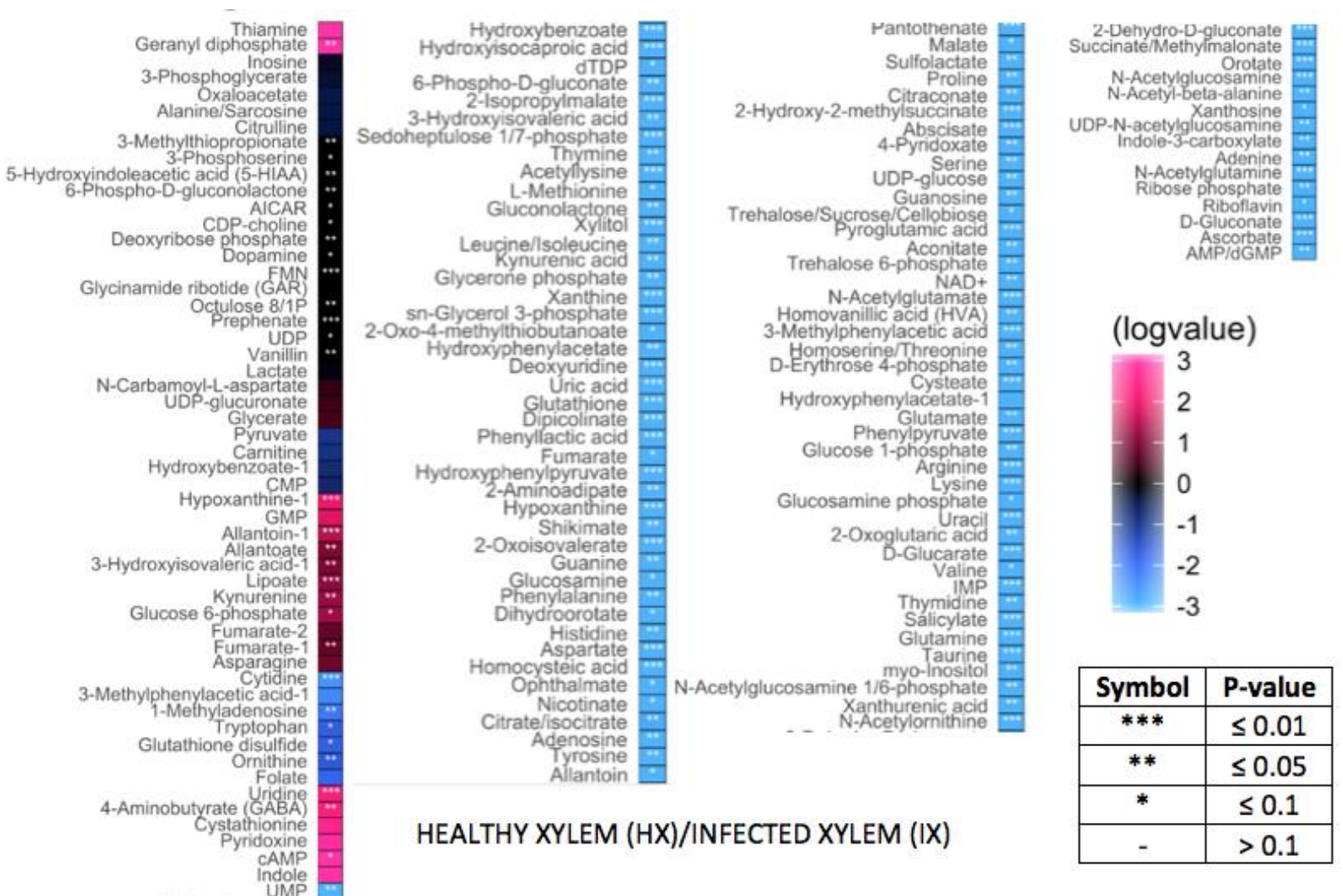

S.Figure 1. The heat maps generate a visual picture of the differences between compounds present in Healthy xylem (HX) versus infected xylem (IX). Color intensities represent concentration fold changes of $\log _{2}$ normalized data. Red indicates higher concentration in the numerator (HX) and blue indicates higher in the denominator (IX) Black indicates no difference. 

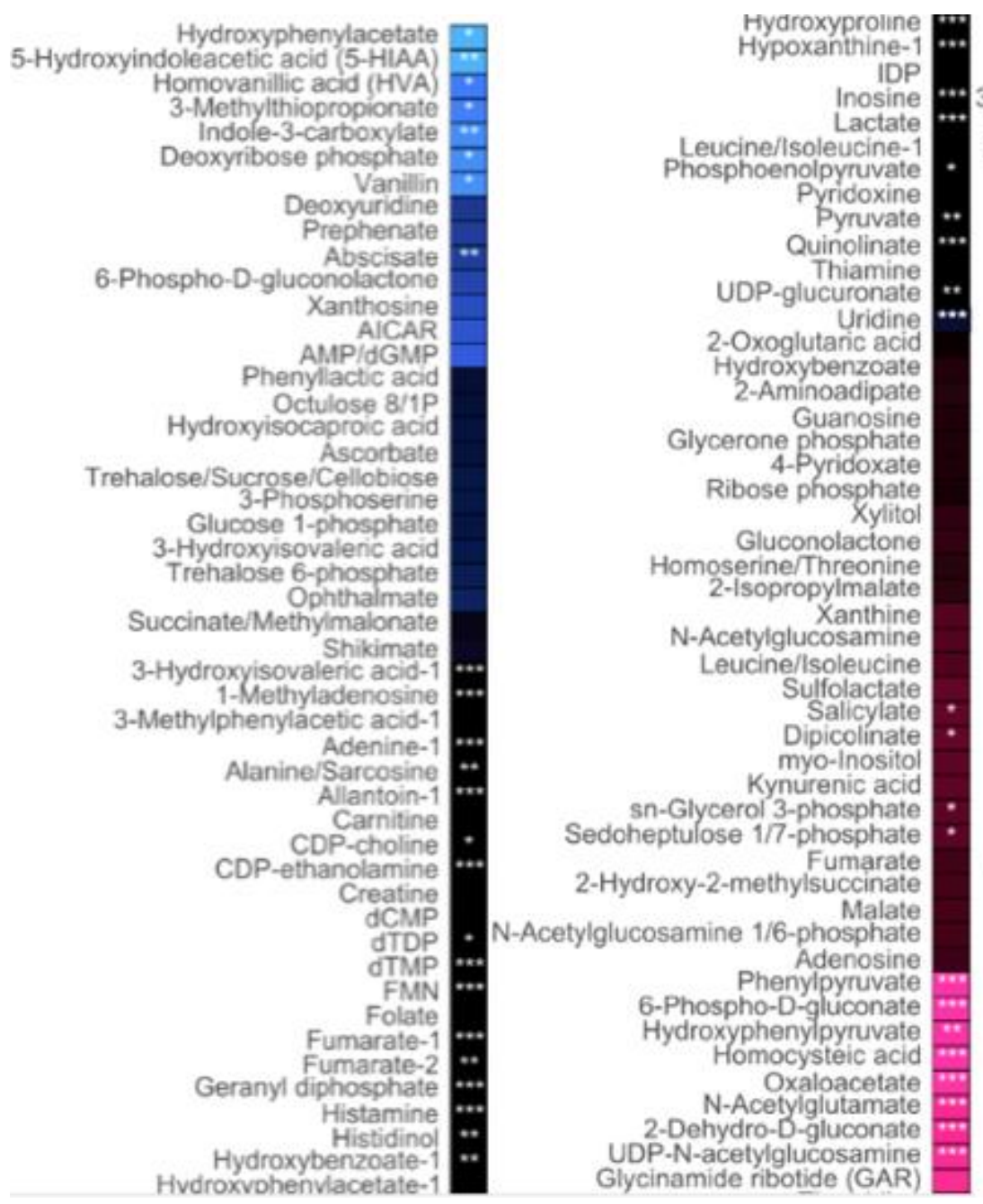

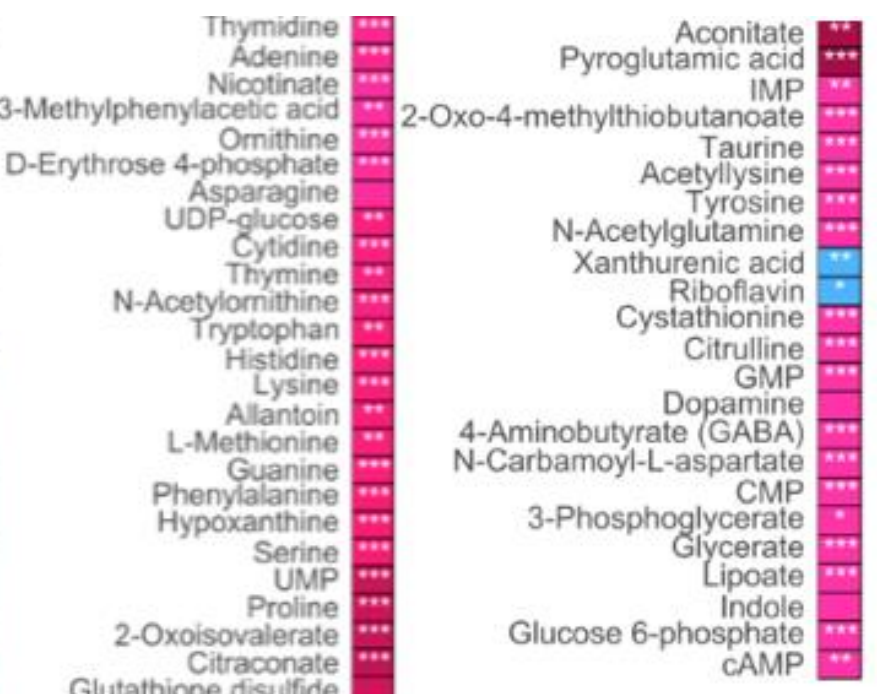

S. Figure 2. The heat maps generate a visual picture of the differences between compounds present in gallery flushes from infected trees (GF) versus infected xylem (IX). Color intensities represent concentration fold changes of $\log _{2}$ normalized data. Red indicates higher concentration in the numerator (GF) and blue indicates higher in the denominator (IX) Black indicates no difference. 


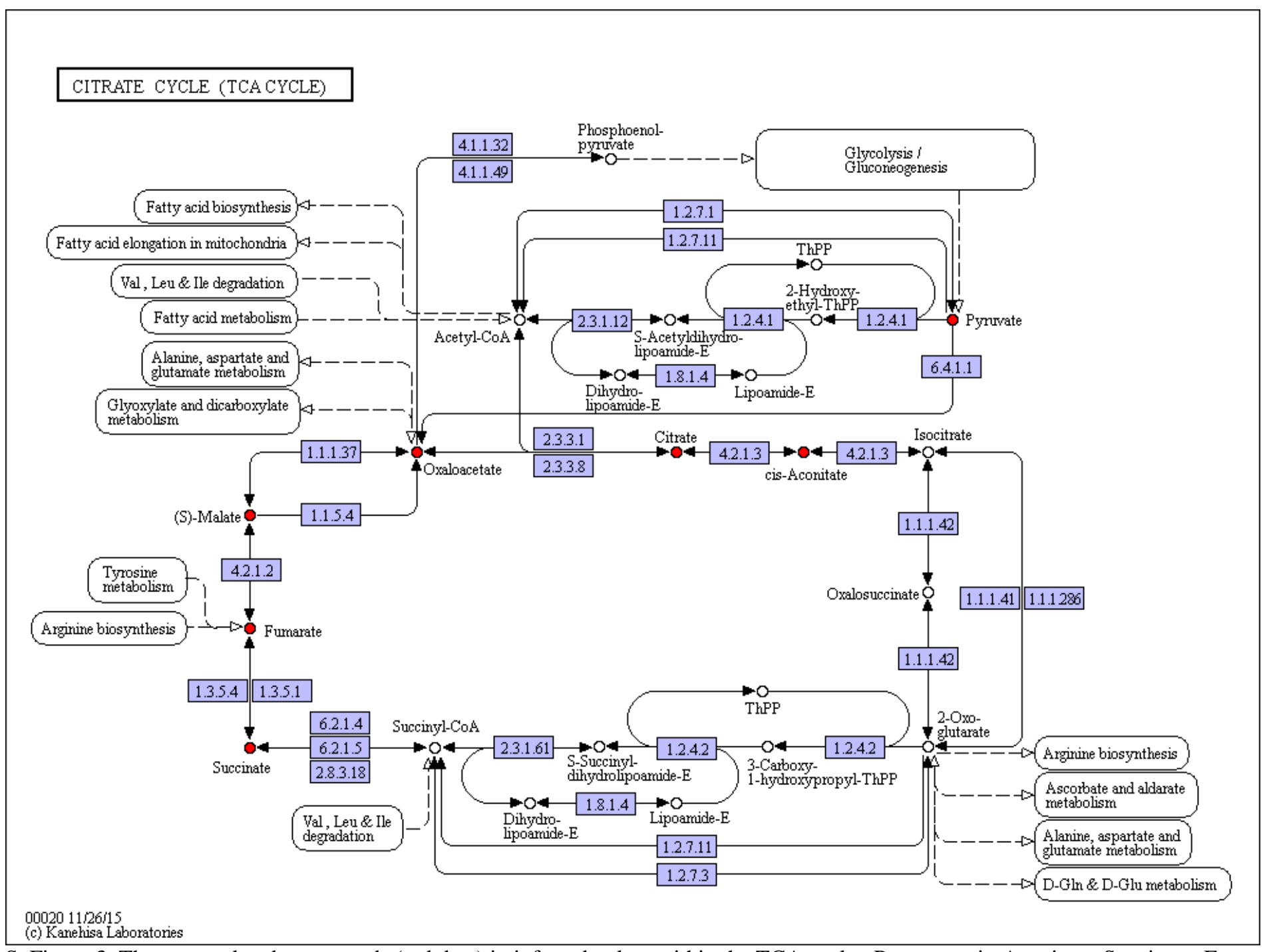

S. Figure 3. The up-regulated compounds (red dots) in infected xylem within the TCA cycle. Pyruvate, cis-Aconitate, Succinate, Fumarate and Oxaloacetate are all significantly increased in infected trees. 


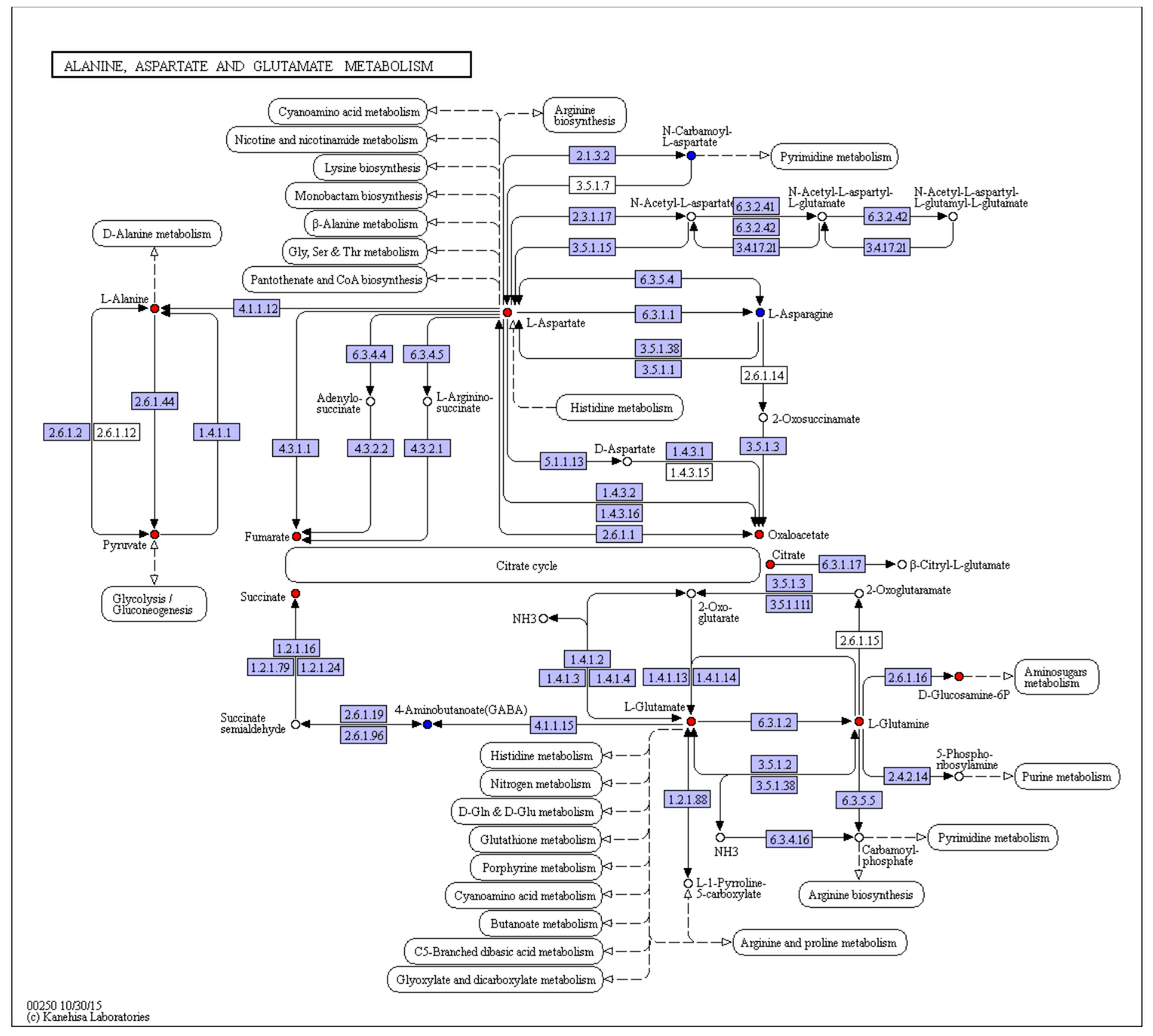

S. Figure 4. The up (red) and down (blue) regulated compounds involved in glutamate metabolism in laurel infected trees. 


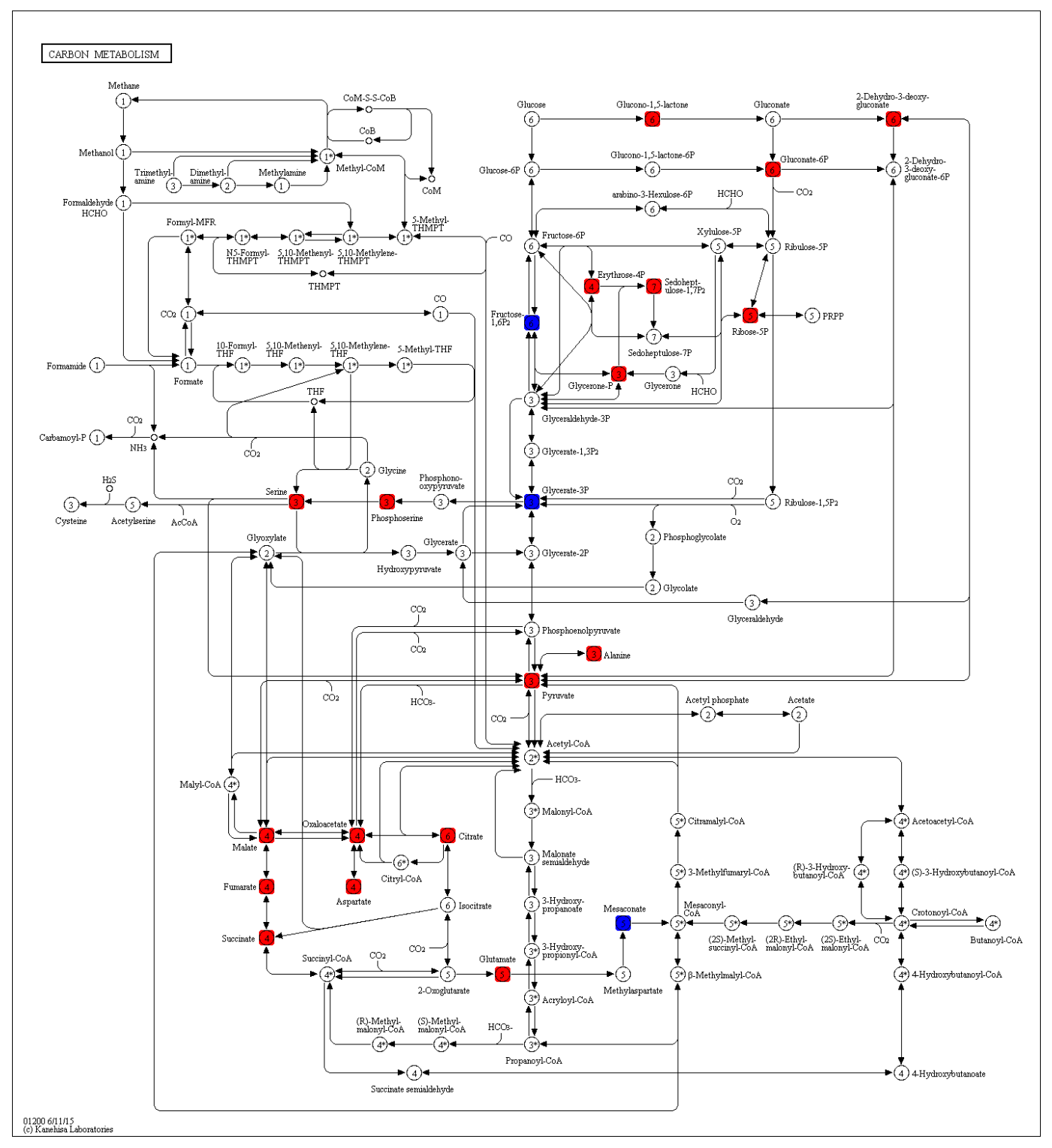

S. Figure 5. The up (red) and down (blue) regulated compounds involved with carbon metabolism in infected trees. 


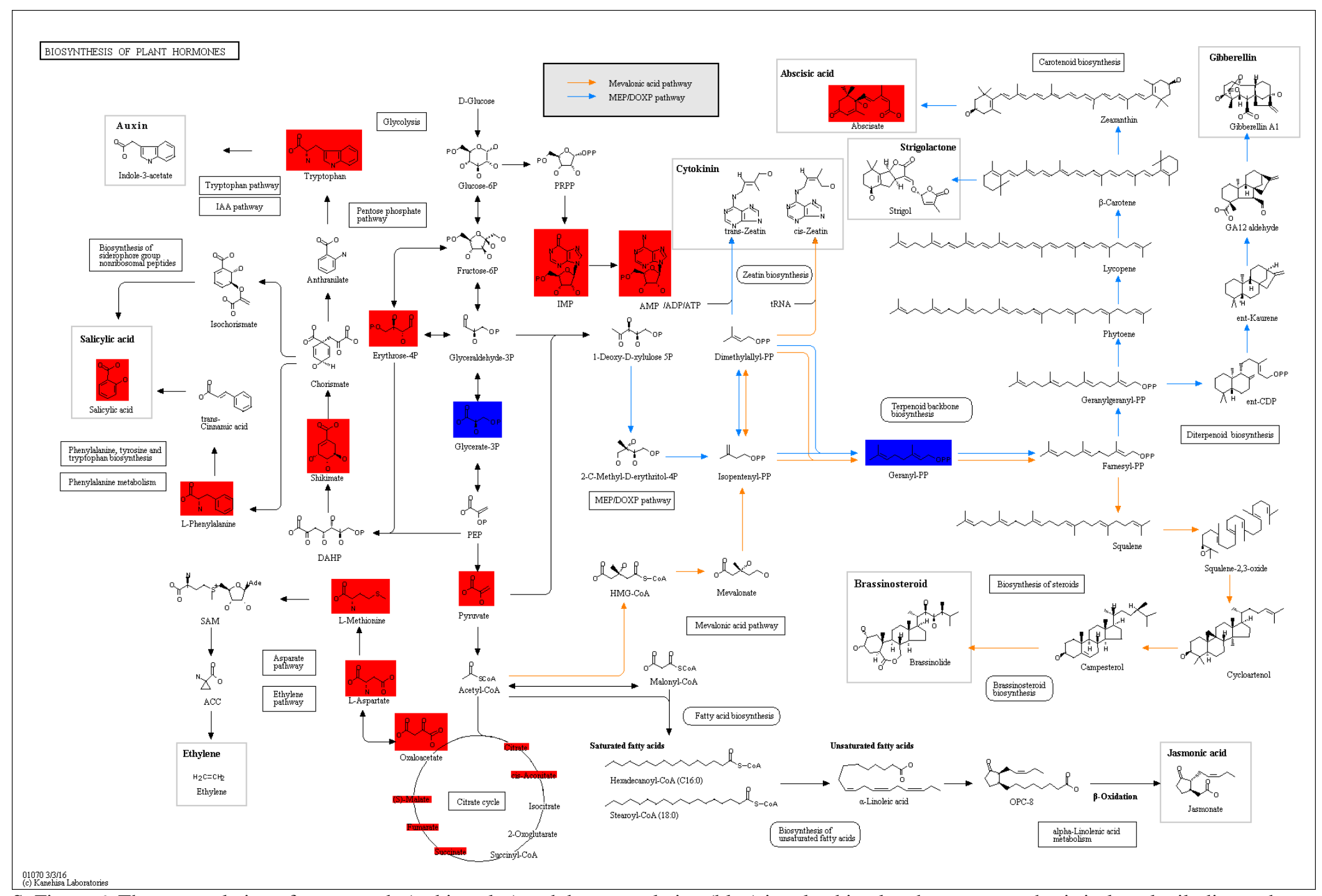

S. Figure 6. The up regulation of compounds (red in color) and down regulation (blue) involved in plant hormone synthesis in laurel wilt diseased trees 


\section{CHAPTER 6}

\section{Concluding Statements}

\section{Introduction}

Laurel wilt disease is a deadly and aggressive vascular disease currently affecting the avocado industry in South Florida as well as the SE and Gulf Coast forests. This disease kills so rapidly that once symptoms are visible, the tree must be removed immediately and the disease will spread from tree to tree through root grafting. Presently there is no cure once the disease signs are visible. To date, DNA tests are not effective in identifying the pathogen because when sampling there is no guarantee the sample will contain the fungus due to its non-uniform distribution within trees and roots. The current management options available to farmers are labor intensive and costly and involve either treating entire groves with a fungistatic, or spot treating several rings of trees after the removal of an infected tree. This study aimed to improve the earliest detection capabilities; sampling and diagnostics of laurel wilt disease through the use of canine olfaction and metabolomics. Additionally, very little is known about the biology of the pathogen, and the disease dynamics. This lack of basic knowledge greatly hinders the ability to develop and test potential cures. The metabolomics study was completed to elucidate key changes that occur in the host and potential areas of interest for metabolomic targets that could potentially lead to a cure. 
Canine olfaction, non-invasive sampling and metabolomic diagnostics

It was found that scent discriminating canines are capable of detecting infected avocado wood with accuracies in excess of $95 \%$ during their training. Subsequently, with deployment to groves, field studies demonstrated high success in mitigating the spread of disease in avocado groves based on an earlier detection and proactive spot treatment and management. The maintenance of the health and fruit-bearing capability of a presymptomatic tree treated with the fungistatic can potentially be repeated every year to allow continued harvest versus the economic loss from removal of trees. The observational, control (no treatment) field study demonstrated the ability of canines to detect the disease as early as 40-46 days prior to visual symptoms.

A novel sample device based on a Venturi vacuum was utilized to collect samples from beetle galleries in infected trees, in a non-destructive manner. Metabolic profiling of diseased and healthy trees revealed significant differences in compound abundances and a classification accuracy of $>98 \%$ with the machine learning tools. Together the ability to detect disease at the earliest stage of infection with the canines, sampling nondestructively and rapidly confirming changes with metabolomics could greatly improve the management tools available for grove owners to battle this disease. The combination of these approaches can result in removing fewer trees, continued gain from harvesting 
treated trees versus removal of a visually diseased tree, which in turn will reduce their financial losses.

\section{Laurel wilt metabolomics}

Through the metabolic profiling of diseased and healthy avocado trees, it was possible to identify compounds that were significantly altered due to disease and the corresponding pathways involved. There were also key defense pathways activated during infection, involving the production of salicylic acid, phenols and ROS generating and scavenging compounds by the host trees. Attempts to dissect fungal/microbial metabolites from plant metabolites proved challenging as the vast majority of compounds were found in all samples and few databases exist to support a dichotomous analyses that can pinpoint plant versus microbe contributions. However, interesting findings based on the metabolic profiles of pure isolates of pathogen were found in that the pathogen produces and secretes the plant hormones salicylic acid and abscisic acid. This may possible be a means of circumventing and manipulating the host defenses but future studies are needed to solidify this finding. However, these preliminary results may provide a potential area to study and possibly target the pathways in the pathogen that mimic the plant hormone defense molecules. The database of metabolites from this study will be used in future studies to obtain more information about laurel wilt and other vascular diseases. These data, in combination with whole genome studies presently under way, can provide information that can possibly unlock the vulnerable pathways that can be targets for pathogen control. 
VITA

JULIAN LIOR MENDEL

Born, Kingston, Jamaica

2005-2008

B.A., Zoology

University of the West Indies

Kingston, Jamaica

2008-2009

Biology Teacher

Ardenne High School, Jamaica

2010-2012

M.S., Forensic Science

Florida International University

Miami, FL

2011-2014

MBRS Rise Fellowship

Florida International University

Miami, FL

$2012-2017$

Doctoral Candidate

Florida International University

Miami, FL

2014-2016

Teaching Assistant

Florida International University

Miami, FL

2016

Florida AGRI Council

William H. Krome Memorial Fellowship

2016

NSF UCF Mini I-Corps Program

\section{PUBLICATIONS AND PATENTS}

Caraballo, N.I., Mendel, J., Holness, H., La Salvia, J., Moroose, T., Eckenrode, B., Stockham, R., Furton, K. and Mills, D., 2016. An investigation into the concurrent collection of human scent and epithelial skin cells using a non-contact sampling device. Forensic Science International, 266, pp.148-159. 
Blackman, S., Dawnay, N., Ball, G., Stafford-Allen, B., Tribble, N., Rendell, P., Neary, K., Hanson, E.K., Ballantyne, J., Kallifatidis, B., Mendel, J., Mills, D.K. and Nagy, R.,. Developmental validation of the ParaDNA® Intelligence System-A novel approach to DNA profiling. Forensic Science International: Genetics, 17, pp.137-148.

Dawnay, N., Stafford-Allen, B., Moore, D., Blackman, S., Rendell, P., Hanson, E.K., Ballantyne, J., Kallifatidis, B., Mendel, J., Mills, D.K. and Nagy, R., 2014.

Developmental Validation of the ParaDNA® Screening System-A presumptive test for the detection of DNA on forensic evidence items. Forensic Science International: Genetics, 11, pp.73-79.

The Venturi vacuum device (VVD) prototype: Biological Sample Collection (patent pending, Serial No. 15/007,501), Julian Mendel \& DeEtta Mills 